Old Dominion University

ODU Digital Commons

Summer 2010

\title{
Intergenerational Conflict Between Emerging Adults and Their Parents in Asian American Families
}

Kathy Nguyen

Old Dominion University

Follow this and additional works at: https://digitalcommons.odu.edu/psychology_etds

Part of the Asian American Studies Commons, Clinical Psychology Commons, Developmental Psychology Commons, and the Family, Life Course, and Society Commons

\section{Recommended Citation}

Nguyen, Kathy. "Intergenerational Conflict Between Emerging Adults and Their Parents in Asian American Families" (2010). Doctor of Psychology (PsyD), Dissertation, Psychology, Old Dominion University, DOI: $10.25777 / 026 e-p f 35$

https://digitalcommons.odu.edu/psychology_etds/305

This Dissertation is brought to you for free and open access by the Psychology at ODU Digital Commons. It has been accepted for inclusion in Psychology Theses \& Dissertations by an authorized administrator of ODU Digital Commons. For more information, please contact digitalcommons@odu.edu. 
INTERGENERATIONAL CONFLICT

\title{
BETWEEN EMERGING ADULTS AND THEIR PARENTS
}

IN ASIAN AMERICAN FAMILIES

\author{
by \\ Kathy Nguyen \\ B.A. May 2006, University of Virginia \\ M.A. May 2008, Norfolk State University \\ A Dissertation Submitted to the Faculties of \\ The College of William and Mary \\ Eastern Virginia Medical School \\ Norfolk State University \\ Old Dominion University \\ In Partial Fulfillment of the Requirement for the Degree of \\ DOCTOR OF PSYCHOLOGY \\ CLINICAL PSYCHOLOGY \\ VIRGINIA CONSORTIUM PROGRAM IN CLINICAL PSYCHOLOGY \\ August 2010
}

Approved by:

Jadis Sanchez (Director

Old Dominion University

Desideria Hacker (Member)

Norfolk State University
Kathrin Hartmann (Member)

Eastern Virginia Medical School
Michelle L. Kelley (Member)

Old Dominion University
Íthice Zeman (XI)mber)

The College of William and Mary 


\section{ABSTRACT \\ INTERGENERATIONAL CONFLICT BETWEEN EMERGING ADULTS AND THEIR PARENTS \\ IN ASIAN AMERICAN FAMILIES}

Kathy Nguyen

Virginia Consortium Program in Clinical Psychology, 2010

Director: Dr. Janis Sanchez

Due to a paucity of research, little is understood about the experiences of Asian American emerging adults as they navigate their relationship with their parents. The purpose of the current study was to investigate intergenerational conflict in Asian American families, specifically when emerging adults are living at home with their parents. Acculturation gap, generational status, birth order, gender, and language proficiency were examined as predictors or mediators of conflict. Participants consisted of 350 Asian American emerging adults who were currently living with their parents, who lived with their parents during certain times of the year (e.g., vacations), or who had once lived with their parents as adults. Intergenerational conflict was measured using the Asian American Family Conflicts Scale (Lee, Choe, Kim, \& Ngo, 2000) and the Intergenerational Conflict Inventory (Chung, 2001). Acculturation was assessed using the Asian American Multidimensional Acculturation Scale (Chung, Kim, \& Abreu, 2004).

One-way between-subjects analysis of variance tests were performed to identify group differences in conflict across several demographic factors. Correlational and hierarchical multiple regression analyses were performed to study the relationship between the predictors, proposed mediator, and intergenerational conflict. Exploratory 
statistical analyses were conducted to investigate factors that may predict level of conflict when emerging adults return home after living away for an extended period of time (i.e., boomerang children). A gap in acculturation to White mainstream culture between emerging adults and their parents was found to be the most powerful and consistent predictor of intergenerational conflict and to mediate fully the relationship between generational status and intergenerational conflict. Overall, the findings highlight the multi-faceted and variable nature of intergenerational conflict as it occurs in Asian American families between emerging adults and their parents. 
Copyright, 2010, by Kathy Nguyen, All Rights Reserved. 
This dissertation is dedicated to individuals and families everywhere who live in and between multiple cultures.

May you find success and peace in balancing your many identities. 


\section{ACKNOWLEDGMENTS}

The ideas and efforts of many individuals contributed to the development and completion of this dissertation, and to these individuals, my gratitude is endless. Of special note is Dr. Janis Sanchez, my dissertation chair, who provided mentoring and encouragement over and beyond her role as chair. Also of note are the members of my committee and specific individuals within the Psychology Department at Old Dominion University, whose helpful feedback and assistance were much appreciated. My thoughts and appreciation go out to my family and friends, whose stories and experiences shed light on the immense need for this research and provided inspiration to complete this work. To my closest loved ones, your support, patience, and faith carried me through this unforgettable journey, and I will love you always.

Correspondence regarding this dissertation should be addressed to Kathy Nguyen via e-mail at kathynguyen14@gmail.com 


\section{TABLE OF CONTENTS}

Page

LIST OF TABLES

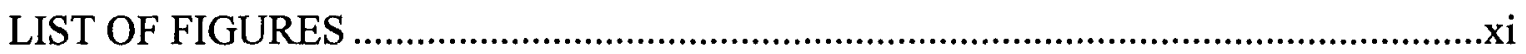

\section{Chapter}

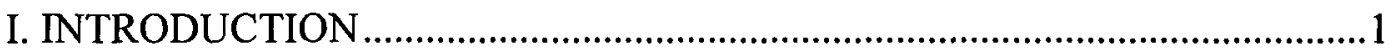

Intergenerational Conflict in Asian American Families............................5

Impact of Intergenerational Conflict ........................................................8

Predictors of Intergenerational Conflict...................................................9

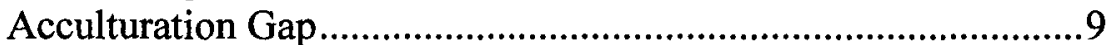

Generational Status.................................................................11

Gender of Child ........................................................................12

Birth Order Status of Child..........................................................13

Language Proficiency .................................................................14

Emerging Adults at Home ....................................................................14

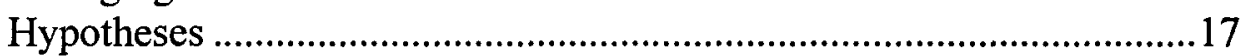

II. METHOD

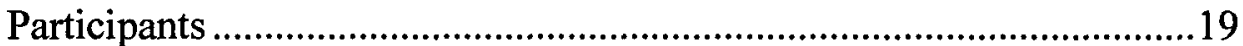

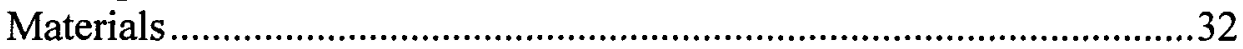

Asian American Family Conflicts Scale (FCS) ………..............32

Intergenerational Conflict Inventory (ICI) .................................34

Asian American Multidimensional Acculturation Scale

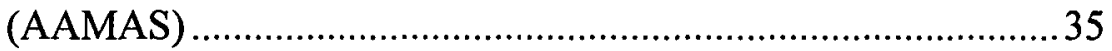

Demographic Questionnaire .....................................................37

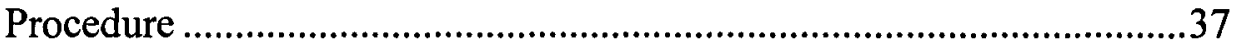

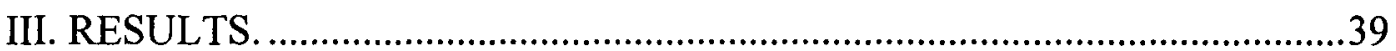

Data Management and Preliminary Analyses ..........................................39

Overall Level of Intergenerational Conflict ..........................................44

Group Differences in Intergenerational Conflict.......................................44

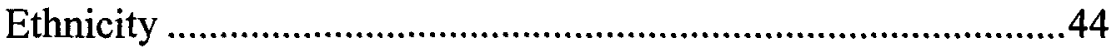

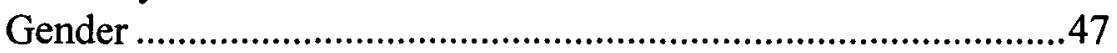

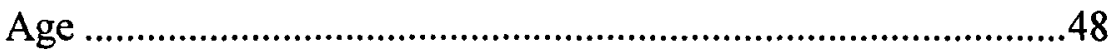

Living Situation...................................................................5

Highest Level of Education........................................................55

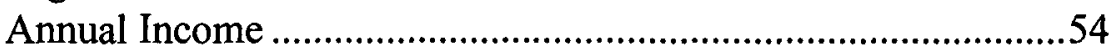

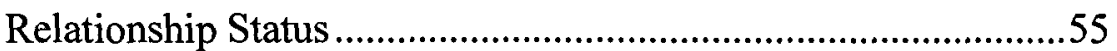

Language Most Spoken in Communicating with Parents ............56

Level of Acculturation and Acculturation Gap ........................................58

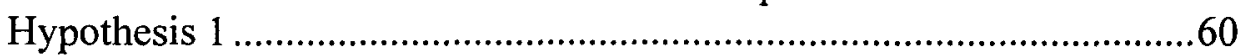




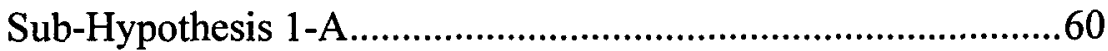

Sub-Hypothesis 1-B .................................................................61

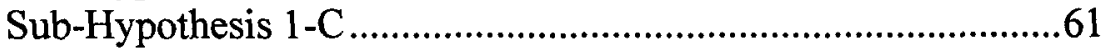

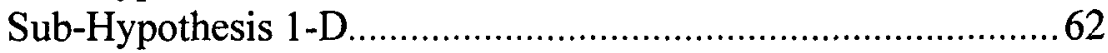

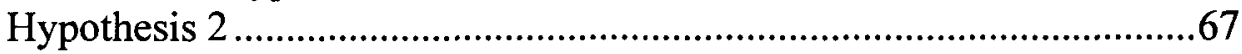

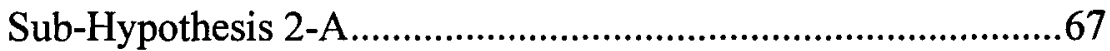

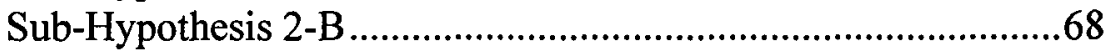

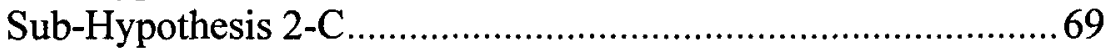

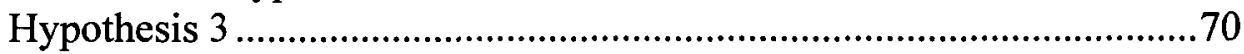

Consideration of Relationship Status and Education Level .....................71

Relationship Status ................................................................71

Highest Level of Education .......................................................72

Additional Research Questions ................................................................73

Best Overall Predictor of Intergenerational Conflict....................74

Boomerang Children.................................................................76

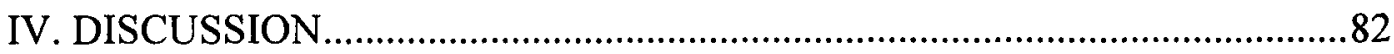

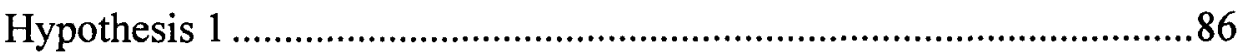

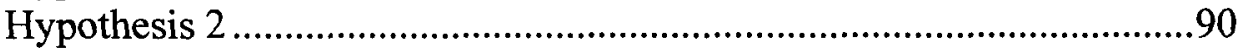

Hypothesis 3 ......................................................................................93

Consideration of Relationship Status and Education Level .....................95

Best Overall Predictor of Intergenerational Conflict ...............................96

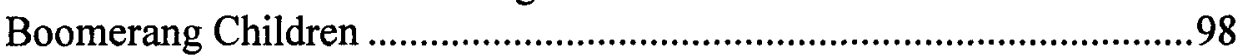

Limitations and Strengths of the Current Study ......................................99

Future Directions for Research ...........................................................103

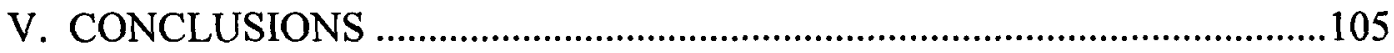

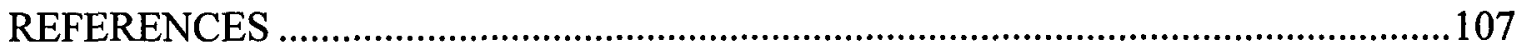

\section{APPENDICES}

A. LIST OF ASIAN AMERICAN CONTACTS ………..............................115

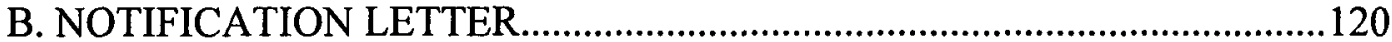

C. ASIAN AMERICAN FAMILY CONFLICTS SCALE (FCS).......................121

D. INTERGENERATIONAL CONFLICT INVENTORY (ICI) ........................126

E. ASIAN AMERICAN MULTIDIMENSIONAL ACCULTURATION SCALE (AAMAS) ..................................................128

F. DEMOGRAPHIC QUESTIONNAIRE......................................................131

VITA 


\section{LIST OF TABLES}

Table

1. Demographic Information of Participants.

23

2. Number of Participants by Ethnicity and Gender Across

Demographic Variables

3. Descriptive Statistics for All Predictor and Dependent Variables

4. Correlations Between All Predictor and Dependent Variables

5. Means (Standard Deviations) for Level of Intergenerational Conflict By Ethnic Group

6. Means (Standard Deviations) for Level of Intergenerational Conflict By Gender

7. Means (Standard Deviations) for Level of Intergenerational Conflict By Age Group

8. Means (Standard Deviations) for Level of Intergenerational Conflict By Living Situation.

9. Means (Standard Deviations) for Level of Intergenerational Conflict By Highest Level of Education.

10. Means (Standard Deviations) for Level of Intergenerational Conflict By Annual Income

11. Means (Standard Deviations) for Level of Intergenerational Conflict By Relationship Status.

12. Means (Standard Deviations) for Level of Intergenerational Conflict By Language Most Frequently Used for Communication with Parents

13. Correlations Between Acculturation Gap, Generational Status, and Intergenerational Conflict (Hypothesis 1)

14. Total and Direct Effect of Generational Status on Intergenerational Conflict Related to Dating and Marriage.

15. Correlations Between Birth Order Status, Gender, and Intergenerational Conflict (Hypothesis 2) 
16. Correlations Between Language Proficiency and Intergenerational Conflict (Hypothesis 3).

17. Overall Predictors of Intergenerational Conflict: Standard Regression Analyses

18. Means and Standard Deviations for Intergenerational Conflict By Decision to Return Home

19. Analysis of Variance Source Table for Differences in Intergenerational Conflict Based on Decision to Return Home

20. Means and Standard Deviations for Intergenerational Conflict By Frequency of Contact While Away 80

21. Analysis of Variance Source Table for Differences in Intergenerational Conflict Based on Frequency of Contact While Away 


\section{LIST OF FIGURES}

Figure

Page

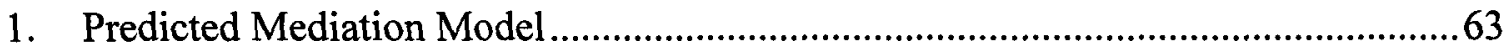

2. Regression 1: Total Effect between Generational Status and

Conflict Related to Dating and Marriage Issues.

3. Regression 2: Relationship between the Predictor and the Hypothesized Mediator.

4. Regression 3: Direct Effect between Generational Status and Conflict Related to Dating and Marriage Issues 


\section{CHAPTER 1}

\section{INTRODUCTION}

Over the past few decades, more young adults are continuing to live with their parents well into adulthood (Messineo \& Wojtkiewicz, 2004). From 1980 to 2008, the percentage of young adults between the ages of 25 and 34 who were currently living with their parents increased from 11 percent to 20 percent (Pew Research Center, 2010). Higher rates of co-residence are, in part, attributed to a delayed flight from the nest as children leave the home at later ages than in the past. Likely contributing to this trend is the increase in the median age of first marriage. In their analysis of census data, the Pew Research Center (2010) found that the average man now marries for the first time at age 28 and the average woman at age 26 , which is about five years older for both genders than it was in 1970.

Higher rates of co-residence are also attributed to more frequent home-returning, as children return to live with their parents after living away for an extended period of time (e.g., after graduating from college). The likelihood of young adults returning to live at home at least once appears to have increased from 22 percent to 40 percent from 1920 to 1980 (Goldscheider \& Goldscheider, 1994). The state of the economy can certainly play a role in the percentage of young adults who return home to live with their parents. Indeed, the most recent economic recession is described to be the reason for returning home by approximately one in eight young adults between the ages of 22 and 29 (Pew Research Center, 2009).

Researchers propose that these changing trends among young adults have altered the normative course of development from childhood to adulthood, such that a new, 
distinct period of life termed "emerging adulthood" now exists (Arnett, 2000; Blinn-Pike, Worthy, Jonkman, \& Smith, 2008). Individuals between the ages of 18 and 25 are identified as "emerging adults", who are neither adolescents nor adults and whose lives are characterized by less stability in terms of their finances, living situation, interpersonal relationships, and cognitive, emotional, and spiritual development. Increases in coresidence due to delayed home-leaving and more frequent home-returning among emerging adults may have significant implications on parent-child relationships as both parents and children may need to adjust to new roles and responsibilities in the family. Exactly what adjustments must occur, however, when emerging adults live at home? Unfortunately, the impact of such events is largely unknown due to a paucity of research on the topic, despite increasing co-residence between emerging adults and parents. Based on the research that has been conducted, some families appear to adjust relatively well to new roles and responsibilities (Mitchell \& Gee, 1996), whereas others seem to struggle and experience a more negative co-residence experience (Umberson, 1992). What could account for these differences in how families cope with emerging adults living at home? If, indeed, a certain percentage of families experience significant difficulties when an emerging adult lives at home, it could be beneficial to investigate the exact nature of intergenerational conflict in families with an emerging adult living at home. Such knowledge may help illuminate what specific factors predict and contribute to greater intergenerational conflict, laying the foundation for future prevention and intervention methods geared towards reducing intergenerational conflict.

As one explores the nature of intergenerational conflict in families and possible predictors of conflict when an emerging adult resides at home, it is imperative to consider 
the influence of culture and context. Cultures may differ significantly in terms of their predominant values, norms, and standards of behavior, which can translate into vast differences in how families interpret and address developmental issues, life changes, and family conflicts. Indeed, research conducted among Asian American families suggests that intergenerational conflict may develop differently in Asian American families than in White American families (Greenberger \& Chen, 1996; Kwak \& Berry, 2001; Lee, Choe, Kim, \& Ngo, 2000; Lee \& Liu, 2001). One ethnic difference that has emerged from the research, for instance, is a trend of increasing intergenerational conflict in Asian American families as children enter late adolescence and adulthood, in contrast to the decrease in conflict typically found in White American families (Greenberger \& Chen, 1996; Lee et al., 2000; Lee \& Liu, 2001).

If intergenerational conflict seems to increase as Asian American children age, questions emerge about what possible conflicts may arise when children are well into adulthood. Unfortunately, most studies assessing intergenerational conflict in Asian American families have only been conducted among adolescent and college-aged Asian American children, leaving a large gap in the research regarding intergenerational conflict between Asian American emerging adults and their parents. The gap in the literature is especially concerning when one considers the increasing rates of emerging adults residing in the home, particularly among ethnic minority groups. Based on 2008 U.S. Census data, Asians, Blacks, and Hispanics are all statistically more likely than Whites to live in a multi-generational family household (Pew Research Center, 2010). Highest rates are found among Asians, with about one out of every four Asians living in a multi-generational family household. 
The paucity of research is also problematic when one considers the possibility that Asian American emerging adults and parents may be at particularly high risk of experiencing intergenerational conflict. It has been theorized that intergenerational conflict increases over the course of adolescence in Asian American families but not White American families because of ethnic differences in how autonomy is viewed (Greenberger \& Chen, 1996). As adulthood approaches, it is generally expected that children should grow more autonomous, particularly if they are reared in a culture that highly values autonomy and perceives it as an indicator of maturity, such as the mainstream American culture. Although autonomy is certainly valued in Asian cultures as well, interdependence and filial obedience are arguably more emphasized, such that autonomous behavior may be viewed negatively if it conflicts with parental authority and family unity. These cultural differences may translate into less encouragement and acceptance of their children's autonomous behavior among Asian American parents, which can be at odds with the growing autonomy one generally expects to see in late adolescence and adulthood. If, moreover, an emerging adult has lived away from home for an extended period of time (e.g., to attend college), one may expect the emerging adult to be accustomed to a relatively high level of autonomy, which may result in even greater conflict when emerging adults return home to live with their parents.

The limited research on this topic coupled with this increased risk for conflict in Asian American families engender a strong need for additional empirical research about intergenerational conflict in Asian American families when emerging adults live at home. The purpose of the current study was to investigate the extent and nature of intergenerational conflict between Asian American emerging adults and their parents 
when emerging adults live with their parents, and what factors may predict intergenerational conflict. It was expected that emerging adults report, on average, a moderate degree of conflict with parents when they live at home. Greater conflict was expected: (a) when a large acculturation gap existed between emerging adults and their parents; (b) among first generation emerging adults; (c) among female emerging adults; (d) among first born emerging adults; and (e) when parents had limited proficiency in the English language and emerging adults had limited proficiency in their parents' native language. Prior to describing the nature and findings of the study in more detail, a review of the literature regarding intergenerational conflict, particularly in Asian American families, is presented.

\section{Intergenerational Conflict in Asian American Families}

As children assume greater responsibility and autonomy with age, a certain degree of conflict with parents may not be surprising and may even be expected. It is commonly believed that intergenerational conflict between parents and children tends to rise during early adolescence but eventually declines by late adolescence and early adulthood (Laursen, Coy, \& Collins, 1998). This viewpoint may be incomplete, however, in that it may not be descriptive of developmental patterns among ethnic minority groups. Because the majority of empirical research supporting this belief was conducted with White American populations, it is uncertain whether these findings on intergenerational conflict during adolescence generalize to other ethnic groups.

Among the few studies that have been conducted with Asian American populations, it seems that intergenerational conflict may, indeed, develop differently in Asian American families than in White American families (Greenberger \& Chen, 1996). 
As discussed earlier, intergenerational conflict has been found to decrease from adolescence to adulthood for White Americans but increase for Asian Americans. Whereas White and Asian American early adolescents reported relatively equal levels of conflict, Asian American college students seemed to experience significantly more conflict with both fathers and mothers than their White American counterparts. Asian American students' higher levels of conflict were associated with reports of less family cohesiveness and greater depressive symptoms, underscoring the influence of parental relationships on children's general well-being, even in adulthood. Common sources of conflict included issues related to children's personal habits, social life, and privacy.

Based on this research, it appears that intergenerational conflict remains a relevant issue for many Asian American families, even well into adulthood. It has been theorized that the process of establishing autonomy may occur later in adolescence for Asian American children, such that conflict is delayed until later as well (Greenberger \& Chen, 1996). As Asian American adolescents begin to seek autonomy, their efforts may receive less support from their parents due to cultural expectations for filial respect and obedience. Children of all Asian ethnic groups are socialized to honor and obey their elders, particularly their parents, even if it requires denying their own personal desires and preferences at times $(\mathrm{Ho}, 1993)$. Although autonomy is highly indicative of maturity in White American culture, it is children's respect and obedience towards elders that tends to be more emphasized as reflective of maturity in Asian cultures. This even applies to such matters as career and marriage choices, due to the belief that the child's choice and the success of their career and relationships ultimately affects and reflects on the family as a unit. 
Adding a layer of complexity to intergenerational conflict as it occurs in Asian American families is the fact that the majority of Asian Americans in the United States are from immigrant backgrounds. Because of this factor, one must consider the influence of socio-economic status and national origin on intergenerational conflict, in addition to ethnic differences. In 2005, of the 13.5 million Asian Americans residing in the U.S., approximately 8.7 million (64 percent) were born in Asia and immigrated to the U.S. (Leong \& Okazaki, 2009). Immediately upon arriving in the U.S., immigrants and their children are exposed to the White mainstream culture. Children are likely to acculturate the most quickly and to the greatest extent because of the intensive educational experiences they receive in the U.S., which their parents are less likely to receive. An acculturation gap may grow between children and parents, as children adopt more of the values, norms, and customs of the dominant culture than do their parents. Whereas the parents may have been predominantly raised in an Asian culture, their children may be raised in both an Asian culture (e.g., in the home) and the White mainstream culture (e.g., in school and society at large). Indeed, feelings of being torn between two conflicting cultures and uncertainty of where they belong are not uncommon among children of immigrant heritage (Chung, 2006; Ying, Coombs, \& Lee, 1999).

If Asian American parents identify with their native Asian culture to a greater extent than their children, who may identify with both White mainstream and Asian culture, intergenerational conflict that is typically normative during adolescence may be exacerbated. Adolescents may seek to establish a degree of autonomy that is normative in White mainstream culture but is considered a cause for concern in their parents' native Asian culture. Thus, they may face significant resistance from their parents, resulting in 
greater conflict than would be expected during adolescence. Indeed, Vietnamese adolescents endorsed greater disagreement with parents about parental authority and children's rights than their White peers, describing an intense struggle for control with their parents (Greenberger \& Chen, 1996; Kwak \& Berry, 2001). Other studies have corroborated these patterns, noting more family conflict among Asian American families due to cultural differences in values and lifestyles, particularly if children are more highly acculturated to U.S. culture than their parents (Lee \& Liu, 2001).

Impact of Intergenerational Conflict. Parent-child conflict has been found to have a direct relationship with children's psychological functioning and may be a significant risk factor for a variety of mental health difficulties. Indeed, intergenerational conflict is reported to be one of the most common presenting problems among Asian American college students who seek counseling services (Lee, Su, \& Yoshida, 2005). The impact of intergenerational conflict is not merely limited to children's current functioning, however. In a longitudinal study with a group of Southeast Asian adolescents, possible long-term effects were detected, as level of perceived intergenerational conflict was found to be predictive of depressive symptoms three years later (Ying \& Han, 2007). Intergenerational conflict has been found to alter both children's emotional and physical states, with an increase in negative affect as well as somatic symptoms of distress noted (Lee et al., 2005).

Beyond depressive symptomatology, research has also found intergenerational conflict to be associated with lower self-esteem in ethnic minority populations (Gil, Vega, \& Dimas, 1994), as well as greater school difficulties (Yao, 1985), gang involvement (Kibria, 1993), and suicidality (Lau, Jernewall, Zane, \& Myers, 2002). In a 
recent study at the University of California-Davis, Asian American college students who reported significant family conflict were three times more likely to attempt suicide than Asian Americans who did not experience significant family conflict (Preventive Medicine Week, 2008).

In qualitative studies, Asian American adolescents have described significant frustration, confusion, fear, and guilt, as they struggle to balance conflicting values, norms, and expectations across their home and school environments (Chung, 2006; Ying et al., 1999). In the majority of cases, children report strong desires and efforts to meet their parents' expectations, but they face obstacles when these expectations do not match those of society at large. From their parents' perspective, however, children's behavior can often be perceived as highly oppositional and reflective of a purposeful refusal to fulfill their family roles and responsibilities (Ying \& Chao, 1996). Asian American parents often report feelings of betrayal by their children, as well as feelings of failure, shame, and anxiety as they question whether they have fulfilled their own roles and responsibilities as parents (Chung, 2006). It is uncertain whether and to what degree children and parents are aware of the other's feelings and perspectives, which could certainly interfere with empathy and conflict resolution. More research is needed regarding parents' perspectives in particular.

\section{Predictors of Intergenerational Conflict}

Acculturation Gap. Acculturation is the psychosocial process of adapting to a new, dominant culture and is, thus, an important concept in understanding the experiences of immigrant families and cultural minorities (Chiu, Feldman, \& Rosenthal, 1992). Individuals acculturate as they learn new languages, change their diets, adopt 
different values and customs (e.g., holidays), and are guided by a different set of norms and standards of behavior (e.g., how to dress). Previous research has indicated a significant relationship between children's level of acculturation to the dominant culture and level of intergenerational conflict with parents. Specifically, children who were found to be more highly acculturated tended to report lower levels of intergenerational conflict (Chung, 2001). Because intergenerational conflict, by definition, involves both children and parents, one must also give consideration to the relationship between parents' level of acculturation and conflict, as well as the relationship between the gap in parents' and children's level of acculturation and conflict.

An acculturation gap refers to a difference in the extent to which individuals or groups have adopted aspects of a new culture, such that one individual or group may have adopted aspects of a new culture to a greater extent than another individual or group. To illustrate, two individuals may have immigrated to the U.S. at the same time, but over the course of a decade, one individual may speak English more fluently, eat more traditional American food in restaurants and at home, practice a greater variety of mainstream American customs and traditions (e.g., Christmas and the Fourth of July), and follow many more American standards and norms of behavior (e.g., regarding dress, speech, and etiquette) than the second individual. The first individual would be described as more acculturated than the second individual who may not speak English as fluently, does not eat a great deal of American food, does not take part in American customs and traditions, and does not follow many American standards and norms. Although these two individuals may have resided in the U.S. for the same amount of time, they have acculturated to different extents, resulting in an acculturation gap between them. 
An acculturation gap may develop in many immigrant families due to parents' and children's differential rates of acculturation to the dominant host culture. Immigrant parents have been found to acculturate at slower rates than their children, who may have been born into the new culture or raised in it from an early age (Szapocznik \& Kurtines, 1993). Due to more opportunities for formal schooling, children tend to receive greater exposure to the behavioral standards, norms, and values of the dominant culture. Children are also less likely to have spent as much time as their parents residing in their parents' native culture, particularly U.S.-born children. In this way, not only are children more acculturated to the dominant culture, but they are also less enculturated to their parents' native culture and may adopt fewer values and norms of that culture than their parents (Kim, 2007).

An acculturation gap between parents and children has consistently been shown to contribute to intergenerational conflict (Farver, Narang, \& Bhadha, 2002; Ying \& Han, 2007). Research has demonstrated a strong, positive relationship between gaps in acculturation and intergenerational conflict, such that the larger the acculturation gap, the higher the family conflict (Ying \& Han, 2007). When an acculturation gap between parents and children was not present, family conflict and anxiety were lower and selfesteem was higher in a group of Asian Indian adolescents compared to when an acculturation gap was present (Farver et al., 2002).

Generational Status. In addition to acculturation gap, children's generational status has also been found to predict degree of intergenerational conflict. First generation status has been linked to greater family conflict and more negative parent-child relationships than second- and third-generation status (Dinh, Sarason, \& Sarason, 1994; 
Ying, Lee, Tsai, Lee, \& Tsang, 2001). An interesting possibility to consider is whether an acculturation gap may explain or contribute to this relationship between generational status and intergenerational conflict. Research has shown that individuals tend to acculturate more with time, such that the acculturation gap tends to be smaller among parents and children who have resided in a host country for longer periods of time than those who may have recently arrived (Dhruvarajan, 1993). Because second and third generation children are more likely to have lived in a host country for a longer period of time than first generation children, it may be the case that a smaller acculturation gap may be accounting for lower intergenerational conflict in second and third generation children compared to first generation children, rather than generational status in and of itself. Because this has not yet been studied in the literature, it is uncertain to what degree an acculturation gap may mediate the relationship between generational status and intergenerational conflict.

Gender of Child. With regard to children's gender as a predictor of intergenerational conflict, the research has been equivocal. Studies have shown daughters to report higher levels of conflict (Chung, 2001; Mitchell, 1998; Rumbaut, 1996), sons to report more conflict (Gil-Rivas et al., 2003) or no gender differences at all (Florsheim, 1997). It is possible that these mixed findings may simply be due to methodological differences across studies in terms of how conflict is measured. Daughters tend to report more conflict related to dating and marriage issues (Chung, 2001), whereas sons tend to report more conflict related to risk-taking behaviors (GilRivas et al., 2003). Since social and romantic relationships, in particular, have been described as very common topics of conflict in Asian American families, one may expect 
to see greater intergenerational conflict with daughters than with sons due to the dating and marriage issues that are likely to arise among emerging adults. This expectation is supported by evidence that parents take somewhat different parenting approaches for their daughters than their sons, often using more protective and restrictive practices that may especially conflict with children's efforts to achieve autonomy during adolescence and young adulthood (Rumbaut, 1996). Among 16 first generation Asian Indian parents, mothers described imposing dating restrictions for their daughters but not for their sons (Inman, Howard, Beaumont, \& Walker, 2007).

Birth Order Status of Child. Similar to the case with gender, current literature suggests that children's birth order status may also contribute to different parent-child dynamics in the family depending on the order in which one is born (Sulloway, 1996). Parents have been shown to enforce higher standards of achievement and responsibility for their first born children than their second born children, regardless of gender (Liu, 1998). This trend appears to be particularly true for Asian American families compared to White American families, with greater responsibility expected of first born Asian American children than first born White American children (Barrett Singer, 2000). Birth order may play a role in dictating proscribed social roles, behaviors, and expectations in Asian American families (Hamilton, 1996), with more strict standards applied to first born children. These differences in standards and parenting approaches may translate into differences in the extent to which first born and later born children experience intergenerational conflict. There is some evidence that parents tend to experience less conflict with their second born children compared to when their first born children were of the same age (Shanahan, McHale, Wayne Osgood, \& Crouter, 2007). One possible 
explanation for this trend is that parents may be learning from their experiences with their first born children such that they become better suited to address sources of conflict with their second born children (Shanahan et al., 2007; Whiteman, McHale, \& Crouter, 2003). Language Proficiency. Limited language proficiency can contribute to a breakdown in communication between parents and children, ultimately setting the stage for intergenerational conflict to arise or else be managed maladaptively (Lee \& Cynn, 1991). This is supported by research showing Asian American adolescents to experience substantial difficulties in communicating effectively with their parents, ultimately contributing to a sense of decreased family cohesion (Tseng \& Fuligni, 2000). Limited language proficiency on both parents' and children's part may increase communication difficulties. Because most children are given ample opportunity to learn and practice the English language through formal schooling, children often become more proficient in English and at a faster rate than do their parents (Uba, 1994). They may also have fewer opportunities to have learned and practiced their parents' native language, particularly if they are U.S.-born and have not undergone any formal schooling in their parents' native language. Together, these two trends may yield children who are more proficient in English and parents who are more proficient in their native language. As such, limited English proficiency among parents and children's limited proficiency in their parents' native language may predict more intergenerational conflict as miscommunication may result in greater conflict or otherwise impede how conflict is addressed.

\section{Emerging Adults at Home}

Although a great deal is known about intergenerational conflict as it occurs between Asian American adolescents and parents, very limited empirical research has 
been conducted investigating intergenerational conflict among Asian American emerging adults and their parents, beyond college. This topic certainly deserves greater attention due to increased rates of emerging adults residing with their parents over past decades (Messineo \& Wojtkiewicz, 2004; Pew Research Center, 2010). Increased rates of coresidence between emerging adults and their parents are due to both delayed homeleaving and more frequent home-returning after an initial departure, such as those emerging adults who return home after graduating from college. The term "boomerang kids" refers collectively to children who have resided away from home for a minimum of 4-6 months before returning home (Mitchell, 2006). Up to 40 percent of U.S. emerging adults have been estimated to return to their parents' home at some point following an initial departure (Goldscheider \& Goldscheider, 1999). Co-residence rates may be even higher among Asian American emerging adults, due to the significant emphasis on collectivist values and filial responsibility in Asian cultures (Pew Research Center, 2010; Turcotte, 2006).

When emerging adults live at home, many changes may occur in parents' and children's roles and responsibilities, requiring the family to adjust to these new changes. Depending on the degree, nature, and context of the changes, as well as family members' perception of those changes, families may adjust differently. Indeed, it seems that some families adjust to new intergenerational roles and responsibilities with relative ease and limited conflict (Mitchell \& Gee, 1996), whereas others seem to struggle, resulting in a more negative co-residence experience (Umberson, 1992). Unfortunately, little is currently known about what specific factors may predict and contribute to a positive or negative experience when an emerging adult lives at home. Factors that have been found 
to enhance co-residence experiences are higher levels of reciprocity between parents and children and more autonomy among children (Mitchell, 1998).

It is uncertain, however, whether these same factors would also predict better adjustment in Asian American families due to the limited representation of ethnic minorities in the research. Indeed, one may even expect reciprocity between parents and children and greater autonomy among children to predict more negative co-residence experiences in Asian American families when one considers the great emphasis placed on parental authority and elder respect in Asian cultures. This is somewhat supported by research showing that role changes between Korean immigrant parents and children may be perceived as threats to parental authority (Shon \& Ja, 1982). Because of different cultural values, Asian American parents may be less open and willing to share authority and decision-making with their children than White American parents, and may be less supportive of children's efforts and desire to establish autonomy from their family.

As the number of Asian American emerging adults who reside in parental homes continues to grow, particularly after returning home from an initial departure, there is an increased need for empirical research investigating how families cope with the changes these moves can bring. Given that intergenerational conflict seems to increase as Asian American children grow older, even into adulthood, Asian American families may be at greater risk of a negative co-residence experience when emerging adults reside with their parents. The purpose of the current study was to investigate the extent and nature of intergenerational conflict between Asian American parents and their emerging adult children residing in the home, and what factors may predict or mediate intergenerational conflict. 


\section{Hypotheses}

Based on the literature reviewed above, the following three hypotheses were formulated:

1. Acculturation Gap, Generational Status, and Intergenerational Conflict:

A. Acculturation and Conflict: Perceived acculturation gap between emerging adults and their parents would be significantly correlated with level of intergenerational conflict, such that the larger the acculturation gap, the more conflict reported.

B. Generational Status and Conflict: Generational status of emerging adults would be significantly correlated with level of intergenerational conflict, with first generation emerging adults reporting more conflict than those of later generations.

C. Generational Status and Acculturation: Generational status of emerging adults would be significantly correlated with acculturation gap, with first generation emerging adults reporting larger acculturation gaps than those of later generations.

D. Acculturation as a Mediator between Generational Status and Conflict: When acculturation gap is accounted for, generational status and conflict would be less significantly related.

2. Birth Order Status, Gender, and Intergenerational Conflict:

A. Birth Order Status and Conflict: Birth order status of emerging adults would be significantly correlated with level of intergenerational conflict, such that first born status would be associated with more 
conflict than later born status.

B. Gender and Conflict: Gender of emerging adults would be significantly correlated with intergenerational conflict, with females reporting more conflict than males.

C. Interaction of Birth Order Status and Gender: Among first born emerging adults, gender would not be significantly related to intergenerational conflict, such that males and females would report similar levels of conflict. Among later born children, gender would be significantly related with conflict, with females reporting more conflict than males.

\section{Language Proficiency:}

A. Parents: Limited proficiency in the English language among parents would be significantly correlated with higher levels of intergenerational conflict.

B. Emerging Adults: Limited proficiency in parents' native language among emerging adults would be significantly correlated with higher levels of intergenerational conflict. 


\section{CHAPTER 2}

\section{METHOD}

\section{Participants}

Participants were primarily recruited via Web-based sources (e.g., online communities, forums, and e-mail listservs) that were specifically geared towards the interests of Asian American ethnic groups (see Appendix A). These sources included Asian American college alumni networks, undergraduate and graduate Asian American ethnic student groups, and national Asian American community groups and forums whose topics focused on issues related to being Asian American (e.g., racial identity, acculturation, racism, vocations, and cultural events). Local Asian American community groups in geographical areas with a high concentration of Asian American young adults were also contacted (e.g., select cities in California, Texas, and New York).

Listserv moderators, discussion leaders, and other representatives of the communities were contacted via e-mail to assess interest in participating in the study and to request permission to distribute or post a description of the study on the community website or listserv. Only those communities, forums, and listservs for which permission to contact was granted were invited to participate in the study. A snowball approach was used as participants were encouraged to contact others who may also be interested in and eligible to participate in the study. Participation through this method of recruitment was completely voluntary with no compensation for participation. One of three Visa Gift Cards, each in the amount of $\$ 30$, was randomly awarded, however, to three participants at the completion of the study.

Because the study was interested in studying intergenerational conflict among 
Asian American emerging adults and their parents, participation was restricted to those individuals who were at least 18 years of age or older and were of Asian American heritage. Individuals with East Asian (e.g., Korean and Japanese), Southeast Asian (e.g., Vietnamese), and South Asian (e.g., Indian) backgrounds were all included. Both females and males were invited to participate.

A secondary method of recruitment was used and consisted of convenience sampling from undergraduate and graduate students enrolled at Old Dominion University, a public university in the southeast region of the United States. Through this method, participants were gathered from the psychology participant pool, all of whom were students enrolled in at least one introductory level psychology course. Students were compensated with one point of departmental research credit for their participation. The aforementioned inclusion criteria were also applied to participants gathered from this college participant pool.

A diverse group of Asian American emerging adults were surveyed, characterized by a wide range of ages, ethnicities, and living situations. Emerging adults who had returned home to live with their parents after living a certain period of time away were recruited (i.e., "boomerang kids"). Four months was set as the minimum length of time away in order for a child to be considered a "boomerang kid" based on the precedence established in the literature (Mitchell, 2006). Emerging adults who were not currently living with their parents, but had once returned home after living away were also recruited to speak retrospectively on their home-returning experience. Additionally, some children were not currently living with their parents, but returned home for brief visits over the course of the year (e.g., college students during school vacations). 
Because intergenerational conflict may emerge during these visits home, these groups were also assessed. College students who were currently living at home with their parents would also provide valuable information regarding intergenerational conflict when emerging adults reside in the home and, thus, were assessed as well.

Through these various methods of recruitment, a final sample of 350 participants was obtained. About 12.6 percent of participants were current boomerang children, meaning that they had returned home to live with their parents after living away for more than four months $(n=44)$. About 23.1 percent were past boomerang children, meaning that they had once returned home after living away but were currently no longer living with their parents $(n=81)$. If participants did not fall into either the current or past boomerang group, they were classified as currently living at school (32.9 percent, $n=$ 115 ), living on their own (12 percent, $n=42$ ), or living at home without ever having left for more than four months (19.4 percent, $n=68)$.

Both women and men were represented in the sample, with approximately 62.6 percent being female $(n=216)$ and 37.4 percent being male $(n=129)$. A variety of Asian ethnicities were represented, including Chinese (22.3 percent, $n=78$ ), Korean (19.7 percent, $n=69$ ), Vietnamese (16.6 percent, $n=58$ ), and Filipino (14.3 percent, $n=$ 50). About 10.2 percent $(n=36)$ of participants reported to be another Asian ethnicity not listed (e.g., Indian, Thai, Laotian, or Japanese), and about 13.4 percent $(n=47)$ were of a mixed ethnic background (e.g., White and Asian or Black/African American and Asian). The ethnic make-up of this sample resembled that of the general U.S. Asian American population, based on 2007 American Community Survey population estimates (U.S. Census Bureau, 2007). Of the 14.9 million individuals reported to be of full or 
partial Asian heritage in the U.S., approximately 23.7 percent identified as Chinese, 20.5 percent identified as Filipino, 11 percent identified as Vietnamese, and 10.5 percent identified as Korean.

The majority of the participants were between the ages of 18 and 22 (57.4 percent, $n=198)$, with about 27 percent between the ages of 23 and $28(n=93)$ and 15.6 percent at the age of 29 or higher $(n=54)$. In terms of generational status, approximately 32.9 percent of participants were first generation children $(n=115), 57.4$ percent were second generation $(n=201)$, and 9.7 percent were third, fourth, or fifth generation or higher ( $n=$ 15). With regard to birth order status, about 36.6 percent were first born children ( $n=$ 128), 33.4 percent were second born $(n=117), 11.4$ percent were third born $(n=40), 6.9$ percent were fourth, fifth, or sixth born or higher $(n=24)$, and 11 percent were only children $(n=38)$.

On average, this study's population of emerging adults reported being "somewhat" proficient in speaking and understanding their parents' native language ( $M=$ $3.21, S D=1.31)$, with 30 percent of participants indicating this level of proficiency ( $n=$ 105). About 20.6 percent indicated "complete" proficiency' in their parents' native language $(n=72), 21.7$ percent indicated being "very" proficient $(n=76), 13.4$ percent reported "a little" proficiency $(n=47)$, and 14.3 percent reported "very little to no" proficiency $(n=50)$. Participants estimated their parents' proficiency in speaking and understanding the English language, with the average level of proficiency falling in the "somewhat" to "very" proficient range $(M=3.64, S D=1.16)$. More specifically, 27.8 percent estimated their parents to be "completely" proficient $(n=97), 29.8$ estimated "very" proficient $(n=104), 27.8$ estimated "somewhat" proficient $(n=97), 8$ percent 
estimated "a little" proficient, and 6.6 percent indicated their parents to have "very little to no" proficiency $(n=23)$ in the English language.

Demographic information for the sample of 350 participants is summarized in Table 1, which includes counts for other variables such as the emerging adult's highest level of education, annual income, relationship status, and the language most used in communicating with parents. Because this study's population of Asian American emerging adults has so rarely been investigated in the literature, particularly in their postcollege years, a more detailed breakdown of the population's demographic information can be found in Table 2 .

This study was approved by the Old Dominion University College of Sciences Human Subjects Committee (COSHSC). All ethical guidelines established by the American Psychological Association were followed (American Psychological Association, 2002).

Table 1

Demographic Information of Participants

\begin{tabular}{lcc}
\hline Variable & $n$ & $\%$ \\
\hline Gender & & \\
Female & 216 & 62.6 \\
Male & 129 & 37.4 \\
& & \\
Ethnicity & & \\
Chinese & 78 & 22.3 \\
Filipino & 50 & 14.3 \\
Korean & 69 & 19.7 \\
Vietnamese & 58 & 16.6 \\
Other Asian Ethnicity & 36 & 10.2 \\
Mixed Ethnicity & 47 & 13.4
\end{tabular}


Table 1 Continued

\begin{tabular}{lll}
\hline Variable & $n$ & $\%$ \\
\hline
\end{tabular}

Age

$\begin{array}{lrr}18-22 & 198 & 57.4 \\ 23-28 & 93 & 27.0 \\ 29-34 & 28 & 8.1 \\ 35 \text { or Higher } & 26 & 7.5\end{array}$

Generational Status

$\begin{array}{lrr}\text { lst } & 115 & 32.9 \\ \text { 2nd } & 201 & 57.4 \\ \text { 3rd } & 11 & 3.1 \\ \text { 4th } & 8 & 2.3 \\ 5^{\text {th }} \text { or Higher } & 15 & 4.3\end{array}$

Birth Order Status

$\begin{array}{lrr}\text { Only Child } & 38 & 11.0 \\ 1^{\text {st }} \text { Born } & 128 & 36.6 \\ 2^{\text {nd }} \text { Born } & 117 & 33.4 \\ 3^{\text {rd }} \text { Born } & 40 & 11.4 \\ 4^{\text {th }} \text { Born } & 11 & 3.1 \\ 5^{\text {th }} \text { Born } & 3 & 0.9 \\ 6^{\text {th }} \text { Born } \text { or Higher } & 10 & 2.9\end{array}$

Child's Proficiency with Parents' Native Language

$\begin{array}{lrr}\text { Very Little to No Proficiency } & 50 & 14.3 \\ \text { A Little Proficient } & 47 & 13.4 \\ \text { Somewhat Proficient } & 105 & 30.0 \\ \text { Very Proficient } & 76 & 21.7 \\ \text { Completely Proficient } & 72 & 20.6\end{array}$

Parents' Proficiency with English

Language

$\begin{array}{lrr}\text { Very Little to No Proficiency } & 23 & 6.6 \\ \text { A Little Proficient } & 28 & 8.0 \\ \text { Somewhat Proficient } & 97 & 27.8 \\ \text { Very Proficient } & 104 & 29.8 \\ \text { Completely Proficient } & 97 & 27.8\end{array}$


Table 1 Continued

\begin{tabular}{lrr}
\hline Variable & $n$ & $\%$ \\
\hline Living Situation & & \\
Current Boomerang Children & 44 & 12.6 \\
Past Boomerang Children & 81 & 23.1 \\
Living at Home (Never & 68 & 19.4 \\
Left) & & \\
Living at School & 115 & 32.9 \\
Living on Own (Never Returned) & 42 & 12.0 \\
& & \\
Annual Income & & \\
Less than \$20,000 & 200 & 60.8 \\
\$20,000-29,999 & 17 & 5.2 \\
\$30,000-39,999 & 26 & 7.9 \\
\$40,000-49,999 & 29 & 8.8 \\
\$50,000-59,999 & 12 & 3.6 \\
\$60,000-69,999 & 12 & 3.6 \\
\$70,000-79,999 & 7 & 2.1 \\
\$80,000-89,999 & 4 & 1.2 \\
\$90,000-99,999 & 3 & 0.9 \\
\$100,000 or more & 19 & 5.8
\end{tabular}

Highest Level of Education

High school degree or less $\quad 40 \quad 11.7$

$\begin{array}{lrr}\text { Some college } & 150 & 43.9\end{array}$

$\begin{array}{lll}\text { Associate's } & 6 & 1.8\end{array}$

$\begin{array}{lll}\text { Bachelor's } & 80 & 23.4\end{array}$

Master's $\quad 43 \quad 12.6$

$\begin{array}{lll}\text { Doctorate } & 23 & 6.7\end{array}$

Current Relationship Status

$\begin{array}{lll}\text { Married } & 35 & 10.1\end{array}$

Divorced or Separated $\quad 2 \quad 0.6$

Single (Not in a Relationship) $\quad 153 \quad 44.0$

In a Relationship $\quad 158 \quad 45.4$

Sexual Orientation

Straight

Gay

$322 \quad 92.0$

$7 \quad 2.0$

Lesbian

$8 \quad 2.3$

Bisexual

$9 \quad 2.6$

Uncertain

$3 \quad 0.9$

Other

10.3


Table 1 Continued

\begin{tabular}{|c|c|c|}
\hline Variable & $n$ & $\%$ \\
\hline \multicolumn{3}{|l|}{ Parents' Relationship Status } \\
\hline Married & 279 & 80.2 \\
\hline Divorced or Separated & 52 & 14.9 \\
\hline Never Married & 2 & 0.6 \\
\hline Other & 15 & 4.3 \\
\hline \multicolumn{3}{|l|}{ Father's Age } \\
\hline $35-40$ & 3 & 0.9 \\
\hline $41-45$ & 29 & 8.4 \\
\hline $46-50$ & 67 & 19.4 \\
\hline $51-55$ & 98 & 28.4 \\
\hline $56-60$ & 60 & 17.4 \\
\hline $61-64$ & 36 & 10.4 \\
\hline 65 or higher & 52 & 15.1 \\
\hline \multicolumn{3}{|l|}{ Mother's Age } \\
\hline $35-40$ & 10 & 2.9 \\
\hline $41-45$ & 36 & 10.3 \\
\hline $46-50$ & 98 & 28.2 \\
\hline $51-55$ & 100 & 28.7 \\
\hline $56-60$ & 57 & 16.4 \\
\hline $61-64$ & 21 & 6.0 \\
\hline 65 or higher & 26 & 7.5 \\
\hline \multicolumn{3}{|c|}{ Father's Highest Level of Education } \\
\hline Some high school or less & 29 & 8.3 \\
\hline High school degree & 48 & 13.8 \\
\hline Some college & 44 & 12.6 \\
\hline Associate's & 21 & 6.0 \\
\hline Bachelor's & 90 & 25.8 \\
\hline Master's & 75 & 21.5 \\
\hline Doctorate & 42 & 12.0 \\
\hline \multicolumn{3}{|c|}{ Mother's Highest Level of Education } \\
\hline Some high school or less & 34 & 9.7 \\
\hline High school degree & 65 & 18.6 \\
\hline Some college & 59 & 16.9 \\
\hline Associate's & 30 & 8.6 \\
\hline Bachelor's & 102 & 29.1 \\
\hline Master's & 49 & 14.0 \\
\hline Doctorate & 11 & 3.1 \\
\hline
\end{tabular}


Table 1 Continued

\begin{tabular}{lrr}
\hline Variable & & \\
\hline Parents' Combined Annual Income & & \\
Less than $\$ 25,000$ & 28 & 8.3 \\
\$25,000-49,999 & 66 & 19.6 \\
\$5,000-99,999 & 103 & 30.7 \\
\$100,000-149,999 & 81 & 24.1 \\
\$150,000-199,999 & 25 & 7.4 \\
\$200,000-299,999 & 19 & 5.7 \\
\$300,000-399,999 & 6 & 1.8 \\
\$400,000 or more & 8 & 2.4 \\
& & \\
Language Most Used to Communicate & & \\
with Parents & 113 & 32.3 \\
Parents' Native Language & 155 & 44.3 \\
English & 74 & 21.1 \\
Equally Parents' Native Language & & \\
and English & 8 & 2.3 \\
Other & & \\
$\quad$
\end{tabular}

Note. $N=350$ 


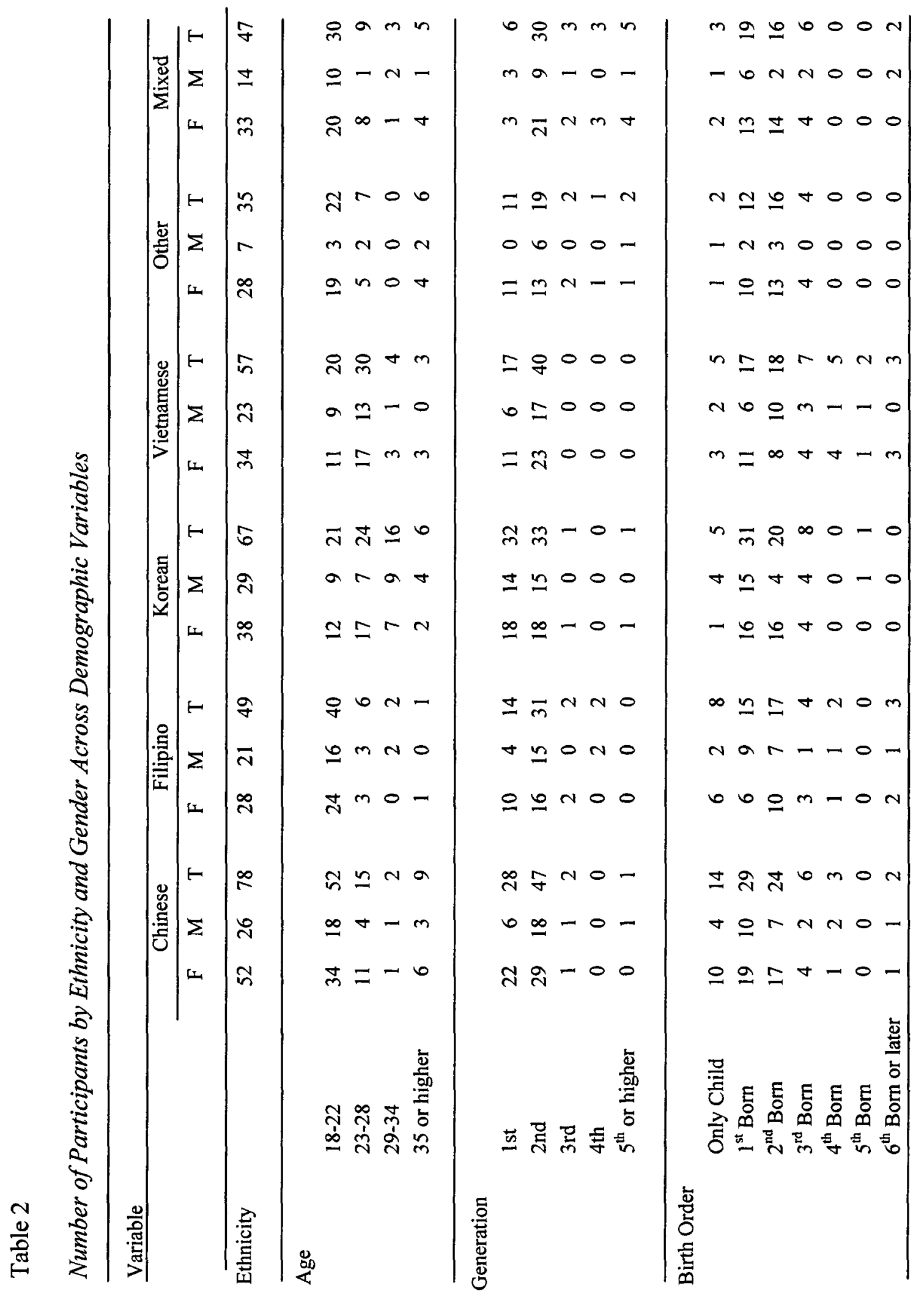




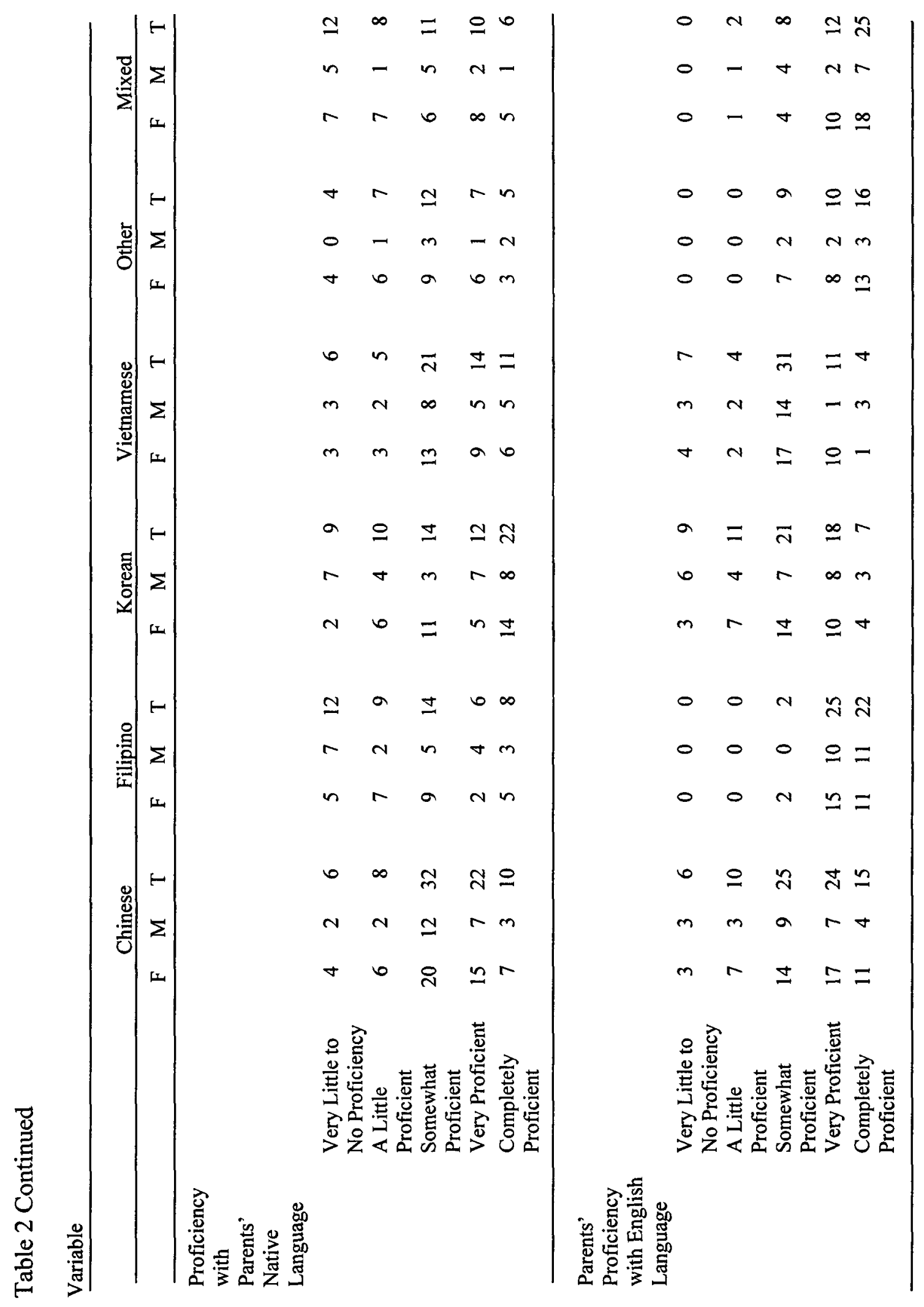




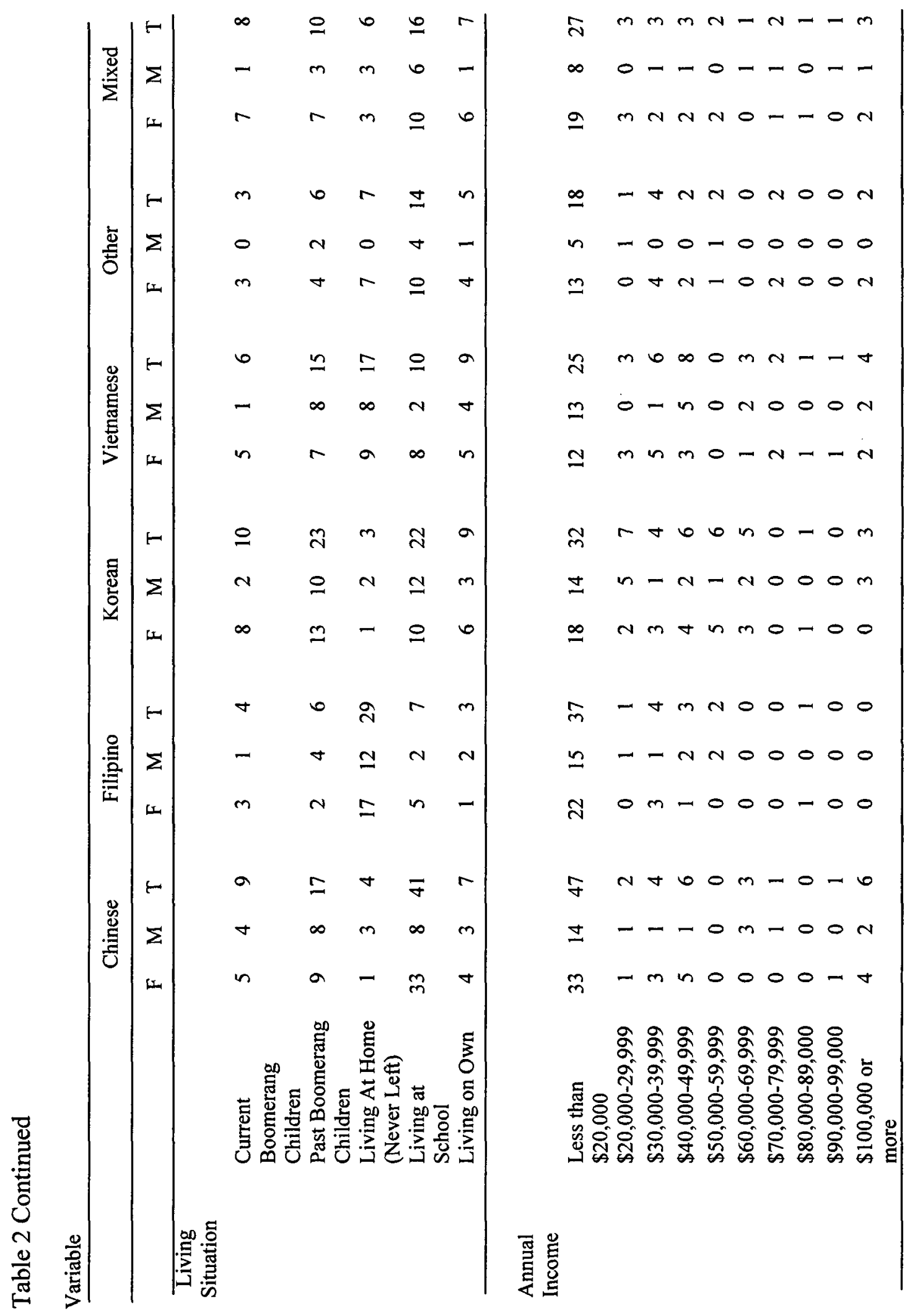




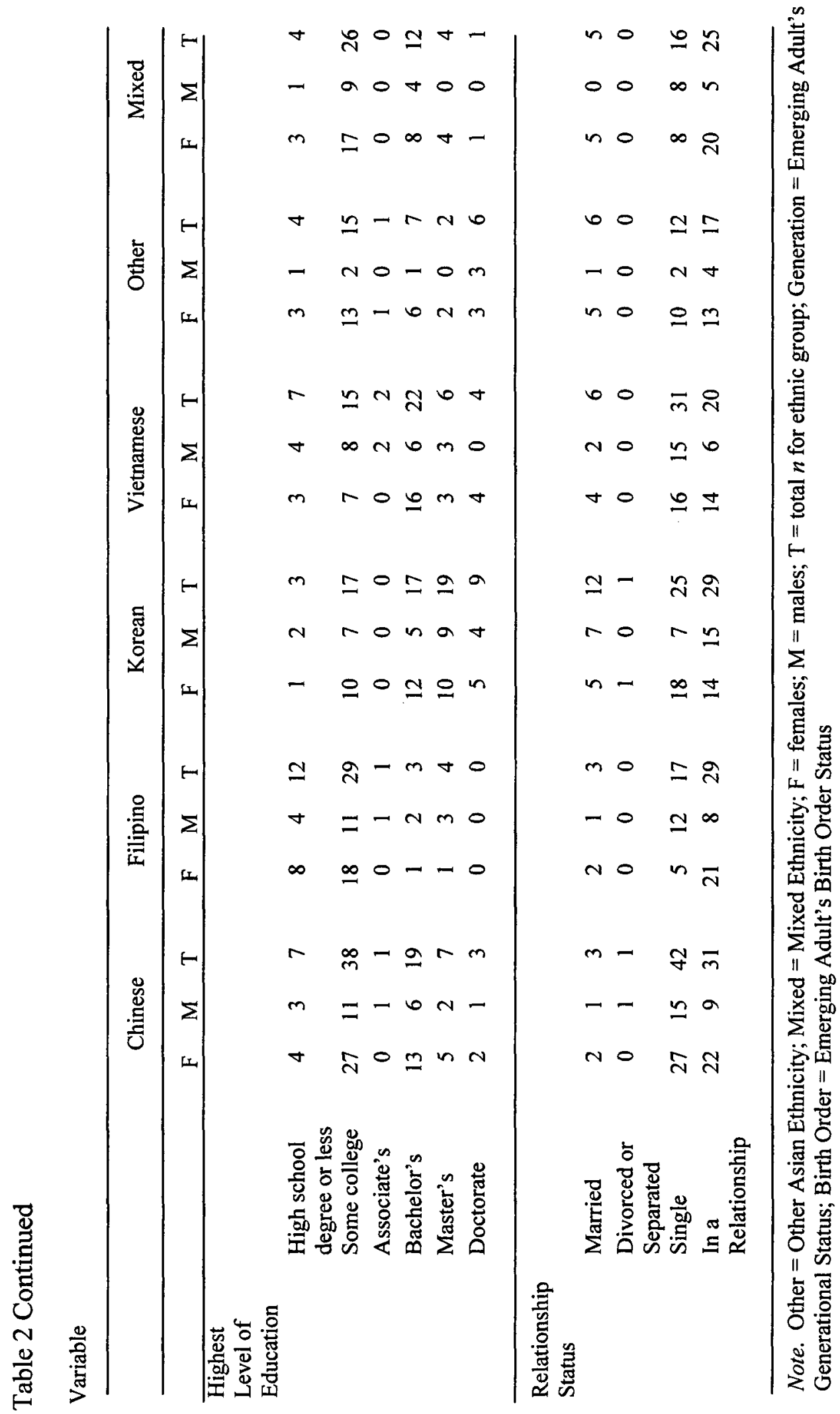


Materials

Because participation in the study was anonymous and no sensitive information was collected, it was not necessary to obtain informed consent. A notification letter was given to each participant, detailing the nature of the study and providing appropriate contact information and resources to participants (see Appendix B).

Asian American Family Conflicts Scale (FCS). Lee et al. (2000)'s Asian American Family Conflicts Scale (FCS) was used to assess intergenerational conflict between Asian American parents and their emerging adult children (see Appendix C). The FCS was a useful tool because it measures family conflict in terms of both the frequency and intensity of conflict. This was an important distinction to make in that families vary significantly in terms of how often conflicts arise as well as how much negative affect or seriousness is associated with that conflict. Some families may experience frequent but relatively minor conflicts whereas others may experience relatively rare but intensely negative conflicts during the few times that they do arise.

Both the frequency and intensity of conflict were also important to measure due to discrepant findings in the literature about whether family conflict increases or decreases across adolescence. When frequency of conflict is assessed, conflict seems to increase during early adolescence but subsequently declines as children approach late adolescence and adulthood (Laursen et al., 1998). When the intensity of conflict is considered, however, conflict appears to increase during late adolescence as it is characterized by more negative affect. It is uncertain why this discrepancy is found, but it has been theorized that decreases in conflict frequency may simply be an artifact of parents and children spending less time together as children age. Although the frequency of 
intergenerational conflict may decrease, conflict may still be problematic if the intensity of conflict is high.

The FCS is a 10-item questionnaire, in which respondents indicate the likelihood that a specific conflict occurs in a child's current relationship with his/her parents as well as the seriousness of the conflict. Because the measure was normed on samples of Asian American college students, the FCS assesses the types of conflicts that most commonly occur in Asian American families during young adulthood. Likelihood of conflict occurrence (FCS-Likelihood) was answered on a 5-point Likert-scale, from 1 (almost never) to 5 (almost always); similarly, seriousness of conflict (FCS-Seriousness) was answered on a 5-point Likert-scale, from 1 (not at all) to 5 (extremely). Scores were summed to yield two subscale scores, each ranging from 10 to 50 , with higher scores indicating greater likelihood or seriousness of conflict. An example of a family situation listed on the FCS follows:

"Your parents want you to sacrifice personal interests for the sake of the family, but you feel this is unfair."

The FCS has been shown to have high internal reliability, with alpha coefficients ranging from .81 to .89 for FCS-Likelihood and from .84 to .91 for FCS-Seriousness (Lee et al., 2000). Internal reliability was found to be high in the current study, with Cronbach's alpha ranging from .94 to .96 across all groups of participants based on their current living situation (e.g., adult children who lived at home with their parents, those who lived at school, and those who lived on their own). Both the Likelihood and Seriousness subscales of the FCS have been found to correlate with the Family Conflict subscale scores on the Social Attitudinal, Familial, Environmental Acculturative Stress 
Scale (SAFE; Padilla, Wagatsuma, \& Lindholm, 1985), an instrument measuring acculturative stress along multiple dimensions. This suggests good concurrent validity for both subscales. Good divergent validity of the FCS has also been established, with FCS scores demonstrated to be unrelated to non-family conflicts on the SAFE.

Intergenerational Conflict Inventory (ICI). Chung (2001)'s Intergenerational Conflict Inventory (ICI) was used to supplement Lee et al. (2000)'s Asian American Family Conflicts Scale (FCS) in measuring intergenerational conflict between Asian American parents and children in the current study (see Appendix D). The ICI, a 24-item questionnaire, assesses family conflict along three different domains: family expectations (11 questions), education and career (10 questions), and dating and marriage (three questions). Respondents rate the extent to which each item is a source of conflict between them and their parents on a 5-point Likert Scale, with higher scores indicating greater conflict. Scores were summed to yield three subscale scores, ranging from 11 to 66 for Family Expectations, 10 to 60 for Education and Career, and 3 to 18 for Dating and Marriage. Sample items from each of the ICI's subscales follow:

Family Expectations: "Your desire for greater independence and autonomy."

Education and Career: "How much time to spend on studying." Dating and Marriage: "Whom to date."

The ICI has been found to show good reliability, with alpha coefficients ranging from .84 to .88 across the three subscales (Chung, 2001). Test-retest reliability after a seven-week re-assessment has been found to range from .81 to .87. With regard to the current study, reliability of ICI scores was found to be 
high, with Cronbach's alpha ranging from .90 to .96 across all groups of participants. The ICI also has demonstrated good face validity (Chung, 2001).

Asian American Multidimensional Acculturation Scale (AAMAS). Chung, Kim, and Abreu (2004)'s Asian American Multidimensional Acculturation Scale (AAMAS) was used to measure emerging adults' level of acculturation to both Asian culture and White mainstream culture (see Appendix E). The AAMAS is a 15 -item questionnaire that assesses acculturation across several domains, including language proficiency, music and food preferences, adherence to traditions, cultural knowledge and attitudes, and cultural and social identity. For each item, respondents indicate the extent to which a specified skill, preference, or behavior applies to them, using a 6-point Likert scale ranging from 1 (not very well) to 6 (very well).

A great benefit of the AAMAS was that it follows a multi-dimensional model of acculturation, under the premise that individuals can identify with two or more cultures simultaneously. This is in contrast to measures that may assess acculturation unidimensionally, such that identification with one culture necessarily indicates less identification with a different culture. The original AAMAS measures acculturation along three dimensions: one's own Asian culture of origin (e.g., Vietnamese culture alone), Pan-ethnic Asian American culture (i.e., all Asian cultures), and one's host society's mainstream culture (e.g., White mainstream culture in the U.S.). In order for the AAMAS to be used with validity, at least two of the three cultural dimensions must be assessed at the same time. For the purposes of this study, only acculturation to one's own Asian culture of origin and to White mainstream culture were assessed. A sample item from the AAMAS as used in the current study follows: 
"How proud are you to be part of...

a. your own Asian culture of origin?

b. the White mainstream groups?

The AAMAS was scored by calculating the sum across all items within the same cultural dimension (e.g., one's own Asian culture of origin) and then dividing the sum by the total number of items. This yielded an average scaled score for that cultural dimension that ranges from 1 to 6 , with a higher score reflecting a higher level of acculturation. Only Item 15 needed to be reverse coded before summing all scores. Because the current study was only interested in measuring acculturation to participants' own Asian culture of origin and to White mainstream culture, only two scaled scores were calculated.

The AAMAS has demonstrated good reliability, with internal consistency alpha coefficients ranging from .76 to .91 and test-retest coefficients ranging from .75 to .89 across all cultural dimension scales (Chung et al., 2004). Reliability of AAMAS scores was high in the current study, with a Cronbach's alpha coefficient of .92 obtained for adult children's acculturation to their own Asian culture of origin and .88 for their acculturation to White mainstream culture.

Because this study investigated the influence of an acculturation gap between parents and children, parents' level of acculturation was also considered. As such, a modified version of the AAMAS was created for use in estimating parents' level of acculturation, with children reporting on their perception of their parents' cultural knowledge, attitudes, and behavior. In the current study, a Cronbach's alpha coefficient 
of .94 was obtained for parents' acculturation to both their own Asian culture of origin and White mainstream culture, demonstrating high reliability. Once an acculturation score was obtained for each child and the parents as a unit, the extent of an acculturation gap was estimated by calculating the difference between the child's and parents' level of acculturation. A larger difference in scores suggested a larger acculturation gap between parents and children. Two acculturation gap scores were ultimately calculated: one for differences in how much parents and children have acculturated to their respective Asian cultures of origin (i.e., Asian acculturation gap) and one for differences in their acculturation to White mainstream culture (i.e., White acculturation gap).

Demographic Questionnaire. A Demographic Questionnaire (see Appendix F) was created to gather socio-demographic information about each emerging adult, including ethnicity, gender, age, highest level of education, annual income, birth order status, generational status, language proficiency, relationship status, and living situation. Data regarding parents' socio-demographic information were also collected, including parents' age, highest level of education, marital status, and language proficiency. Among current or past boomerang children, information was gathered about the circumstances surrounding children's time away from home (e.g., reason for leaving home and length of time away) and their return home (e.g., reason for returning home) when applicable.

\section{Procedure}

Using Inquisite Survey Builder, an online survey was created, compiling the Asian American Family Conflict Scale (FCS), the Intergenerational Conflict Inventory (ICI), the Asian American Multidimensional Acculturation Scale (AAMAS), and the Demographic Questionnaire into a single survey. Upon project approval from the 
College of Sciences Human Subjects Committee (COSHSC) at Old Dominion University, appropriate contacts with listserv moderators and forum discussion leaders were made to request permission to distribute or post a description of the study and a link to the website where participants could complete the survey online. The survey link was also posted on the Old Dominion University Psychology Research website, where registered students could complete the survey for one point of research credit.

Individuals who were interested in participating were directed to complete the survey at their own convenience. In completing the survey, participants first viewed a notification letter, describing to them the nature of the study. Following the notification letter, each questionnaire was presented for completion. Once all questionnaires were completed, participants were directed to a separate survey where they could enter into a raffle to win one of three $\$ 30$ Visa Gift Cards or enter their student identification numbers in order to obtain course credit. All identifying information was kept separate from survey responses and could not be linked back to participants, maintaining the anonymity of their responses. 


\section{CHAPTER 3}

\section{RESULTS}

All statistical analyses were performed with the Statistical Package for the Social Sciences (SPSS) Version 16.0 for Windows.

\section{Data Management and Preliminary Analyses}

Prior to conducting hypothesis testing, the data were scrutinized for missing values. A total of 18 participants omitted all or the majority of items for at least one questionnaire (e.g., the Family Conflict Scale or the Asian American Multidimensional Acculturation Scale). Data from these 18 cases were deleted, reducing the sample size from a total of 368 to 350 participants. This sample size met the minimum of 220 participants that was needed to achieve adequate power, as determined by a power analysis conducted a priori, with power set at .80 and the alpha level set at .05 .

If a participant was found to have omitted only a few items for a specific questionnaire, mean substitution was used to estimate the values for those missing items. Through this method, the mean of a participant's own scores on items that were answered was used to replace the value of the missing item. For example, if a participant in this current study failed to answer one item on the Asian American Multicultural Acculturation Scale (AAMAS), the mean of his/her scores on the other 14 items was used to estimate the value of the missing item. This method of mean substitution is commonly regarded as conservative, since the mean for that individual does not change (Tabachnick \& Fidell, 2007). Of the 350 participants, a total of 89 participants had 1 to 4 missing values on any one questionnaire that were estimated via mean substitution. In order to assess whether missing values were randomly distributed, participants were divided into 
two groups: cases with missing values and cases without missing values. No significant differences were found in level of intergenerational conflict between groups, suggesting that data were missing in a random pattern.

The data were also screened for potential outliers, using the cutoff of three standard deviations above or below the mean to identify an outlier (Tabachnick \& Fidell, 2007). Through the method of Winsorizing, all outliers were appropriately dealt with by transforming them to a number one unit larger or smaller than the next most extreme score in the distribution. This method reduced the impact of the outliers on the shape of the distribution while still allowing the observed values to remain deviant. Across all scales, a total of 20 scores were transformed via this method.

Data were also tested for normality, screening for any significant skewness and kurtosis. The level of skewness for all variables fell within the acceptable range to justify normality. However, some kurtosis was found in the distribution of parents' scores in level of Asian acculturation, which was slightly leptokurtic (kurtosis $=2.54)$. The impact of statistically significant kurtosis diminishes with a large sample size, so the scores did not deviate enough from normality to have had a substantial effect on the validity of analyses in this current study (Tabachnick \& Fidell, 2007). Thus, all scales were found to be normally distributed.

Restricted range in scores did not appear to be a significant problem for most variables, with the one exception of parents' level of Asian acculturation. A box plot graph revealed that the majority of parents were identified as being highly acculturated to Asian culture. This case of restricted range was not believed to pose a significant problem, however, given that these scores were not directly used in the primary analyses. 
These scores were only used to calculate acculturation gap, which was the key variable of interest and was not characterized by the same problem of a restricted range in scores.

Descriptive statistics (i.e., means, standard deviations, Cronbach's alpha coefficients, skewness and kurtosis statistics) for predictor variables and dependent variables are reported in Table 3. Table 4 presents correlation coefficients for relationships between all predictor variables and dependent variables.

Table 3

Descriptive Statistics for All Predictor and Dependent Variables

\begin{tabular}{|c|c|c|c|c|c|}
\hline Variable & $M$ & $S D$ & Cronbach's $\alpha$ & Skewness & Kurtosis \\
\hline Family Conflict Scale & & & $0.94-0.96$ & & \\
\hline $\begin{array}{l}\text { Likelihood of } \\
\text { Conflict }\end{array}$ & 2.59 & 0.94 & & 0.37 & -0.68 \\
\hline $\begin{array}{l}\text { Seriousness of } \\
\text { Conflict }\end{array}$ & 2.27 & 0.90 & & 0.55 & -0.35 \\
\hline $\begin{array}{l}\text { Intergenerational Conflict } \\
\text { Inventory }\end{array}$ & & & $0.90-0.96$ & & \\
\hline Family Expectations & 2.22 & 0.77 & & 0.45 & -0.20 \\
\hline $\begin{array}{l}\text { Education and } \\
\text { Career }\end{array}$ & 2.35 & 0.98 & & 0.59 & -0.36 \\
\hline $\begin{array}{l}\text { Dating and } \\
\text { Marriage }\end{array}$ & 2.52 & 1.36 & & 0.56 & -0.93 \\
\hline Overall & 2.31 & 0.81 & & 0.56 & -0.10 \\
\hline Asian Acculturation Gap & 1.36 & 0.89 & & 0.60 & -0.19 \\
\hline $\begin{array}{l}\text { Emerging Adult: Level } \\
\text { of Asian Acculturation }\end{array}$ & 3.98 & 1.09 & 0.92 & -0.34 & -0.35 \\
\hline $\begin{array}{l}\text { Parents: Level of Asian } \\
\text { Acculturation }\end{array}$ & 5.29 & 0.86 & 0.94 & -1.80 & 2.54 \\
\hline White Acculturation Gap & 1.37 & 0.96 & & 0.67 & -0.04 \\
\hline $\begin{array}{l}\text { Emerging Adult: Level } \\
\text { of White Acculturation }\end{array}$ & 4.87 & 1.09 & 0.88 & -0.77 & -0.31 \\
\hline $\begin{array}{l}\text { Parents: Level of White } \\
\text { Acculturation }\end{array}$ & 3.57 & 1.15 & 0.94 & 0.04 & -0.78 \\
\hline
\end{tabular}


Table 3 Continued

\begin{tabular}{lccccc}
\multicolumn{1}{c}{ Variable } & $M$ & $S D$ & Cronbach's a & Skewness & Kurtosis \\
\hline Generational Status & 1.88 & 0.91 & 1.82 & 4.16 \\
Birth Order & 1.73 & 1.23 & 1.31 & 2.61 \\
$\begin{array}{l}\text { Emerging Adult's Proficiency } \\
\text { in Parents' Native Language }\end{array}$ & 3.21 & 1.31 & -0.22 & -0.96 \\
$\begin{array}{l}\text { Parents' Proficiency in English } \\
\text { Language }\end{array}$ & 3.64 & 1.16 & & -0.60 & -0.33 \\
& & & & \\
\hline
\end{tabular}

Note. $N=350$. 


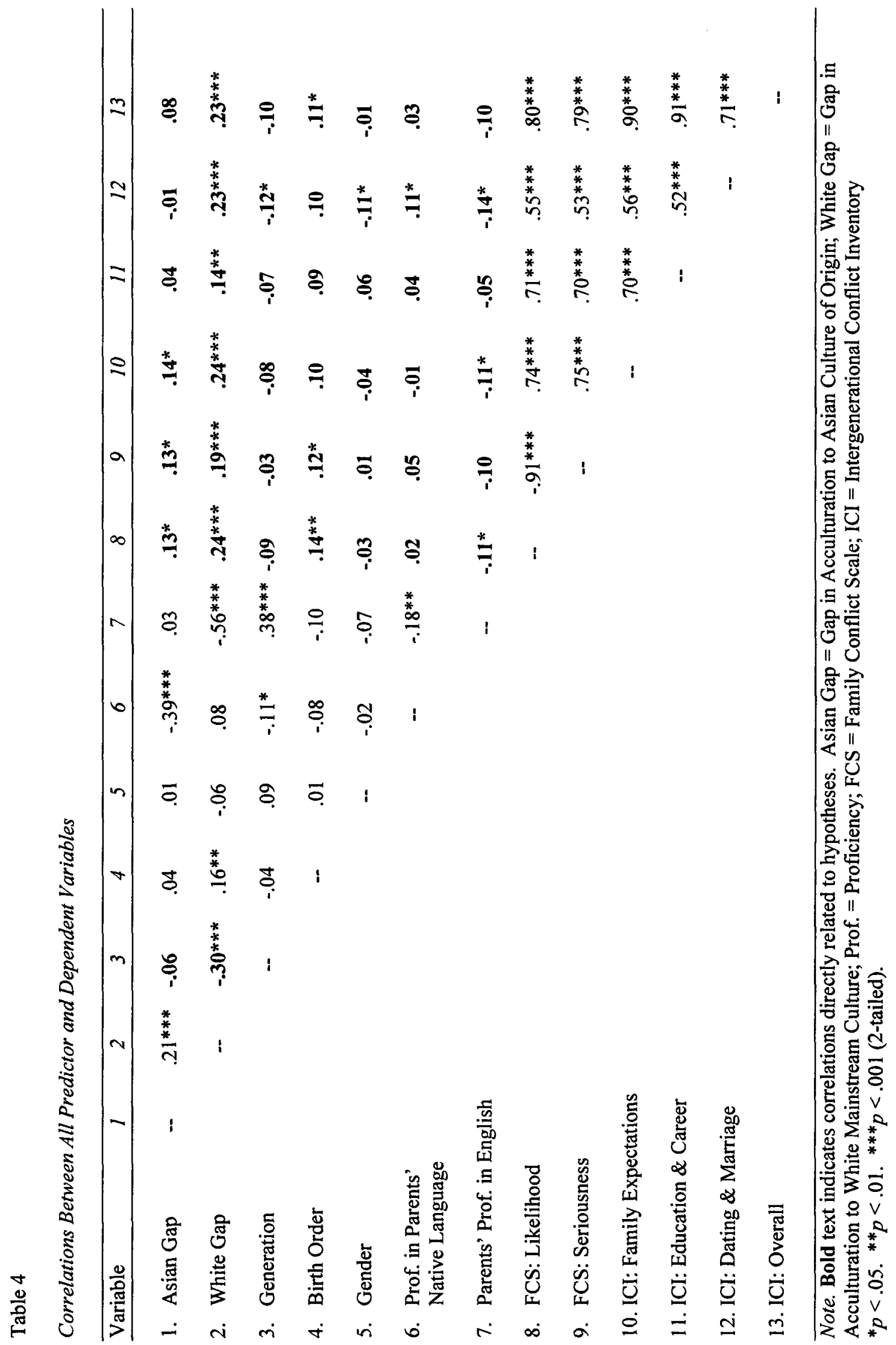


Overall Level of Intergenerational Conflict

For the total sample of 350 Asian American emerging adults collected in this study, a low to medium level of intergenerational conflict was generally reported across all measures of conflict. On the Family Conflict Scale (FCS), likelihood of conflict occurred on average between "once in a while" and "sometimes" $(M=2.59, S D=.94)$, and seriousness of conflict was indicated to be "slight" or "moderate" on average ( $M=$ $2.27, S D=.90)$. On the Intergenerational Conflict Inventory $(\mathrm{ICI})$, overall conflict $(M=$ $2.31, S D=.81)$ and conflict specifically related to family expectations $(M=2.22, S D=$ $.77)$, education and career $(M=2.35, S D=.98)$, and dating and marriage $(M=2.52, S D=$ 1.36) were also found to be in the low to medium range.

Group Differences in Intergenerational Conflict

Analyses were performed to detect group differences in level of conflict across several demographic variables, specifically ethnicity, gender, age, current living situation, highest level of education, relationship status, and the language most used in communicating with parents.

Ethnicity. A one-way between-subjects analysis of variance (ANOVA) was performed to determine whether level of intergenerational conflict differed across ethnic groups. All necessary assumptions were met in order to justify running this analysis, including normality of sampling distributions of means and homogeneity of variance (Aron \& Aron, 2003). Between-groups effects were found for five out of the six measures of intergenerational conflict. Post-hoc comparisons were performed using the Tukey HSD test in order to determine where group differences specifically occurred. In terms likelihood of conflict, the between-groups effect, $F(6,343)=5.49, p<.001$, partial 
$\eta^{2}=.09$, yielded a large effect size according to Cohen (1988)'s standards. The Tukey HSD post-hoc comparison revealed that emerging adults of Vietnamese heritage ( $M=$ $3.09, S D=.82)$ reported greater likelihood of conflict with their parents than those of Korean heritage $(M=2.27, S D=.77)$ or of mixed ethnicities (e.g., Asian and White; $M=$ $2.53, S D=.73$ ). It was also revealed that emerging adults of another Asian ethnicity not listed (e.g., Indian, Japanese, Thai, or Laotian; $M=2.84, S D=1.24$ ) reported greater likelihood of conflict with their parents than those of Korean heritage.

In terms of seriousness of conflict, the between-groups effect, $F(6,343)=4.22, p$ $<.001$, partial $\eta^{2}=.07$, yielded a medium effect size (Cohen, 1988). Emerging adults of Vietnamese heritage $(M=2.69, S D=.92)$ were found to report more serious conflict than their peers of Chinese $(M=2.09, S D=.87)$ or Korean $(M=2.02, S D=.80)$ heritage. With regard to intergenerational conflict related to specific topics, three significant between-groups effect were detected: conflict related to family expectations, $F(6,343)=$ $3.97, p<.01$, partial $\eta^{2}=.07$; conflict related to dating and marriage, $F(6,343)=2.65, p$ $<.05$, partial $\eta^{2}=.05$; and overall conflict, $F(6,343)=3.34, p<.01$, partial $\eta^{2}=.06$. A medium effect size was obtained for all three between-groups effects (Cohen, 1988). The Tukey HSD post-hoc comparison indicated that emerging adults of Vietnamese heritage $(M=2.44, S D=.61)$ and of another Asian ethnicity not listed (e.g., Indian, Thai, or Laotian; $M=2.54, S D=1.01$ ) reported greater conflict related to family expectations than their Korean counterparts $(M=1.94, S D=.68)$. For conflict related to dating and marriage issues, emerging adults of another Asian ethnicity not listed $(M=3.06, S D=$ 1.63) reported greater conflict than those of mixed ethnicities $(M=2.12, S D=1.11)$. Korean emerging adults $(M=2.06, S D=.70)$ described less overall conflict than 
Vietnamese emerging adults $(M=2.53, S D=.70)$ or those of another Asian ethnicity not listed $(M=2.65, S D=1.06)$. See Table 5 for all means and standard deviations for each level of intergenerational conflict across ethnicity.

Table 5

Means (Standard Deviations) for Level of Intergenerational Conflict By Ethnic Group

Ethnic Group

$n$

Family Conflict Scale

Likelihood

Seriousness

Chinese

78

$2.42_{\mathrm{ab}}(.94)$

$2.09_{b}(.87)$

Filipino

50

$2.62(1.03)$

$2.24(.87)$

Korean

69

$2.27_{\mathrm{a}}(.77)$

$2.02_{b}(.80)$

Vietnamese

58

$3.09_{c}(.82)$

$2.69 \mathrm{a}(.92)$

Other Asian

36

$2.84_{b c}(1.24)$

$2.52(1.16)$

Ethnicities

Mixed Ethnicities

47

$2.53_{\mathrm{ab}}(.73)$

$2.23(.73)$ 
Table 5 Continued

Ethnic Group $\quad n$

Intergenerational Conflict Inventory

\begin{tabular}{lccccc}
\cline { 3 - 5 } & & $\begin{array}{c}\text { Family } \\
\text { Expectations }\end{array}$ & $\begin{array}{c}\text { Education } \\
\text { and Career }\end{array}$ & $\begin{array}{c}\text { Dating } \\
\text { and Marriage }\end{array}$ & Overall \\
\hline Chinese & 78 & $2.11(.75)$ & $2.31(1.05)$ & $2.41(1.45)$ & $2.23(.87)$ \\
Filipino & 50 & $2.26(.85)$ & $2.49(1.09)$ & $2.49(1.52)$ & $2.38(.92)$ \\
Korean & 69 & $1.94_{\mathrm{a}}(.68)$ & $2.09(.85)$ & $2.37(1.12)$ & $2.06_{\mathrm{a}}(.70)$ \\
Vietnamese & 58 & $2.44_{\mathrm{b}}(.61)$ & $2.53(.93)$ & $2.89(1.36)$ & $2.53_{\mathrm{b}}(.70)$ \\
$\begin{array}{l}\text { Other Asian } \\
\text { Ethnicities }\end{array}$ & 36 & $2.54_{\mathrm{b}}(1.01)$ & $2.65(1.21)$ & $3.06_{\mathrm{a}}(1.63)$ & $2.65_{\mathrm{b}}(1.06)$ \\
$\begin{array}{l}\text { Mixed } \\
\text { Ethnicities }\end{array}$ & 47 & $2.27(.67)$ & $2.21(.78)$ & $2.12_{\mathrm{b}}(1.11)$ & $2.23(.56)$
\end{tabular}

Note. Means within columns not sharing subscripts are significantly different from each other at the $p<.05$ level according to the Tukey HSD test.

Gender. A one-way between-subjects analysis of variance (ANOVA) was performed to determine whether males and females reported significantly different levels of intergenerational conflict. All necessary assumptions were met (Aron \& Aron, 2003). There were more female participants $(n=216)$ than males $(n=129)$, but the unequal group sizes were not expected to be problematic, given that only one-way betweensubjects ANOVAs were performed and the assumption of homogeneity of variance was not violated (Tabachnick \& Fidell, 2007). A significant between-groups effect was only detected for conflict related to dating and marriage issues, $F(1,343)=3.95, p<.05$, partial $\eta^{2}=.01$, with a small effect size obtained (Cohen, 1988). Female emerging adults 
$(M=2.62, S D=1.43)$ were found to report more conflict related to dating and marriage issues than male emerging adults $(M=2.32, S D=1.23)$. See Table 6 for means and standard deviations for all levels of intergenerational conflict across gender.

Table 6

Means (Standard Deviations) for Level of Intergenerational Conflict By Gender

Gender $n \quad$ Family Conflict Scale

Likelihood Seriousness

\begin{tabular}{llll}
\hline Females & 216 & $2.61(1.02)$ & $2.26(.97)$
\end{tabular}

$\begin{array}{ll}\text { Males } & 129 \\ \end{array}$

$2.28(.79)$

Gender

$n$

Intergenerational Conflict Inventory

\begin{tabular}{cccc}
\hline $\begin{array}{c}\text { Family } \\
\text { Expectations }\end{array}$ & $\begin{array}{c}\text { Education } \\
\text { and Career }\end{array}$ & $\begin{array}{c}\text { Dating } \\
\text { and Marriage }\end{array}$ & Overall \\
\end{tabular}

\begin{tabular}{llllll}
\hline Females & 216 & $2.24(.80)$ & $2.30(1.00)$ & $2.62_{\mathrm{a}}(1.43)$ & $2.31(.85)$
\end{tabular}

$\begin{array}{llllll}\text { Males } & 129 & 2.18(.67) & 2.42(.92) & 2.32_{b}(1.23) & 2.30(.72)\end{array}$

Note. Means within columns not sharing subscripts are significantly different from each other at the $p<.05$ level.

Age. Participants were designated into one of the following four age groups: 18$22,23-28,29-34$, and 35 or higher. This permitted the use of a one-way betweensubjects ANOVA to assess for differences in level of intergenerational conflict across age group. All necessary assumptions were met, and unequal group sizes were not expected 
to be problematic (Aron \& Aron, 2003; Tabachnick \& Fidell, 2007). A significant between-groups effect was only found for conflict related to education and career issues, $F(3,346)=3.70, p<.05$, partial $\eta^{2}=.03$, with a small effect size obtained (Cohen, 1988). The Tukey HSD post-hoc comparison revealed that emerging adults between the ages of $18-22(M=2.50, S D=.98)$ reported greater conflict related to education and career issues than their 23 to 28 -year-old counterparts $(M=2.16, S D=.96)$. Table 7 provides the means and standard deviations for all levels of intergenerational conflict across age group.

Table 7

Means (Standard Deviations) for Level of Intergenerational Conflict By Age Group Age Group $\quad n \quad$ Family Conflict Scale

\begin{tabular}{lccc}
\cline { 3 - 3 } & & Likelihood & Seriousness \\
\hline $18-22$ & 198 & $2.65(.93)$ & $2.33(.91)$ \\
$23-28$ & 93 & $2.54(.95)$ & $2.16(.86)$ \\
$29-34$ & 28 & $2.60(.97)$ & $2.44(.96)$ \\
35 or higher & 31 & $2.27(.94)$ & $2.06(.91)$
\end{tabular}


Table 7 Continued

Age Group

Intergenerational Conflict Inventory

\begin{tabular}{cccc}
\hline $\begin{array}{c}\text { Family } \\
\text { Expectations }\end{array}$ & $\begin{array}{l}\text { Education } \\
\text { and Career }\end{array}$ & $\begin{array}{c}\text { Dating } \\
\text { and Marriage }\end{array}$ & Overall \\
\end{tabular}

$18-22$

198

$2.23(.78)$

$2.50_{\mathrm{a}}(.98)$

$2.56(1.41)$

$2.38(.81)$

23-28

93

$2.14(.72)$

$2.16_{b}(.96)$

$2.47(1.33)$

$2.19(.79)$

29-34

28

$2.43(.77)$

$2.21(.76)$

$2.70(1.32)$

$2.37(.74)$

35 or higher

31

$2.17(.83)$

$2.09(1.12)$

$2.20(1.22)$

$2.14(.88)$

Note. Means within columns not sharing subscripts are significantly different from each other at the $p<.05$ level according to the HSD Tukey test.

Living Situation. A one-way between-subjects ANOVA was performed to detect differences in level of intergenerational conflict across living situation. All necessary assumptions were met, and unequal group sizes were not expected to be problematic (Aron \& Aron, 2003; Tabachnick \& Fidell, 2007). Two significant between-groups effect were found: likelihood of conflict, $F(4,345)=2.81, p<.05$, partial $\eta^{2}=.03$; and seriousness of conflict, $F(4,345)=2.57, p<.05$, partial $\eta^{2}=.03$. A small effect size was obtained for both between-groups effects (Cohen, 1988). The Tukey HSD post-hoc comparison revealed that those emerging adults who were currently living with their parents and had never left home $(M=2.88, S D=.96)$ reported greater likelihood of conflict than those emerging adults who were currently living at school and only returned home at certain times of the year (e.g., vacations; $M=2.46, S D=.91$ ). In terms of seriousness of conflict, the Tukey HSD post-hoc comparison did not reveal any 
statistically significant group differences, but the LSD test found those emerging adults who were currently living with their parents and had never left $(M=2.51, S D=.95)$ to report more serious conflict than those who were currently living at home but only after living away from home for a period of time (e.g., Boomerang children; $M=2.08, S D=$ $.80)$, those who are currently living at school $(M=2.16, S D=.90)$, and those who are currently living on their own and had never returned home after living away $(M=2.15$, $S D=.96)$. See Table 8 for the means and standard deviations for all levels of conflict across living situation.

Table 8

Means (Standard Deviations) for Level of Intergenerational Conflict By Living Situation

Living Situation $\quad n \quad$ Family Conflict Scale

\begin{tabular}{lccc}
\cline { 3 - 3 } & & Likelihood & Seriousness \\
\hline $\begin{array}{l}\text { Current Boomerang } \\
\text { Children }\end{array}$ & 44 & $2.49(.87)$ & $2.08(.80)$ \\
$\begin{array}{l}\text { Past Boomerang } \\
\text { Children }\end{array}$ & 81 & $2.66(.91)$ & $2.38(.87)$ \\
$\begin{array}{l}\text { Living w/ Parents } \\
\text { (Never Left) }\end{array}$ & 68 & $2.88_{\mathrm{a}}(.96)$ & $2.51(.95)$ \\
$\begin{array}{l}\text { Living at School } \\
\text { Living on Own } \\
\text { (Never Returned) }\end{array}$ & 115 & $2.46_{\mathrm{b}}(.91)$ & $2.16(.90)$ \\
& 42 & $2.41(1.06)$ & $2.15(.96)$
\end{tabular}


Table 8 Continued

\begin{tabular}{|c|c|c|c|c|c|}
\hline \multirow[t]{2}{*}{ Living Situation } & \multirow[t]{2}{*}{$n$} & \multicolumn{4}{|c|}{ Intergenerational Conflict Inventory } \\
\hline & & $\begin{array}{c}\text { Family } \\
\text { Expectations }\end{array}$ & $\begin{array}{l}\text { Education } \\
\text { and Career }\end{array}$ & $\begin{array}{c}\text { Dating } \\
\text { and Marriage }\end{array}$ & Overall \\
\hline $\begin{array}{l}\text { Current } \\
\text { Boomerang } \\
\text { Children }\end{array}$ & 44 & $2.14(.67)$ & $2.12(.87)$ & $2.43(1.38)$ & $2.17(.71)$ \\
\hline $\begin{array}{l}\text { Past Boomerang } \\
\text { Children }\end{array}$ & 81 & $2.36(.70)$ & $2.41(.83)$ & $2.44(1.30)$ & $2.39(.69)$ \\
\hline $\begin{array}{l}\text { Living w/ Parents } \\
\text { (Never Left) }\end{array}$ & 68 & $2.29(.83)$ & $2.50(1.06)$ & $2.61(1.39)$ & $2.41(.89)$ \\
\hline Living at School & 115 & $2.15(.76)$ & $2.37(1.01)$ & $2.61(1.43)$ & $2.30(.82)$ \\
\hline $\begin{array}{l}\text { Living on Own } \\
\text { (Never Returned) }\end{array}$ & 42 & $2.09(.90)$ & $2.16(1.12)$ & $2.35(1.27)$ & $2.15(.94)$ \\
\hline
\end{tabular}

Note. Means within columns not sharing subscripts are significantly different from each other at the $p<.05$ level according to the Tukey HSD test.

Highest Level of Education. A one-way between-subjects ANOVA was performed to detect differences in level of intergenerational conflict depending upon the emerging adult's highest level of education. All necessary assumptions were met, and unequal group sizes were not expected to be problematic (Aron \& Aron, 2003;

Tabachnick \& Fidell, 2007). No statistically significant group differences were found for any level of intergenerational conflict. Table 9 provides the means and standard deviations for all levels of conflict across education levels. 
Table 9

Means (Standard Deviations) for Level of Intergenerational Conflict By Child's Highest Level of Education

\begin{tabular}{lccc} 
Education Level & $n$ & \multicolumn{2}{l}{ Family Conflict Scale } \\
\cline { 3 - 4 } & & Likelihood & Seriousness \\
\hline $\begin{array}{l}\text { High school degree } \\
\text { or less }\end{array}$ & 40 & $2.72(.97)$ & $2.36(.97)$ \\
Some college & 150 & $2.60(.96)$ & $2.30(.92)$ \\
Associate's & 6 & $2.43(1.02)$ & $2.28(.95)$ \\
Bachelor's & 80 & $2.47(.84)$ & $2.09(.73)$ \\
Master's & 43 & $2.64(1.02)$ & $2.35(.98)$ \\
Doctorate & 23 & $2.55(1.10)$ & $2.29(1.13)$
\end{tabular}

Education Level $\quad n \quad$ Intergenerational Conflict Inventory

$\begin{array}{clcc}\text { Family } & \text { Education } & \text { Dating } & \text { Overall } \\ \text { Expectations } & \text { and Career } & \text { and Marriage } & \end{array}$

\begin{tabular}{lccccc}
\hline $\begin{array}{l}\text { High school } \\
\text { degree or less }\end{array}$ & 40 & $2.32(.73)$ & $2.48(.93)$ & $2.47(1.37)$ & $2.40(.76)$ \\
Some college & 150 & $2.22(.80)$ & $2.47(1.00)$ & $2.55(1.42)$ & $2.36(.84)$ \\
Associate's & 6 & $2.00(.72)$ & $2.27(.75)$ & $1.78(1.22)$ & $2.06(.51)$ \\
Bachelor's & 80 & $2.07(.65)$ & $2.10(.92)$ & $2.43(1.33)$ & $2.13(.72)$ \\
Master's & 43 & $2.44(.81)$ & $2.30(1.05)$ & $2.60(1.26)$ & $2.40(.89)$ \\
Doctorate & 23 & $2.26(.93)$ & $2.15(.99)$ & $2.51(1.37)$ & $2.24(.90)$ \\
& & & & & \\
\hline
\end{tabular}


Annual Income. A one-way between-subjects ANOVA was conducted to assess for differences in level of intergenerational conflict depending upon the emerging adults' annual income group. All necessary assumptions were met, and unequal group sizes were not expected to be problematic (Aron \& Aron, 2003; Tabachnick \& Fidell, 2007). No statistically significant group differences across income level were detected for any level of intergenerational conflict. Means and standard deviations for all levels of conflict across income level are provided in Table 10.

Table 10

Means (Standard Deviations) for Level of Intergenerational Conflict By Annual Income

Annual Income

$n$

Family Conflict Scale

Likelihood Seriousness

\begin{tabular}{lccc}
\hline Less than $\$ 20,000$ & 200 & $2.59(.91)$ & $2.27(.88)$ \\
$\$ 20,000-39,999$ & 43 & $2.47(.94)$ & $2.23(.93)$ \\
$\$ 40,000-59,999$ & 41 & $2.49(.96)$ & $2.17(.91)$ \\
$\$ 60,000-99,999$ & 26 & $2.53(1.05)$ & $2.13(.94)$ \\
$\$ 100,000$ or more & 19 & $2.85(.90)$ & $2.44(1.01)$
\end{tabular}


Table 10 Continued

\begin{tabular}{lccccc}
\hline Annual Income & $n$ & \multicolumn{4}{c}{ Intergenerational Conflict Inventory } \\
\cline { 3 - 6 } & & $\begin{array}{c}\text { Family } \\
\text { Expectations }\end{array}$ & $\begin{array}{c}\text { Education } \\
\text { and Career }\end{array}$ & $\begin{array}{c}\text { Dating } \\
\text { and Marriage }\end{array}$ & Overall \\
\hline $\begin{array}{l}\text { Less than } \\
\$ 20,000\end{array}$ & 200 & $2.21(.76)$ & $2.41(.95)$ & $2.54(1.39)$ & $2.33(.80)$ \\
$\$ 20,000-39,999$ & 43 & $2.17(.69)$ & $2.16(.91)$ & $2.36(1.31)$ & $2.19(.72)$ \\
$\$ 40,000-59,999$ & 41 & $2.27(.79)$ & $2.03(.85)$ & $2.53(1.37)$ & $2.21(.82)$ \\
$\$ 60,000-99,999$ & 26 & $2.08(.89)$ & $2.27(1.16)$ & $2.38(1.22)$ & $2.20(.91)$ \\
$\$ 100,000$ or & 19 & $2.42(.93)$ & $2.49(1.21)$ & $2.70(1.47)$ & $2.48(.97)$ \\
more & & & & & \\
\hline
\end{tabular}

Relationship Status. A one-way between-subjects ANOVA was performed to assess for differences in level of intergenerational conflict depending upon the emerging adult's relationship status (e.g., married, single, or in a relationship). Because only two participants indicated that they were either divorced or separated, this category was not included in the analysis so as to not violate the assumption of homogeneity of variance. All necessary assumptions were met (Aron \& Aron, 2003; Tabachnick \& Fidell, 2007). No statistically significant group differences across relationship status were found for any level of intergenerational conflict. See Table 11 for the means and standard deviations for all levels of conflict depending upon participants' relationship status. 
Table 11

Means (Standard Deviations) for Level of Intergenerational Conflict By Relationship Status

\begin{tabular}{lccc}
$\begin{array}{l}\text { Relationship } \\
\text { Status }\end{array}$ & $n$ & \multicolumn{2}{c}{ Family Conflict Scale } \\
\cline { 3 - 4 } & & Likelihood & Seriousness \\
\hline Married & 35 & $2.62(.96)$ & $2.29(.89)$ \\
Single & 153 & $2.53(.93)$ & $2.20(.90)$ \\
In a Relationship & 158 & $2.63(.96)$ & $2.31(.90)$ \\
\end{tabular}

Relationship $n$

Status
Intergenerational Conflict Inventory

\begin{tabular}{clcc}
\hline Family & Education & Dating & Overall \\
Expectations & and Career & and Marriage &
\end{tabular}

\begin{tabular}{lrrrrr}
\hline Married & 35 & $2.28(.78)$ & $2.20(.96)$ & $2.27(1.17)$ & $2.24(.81)$ \\
Single & 153 & $2.19(.74)$ & $2.32(.98)$ & $2.42(1.33)$ & $2.27(.78)$ \\
$\begin{array}{l}\text { In a } \\
\text { Relationship }\end{array}$ & 158 & $2.22(.78)$ & $2.40(.98)$ & $2.66(1.42)$ & $2.35(.81)$ \\
\hline
\end{tabular}

Language Most Spoken in Communicating with Parents. Four categories were created for assessing the language that emerging adults most frequently use in communicating with their parents: parents' native language $(n=113)$, English $(n=155)$, equally parents' native language and English $(n=74)$, and a language other than parents' native language or English $(n=8)$. A one-way between-subjects ANOVA was performed to detect differences in level of intergenerational conflict depending upon the language most used for communication. All necessary assumptions were met, and 
unequal group sizes were not expected to be problematic (Aron \& Aron, 2003;

Tabachnick \& Fidell, 2007). A between-groups effect was observed for conflict related to dating and marriage issues, $F(3,346)=2.75, p<.05$, partial $\eta^{2}=.02$, with a small effect size obtained (Cohen, 1988). The Tukey HSD test demonstrated that those emerging adults who used their parents' native language most frequently in communicating with their parents $(M=2.74, S D=1.34)$ reported higher levels of conflict related to dating and marriage issues than those who used English most frequently ( $M=$ $2.29, S D=1.34)$. See Table 12 for the means and standard deviations for all levels of conflict depending upon the language most used in communication.

Table 12

Means (Standard Deviations) for Level of Intergenerational Conflict By Language Most Frequently Used for Communication with Parents

\begin{tabular}{|c|c|c|c|}
\hline \multirow{2}{*}{$\begin{array}{l}\text { Language } \\
\text { Most Used }\end{array}$} & \multirow[t]{2}{*}{$n$} & \multicolumn{2}{|c|}{ Family Conflict Scale } \\
\hline & & Likelihood & Seriousness \\
\hline $\begin{array}{l}\text { Parents' Native } \\
\text { Language }\end{array}$ & 113 & $2.66(.94)$ & $2.33(.95)$ \\
\hline English & 155 & $2.52(.93)$ & $2.23(.88)$ \\
\hline $\begin{array}{l}\text { Equally Parents' } \\
\text { Native Language } \\
\text { and English }\end{array}$ & 74 & $2.65(.97)$ & $2.27(.90)$ \\
\hline Other & 8 & $2.23(.98)$ & $2.04(.87)$ \\
\hline
\end{tabular}


Table 12 Continued

\begin{tabular}{|c|c|c|c|c|c|}
\hline \multirow{2}{*}{$\begin{array}{l}\text { Language } \\
\text { Most Used }\end{array}$} & \multirow[t]{2}{*}{$n$} & \multicolumn{4}{|c|}{ Intergenerational Conflict Inventory } \\
\hline & & $\begin{array}{l}\text { Family } \\
\text { Expectations }\end{array}$ & $\begin{array}{l}\text { Education } \\
\text { and Career }\end{array}$ & $\begin{array}{c}\text { Dating } \\
\text { and Marriage }\end{array}$ & Overall \\
\hline $\begin{array}{l}\text { Parents' Native } \\
\text { Language }\end{array}$ & 113 & $2.28(.76)$ & $2.37(1.03)$ & $2.74_{a}(1.34)$ & $2.37(.81)$ \\
\hline English & 155 & $2.20(.74)$ & $2.35(.96)$ & $2.29_{b}(1.34)$ & $2.27(.78)$ \\
\hline $\begin{array}{l}\text { Equally } \\
\text { Parents' Native } \\
\text { Language and } \\
\text { English }\end{array}$ & 74 & $2.17(.84)$ & $2.31(.96)$ & $2.66(1.42)$ & $2.29(.87)$ \\
\hline Other & 8 & $2.23(.85)$ & $2.36(1.18)$ & $2.38(1.05)$ & $2.30(.93)$ \\
\hline
\end{tabular}

Note. Means within columns not sharing subscripts are significantly different from each other at the $p<.05$ level according to the Tukey HSD test.

Level of Acculturation and Acculturation Gap.

In terms of level of acculturation to one's own Asian culture of origin, parents were estimated to have significantly higher levels of acculturation $(M=5.29, S D=.86)$ than emerging adults $(M=3.98, S D=1.09)$, Mann Whitney $U=19,143.50, p<.001$. Because heterogeneity of variance was detected, an independent t-test was not justified, and the non-parametric, Mann Whitney U-Test was performed instead. Parents' estimated level of Asian acculturation fell in the very high range on average whereas children's level fell in the medium to moderately high range. This trend was consistent with the literature and was expected given that parents tend to have greater exposure to the family's Asian culture of origin than their children do and, thus, are expected to 
report higher levels of acculturation to the Asian culture of origin than children (Kim, 2007).

With regard to level of acculturation to White mainstream culture, emerging adults reported significantly higher levels of acculturation $(M=4.87, S D=1.09)$ than their parents $(M=3.57, S D=1.15)$, Mann Whitney $\mathrm{U}=22,222.00, p<.001$. Because heterogeneity of variance was detected, the non-parametric, Mann Whitney U-Test was performed. On average, emerging adults' level of White acculturation fell in the moderately high range whereas parents' estimated level of acculturation fell in the medium range. This trend was consistent with the literature, which has shown children to acculturate more quickly and to a greater extent to the dominant culture than their parents (Szapocznik \& Kurtines, 1993).

In terms of acculturation gap, emerging adults and their parents differed in the extent to which they had acculturated to their own Asian culture of origin (i.e., Asian acculturation gap) by a mean of approximately $1.36(S D=.89)$. They differed in the extent to which they have acculturated to White mainstream culture (i.e., White acculturation gap) by a similar mean of $1.37(S D=.96)$. Compared to previous studies assessing acculturation to White mainstream culture (Chung, 2001; Ying \& Han, 2007), the current study's sample of emerging adults was found to be more highly acculturated and to experience larger acculturation gaps. Estimates of parents' level of acculturation to White mainstream culture were relatively similar between this study's population and Ying and Han (2007)'s population of Asian adolescents. 


\section{Hypothesis 1}

The current study's first overall hypothesis consisted of four sub-hypotheses that together discussed the relationship between acculturation gap, generational status, and intergenerational conflict.

Sub-Hypothesis 1-A. The first sub-hypothesis predicted that larger acculturation gaps (i.e., differences in acculturation between parents and children) would correlate with higher levels of intergenerational conflict. Pearson product moment correlations $(r)$ were performed to test this sub-hypothesis (as well as the second and third sub-hypotheses), which were justified in that all variables are normally distributed and continuous.

The first sub-hypothesis was partially supported by the data. Both Asian acculturation gap and White acculturation gap were significantly and positively correlated with multiple measures of intergenerational conflict, such that the larger the acculturation gap, the greater the conflict. Asian acculturation gap, specifically, was significantly and positively correlated with three of the six measures of conflict: likelihood of conflict $(r(348)=.13, p<.05)$, seriousness of conflict $(r(348)=.13, p<$ $.05)$, and conflict related to family expectations $(r(348)=.14, p<.05)$. Furthermore, White acculturation gap was significantly and positively correlated with all six measures of conflict: likelihood of conflict $(r(348)=.24, p<.001)$, seriousness of conflict $(r(348)$ $=.19, p<.001)$, overall conflict $(r(348)=.23, p<.001)$, and conflict related to family expectations $(r(348)=.24, p<.001)$, education and career $(r(348)=.14, p<.01)$, and dating and marriage $(r(348)=.23, p<.001)$. All of the statistically significant correlations obtained indicate a small to medium sized relationship (Cohen, 1988). 
Sub-Hypothesis 1-B. The second sub-hypothesis predicted that lower generational status (i.e., $1^{\text {st }}$ generation) among adult children would correlate with higher levels of intergenerational conflict. Partial support of this sub-hypothesis was obtained, with emerging adults' generational status found to be significantly and negatively correlated with conflict related to dating and marriage only $(r(348)=-.12, p<.05)$. First generation emerging adults tended to report more conflict related to dating and marriage issues than their later generation peers. A small effect size was obtained (Cohen, 1988).

Sub-Hypothesis 1-C. The third sub-hypothesis predicted that larger acculturation gaps would correlate with lower generational status among emerging adults, which was partially supported by the data. As expected, emerging adults' generational status was found to be significantly and negatively correlated with White acculturation gap $(r(348)=$ $-.30, p<.001$ ), with a medium effect size obtained (Cohen, 1988). No significant relationship was found between generational status and Asian acculturation gap. First generation children tended to report larger differences in terms of how much they and their parents have acculturated to White mainstream culture but not to their respective Asian cultures. See Table 13 for a summary of correlation coefficients and significance levels related to sub-hypotheses 1-A, 1-B, and 1-C. 
Table 13

Correlations Between Acculturation Gap, Generational Status, and Intergenerational Conflict (Hypothesis 1)

Variable

Family Conflict Scale

Likelihood

Seriousness

1. Asian Gap

$.13^{*}$

$.13^{*}$

2. White Gap

$.24 * * *$

$.19^{* * *}$

3. Generational Status

$-.09$

$-.03$

\begin{tabular}{lcccc}
\hline & \multicolumn{4}{c}{ Intergenerational Conflict Inventory } \\
\cline { 2 - 5 } & $\begin{array}{c}\text { Family } \\
\text { Expectations }\end{array}$ & $\begin{array}{c}\text { Education } \\
\text { and Career }\end{array}$ & $\begin{array}{c}\text { Dating } \\
\text { and Marriage }\end{array}$ & Overall \\
\hline 1. Asian Gap & $.14^{*}$ & .04 & -.01 & .08 \\
2. White Gap & $.24^{* * *}$ & $.14^{* *}$ & $.23^{* * *}$ & $.23^{* * *}$ \\
3. Generational Status & -.08 & -.07 & $-.12^{*}$ & -.10 \\
\hline
\end{tabular}

Note. Asian Gap = Gap in Acculturation to Asian Culture of Origin; White Gap = Gap in Acculturation to White mainstream culture ${ }^{*} p<.05 .{ }^{* * *} p<.001$ (2-tailed)

Sub-Hypothesis 1-D. The fourth and final sub-hypothesis of Hypothesis 1 predicted that acculturation gap would mediate the relationship between generational status and intergenerational conflict. Findings in support of the first three sub-hypotheses showed significant relationships between generational status, White acculturation gap, and intergenerational conflict related to dating and marriage, so only these variables were used in exploring the relationship between acculturation gap, generational status, and intergenerational conflict. The final sub-hypothesis sought to elucidate the exact nature 
of this relationship and predicted that that when the influence of acculturation gap is taken into account, the relationship between generational status and conflict will be significantly reduced. In this way, it was hypothesized that generational status only had an indirect relationship with intergenerational conflict through its direct relationship with acculturation gap. A flowchart depicting this predicted mediation model is presented in Figure 1.

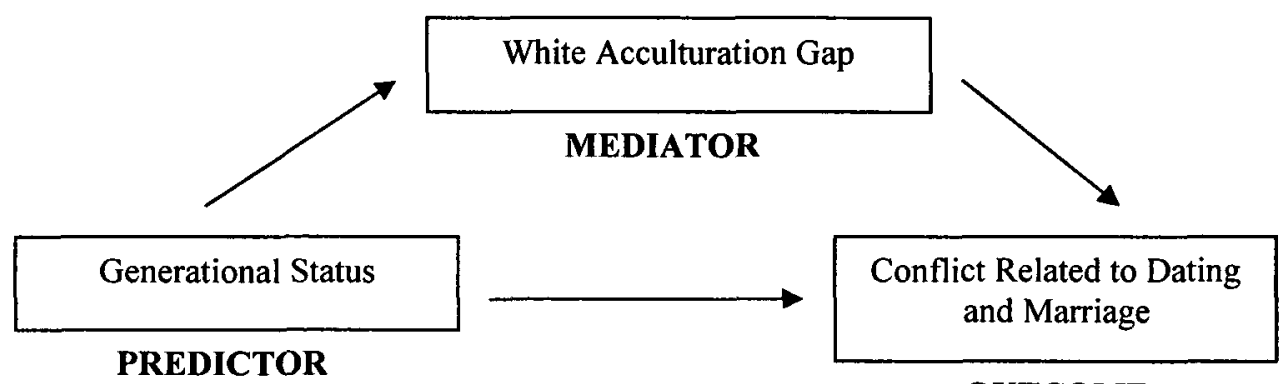

OUTCOME

Figure 1. Predicted Mediation Model. White acculturation gap was hypothesized to mediate the relationship between generational status and conflict related to dating and marriage issues.

Following the strategy outlined by Baron and Kenny (1986), a series of three regression analyses were performed to test this model of mediation. All appropriate assumptions were met in order to justify multiple regression analyses, including an absence of multicolinearity and singularity, sufficient ratio of cases to independent variables, independence of errors, and normality, linearity, and homoschedasticity of residuals (Tabachnick \& Fidell, 2007). In the first regression, a relationship must be established between the predictor variable (i.e., generational status) and the outcome 
variable (i.e., conflict related to dating and marriage). Generational status was found to significantly predict conflict related to dating and marriage, $F(1,348)=4.68, p<.05$, accounting for approximately one percent of the variance in conflict $\left(\mathrm{sr}_{i}{ }^{2}=.01\right)$. This established that there, indeed, existed a total effect between generational status and conflict related to dating and marriage that may be mediated, which is illustrated in Figure 2, with the beta value reported.

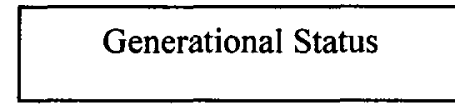

PREDICTOR

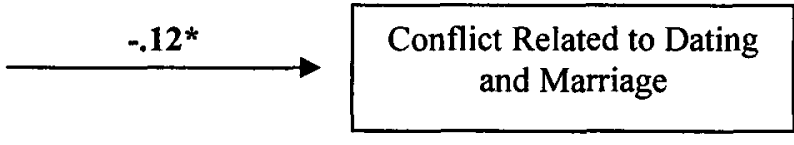

OUTCOME

Figure 2. Regression 1: Total Effect between Generational Status and Conflict Related to Dating and Marriage Issues. This is the relationship that is predicted to be mediated by acculturation gap.

${ }^{*} p<.05$.

In the second regression, a relationship must be established between the predictor variable (i.e., generational status) and the hypothesized mediator (i.e., White acculturation gap). Generational status was found to significantly predict White acculturation gap, $F(1,348)=34.80, p<.001$, accounting for nine percent of the variance in White acculturation gap $\left(\mathrm{sr}_{i}^{2}=.09\right)$. This relationship is illustrated in Figure 3, with the beta value reported. 


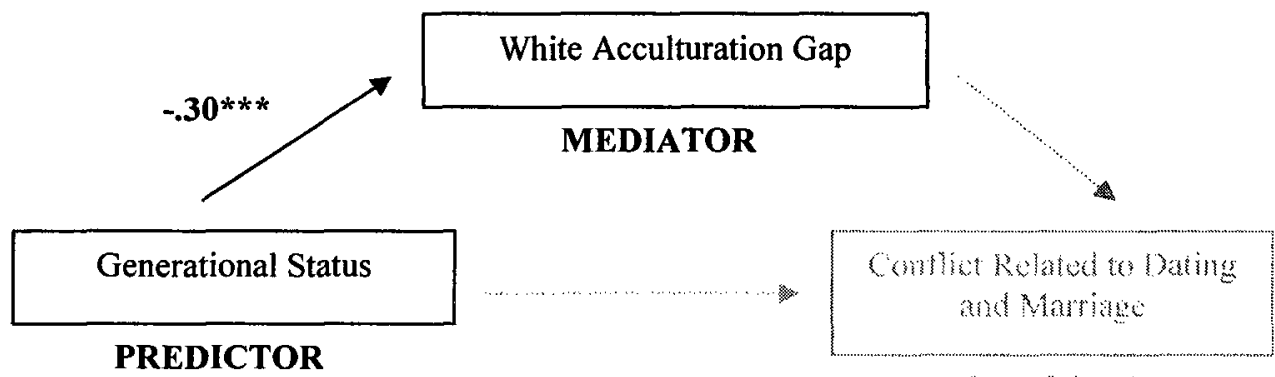

TUTCOMI

Figure 3. Regression 2: Relationship between the Predictor and the Hypothesized Mediator. Generational status is found to be a significant predictor of White acculturation gap.

$* * * p<.001$.

In the third regression, a relationship must be established between the hypothesized mediator (i.e., White acculturation gap) and the outcome (i.e., conflict related to dating and marriage). Both the mediator and predictor variable were entered into the regression, however, in order to identify the predictor's direct relationship with the outcome when the mediator's influence was taken into account. White acculturation gap was found to significantly predict intergenerational conflict related to dating and marriage, $F(2,347)=10.01, p<.001$, accounting for about four percent of the variance in conflict $\left(\mathrm{sr}_{\mathrm{i}}^{2}=.04\right)$. When White acculturation gap was taken into account, generational status was not found to significantly predict conflict related to dating and marriage. Figure 4 provides the beta values for the direct effect of generational status on conflict related to dating and marriage when the indirect effect of White acculturation gap was taken into account. 


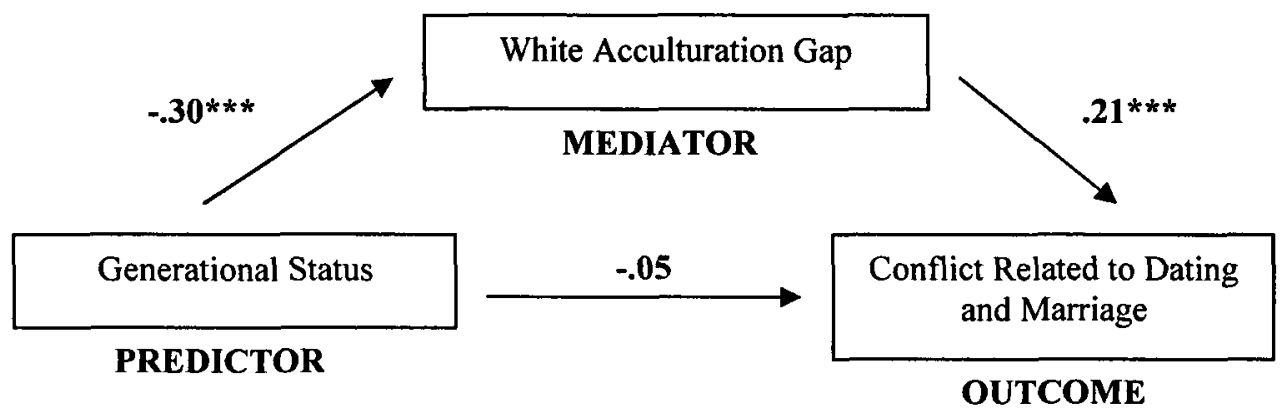

Figure 4. Regression 3: Direct Effect between Generational Status and Conflict Related to Dating and Marriage Issues. Generational status was not found to be a significant predictor of conflict related to dating and marriage issues when one accounts for the indirect effect of White acculturation gap.

$* * * p<.001$

The final step in testing this hypothesized model of mediation was to evaluate whether the relationship between the predictor and the outcome variables significantly changes due to the indirect effect of the mediator. A Sobel test was performed to test for significance (MacKinnon, Warsi, \& Dwyer, 1995). The results of the Sobel test indicated that the relationship between generational status and conflict related to dating and marriage significantly changed when White acculturation gap was taken into account (test statistic $=-3.24, p<.01$ ). This supported the fourth sub-hypothesis, which predicted White acculturation gap to mediate the relationship between generational status and conflict related to dating and marriage. Because generational status did not significantly predict conflict related to dating and marriage when White acculturation gap was taken into account, a full mediational model was supported. Table 14 provides a comparison of generational status' relationship with conflict related to dating and marriage when the 
influence of White acculturation gap was not taken into account (i.e., Total Effect) and when it was taken into account (i.e., Direct Effect). As can be seen, generational status' direct effect on conflict related to dating and marriage was not found to be statistically significant when White acculturation gap was taken into account.

Table 14

Total and Direct Effect of Generational Status on Intergenerational Conflict Related to Dating and Marriage

\begin{tabular}{|c|c|c|c|c|c|}
\hline Variable & Adj. $R^{2}$ & $\Delta \mathrm{R}^{2}$ & B & $\beta$ & $\mathrm{sr}_{\mathrm{i}}^{2}$ \\
\hline Total Effect: & .01 & .01 & & & \\
\hline Generational Status & & & -.17 & $-.12^{*}$ & .01 \\
\hline Direct Effect: & .05 & .04 & & & \\
\hline Generational Status & & & -.08 & -.05 & .00 \\
\hline
\end{tabular}

Note. $\mathrm{R}=.23$ and Adj. $\mathrm{R}^{2}=.05(\mathrm{~N}=350)$.

$* p<.05$.

\section{Hypothesis 2}

The study's second overall hypothesis explored the relationship between birth order status, gender, and intergenerational conflict and included three sub-hypotheses.

Sub-Hypothesis 2-A. The first sub-hypothesis predicted that birth order would be significantly and negatively correlated with level of intergenerational conflict, such that first born status would be associated with greater conflict. Birth order status was dummy-coded, permitting the use of Pearson product moment correlations to test this 
sub-hypothesis. The following guidelines were used in coding birth order status: only child $=0$, first born $=1$, second born $=2$, third born $=3$, fourth born $=4$, fifth born $=5$, and sixth born or greater $=6$. Birth order status was found to be normally distributed. In contrast to the hypothesis, birth order was found to be significantly and positively correlated with three of the six measures of conflict: likelihood of conflict $(r(347)=.14$, $p<.01)$, seriousness of conflict $(r(347)=.12, p<.05)$, and overall conflict $(r(347)=.11$, $p<.05)$, rather than negatively correlated as had been expected. As such, the findings showed that later born status was associated with greater conflict than first born status.

Sub-Hypothesis 2-B. The second sub-hypothesis predicted that gender would be significantly correlated with level of intergenerational conflict, such that female gender would be associated with more conflict than male gender. Gender was dummy-coded according to the following codes: female $=0$, male $=1$. This sub-hypothesis was partially supported by the data, which found a significant correlation between gender and one of the six measures of conflict. Specifically, females reported greater conflict related to dating and marriage issues than males $(r(345)=-.11, p<.05)$. Table 15 provides the correlation coefficients and significance levels for sub-hypothesis 2-A and 2-B.

Table 15

Correlations Between Birth Order Status, Gender, and Intergenerational Conflict (Hypothesis 2)

Variable

Family Conflict Scale

Likelihood Seriousness

1. Birth Order Status

$.14 * *$

$.12^{*}$

2. Gender $-.03$ 
Table 15 Continued

\begin{tabular}{cccc}
\multicolumn{4}{c}{ Intergenerational Conflict Inventory } \\
$\begin{array}{c}\text { Family } \\
\text { Expectations }\end{array}$ & $\begin{array}{c}\text { Education } \\
\text { and Career }\end{array}$ & $\begin{array}{c}\text { Dating } \\
\text { and Marriage }\end{array}$ & Overall \\
.10 & .09 & .10 & $.11^{*}$ \\
-.04 & .06 & $-.11^{*}$ & -.01 \\
\hline
\end{tabular}

Note. ${ }^{*} p<.05 .{ }^{* *} p<.01 .(2$-tailed)

Sub-Hypothesis 2-C. The third sub-hypothesis predicted an interaction effect between birth order status and gender. Specifically, it was hypothesized that gender would significantly correlate with conflict among later born children (with female gender associated with greater conflict) but would not significantly correlate with conflict among first born children. Standard multiple regression analyses were performed to evaluate whether the interaction between birth order status and gender would significantly predict level of intergenerational conflict. In order to prevent multicolinearity, scores of all independent and dependent variables were standardized before creating the interaction term (Tabachnick \& Fidell, 2007). All appropriate assumptions were met in order to justify the regression analyses, including an absence of multicolinearity and singularity, sufficient ratio of cases to independent variables, independence of errors, and normality, linearity, and homoschedasticity of residuals (Tabachnick \& Fidell, 2007).

In running the regression analyses, gender, birth order, and the interaction of gender and birth order were entered simultaneously in order to evaluate whether the interaction term was a unique predictor of intergenerational conflict. Contrary to the 
third sub-hypothesis, the interaction of birth order and gender did not significantly predict any measure of intergenerational conflict.

\section{Hypothesis 3}

The third overall hypothesis of the present study discussed the relationship between language proficiency and level of intergenerational conflict. Among parents, limited English proficiency among parents was predicted to significantly correlate with greater conflict with their emerging adult children. Among emerging adults, limited proficiency in parents' native language was expected to significantly correlate with greater conflict with their parents. Pearson product moment correlations were performed to test this hypothesis. The variables were all continuous and normally distributed, justifying these analyses.

Partial support was found for the relationship between both parents' and emerging adults' language proficiency and level of intergenerational conflict. Parents' proficiency in the English language was found to be significantly and negatively correlated with three measures of intergenerational conflict: likelihood of conflict $(r(347)=-.11, p<.05)$, conflict related to family expectations $(r(347)=-.11, p<.05)$, and conflict related to dating and marriage issues $(r(347)=-.14, p<.05)$, such that parents' lower proficiency in English was associated with greater conflict. Emerging adults' proficiency in their parents' native language was found to be significantly and negatively correlated with only one measure of conflict, which was conflict related to dating and marriage issues $(r(348)=.11, p<.05)$. Emerging adults' lower proficiency in their parents' native language was associated with greater conflict related to dating and marriage issues. See Table 16 for all correlation coefficients and significance levels related to Hypothesis 3. 
Table 16

Correlations Between Language Proficiency and Intergenerational Conflict (Hypothesis 3)

Variable

Family Conflict Scale

Likelihood

Seriousness

1. Child's Proficiency

.02

.05

With Native Language

2. Parents' Proficiency

$-.11^{*}$

$-.10$

With English Language

\begin{tabular}{|c|c|c|c|c|}
\hline & \multicolumn{4}{|c|}{ Intergenerational Conflict Inventory } \\
\hline & $\begin{array}{l}\text { Family } \\
\text { Expectations }\end{array}$ & $\begin{array}{l}\text { Education } \\
\text { and Career }\end{array}$ & $\begin{array}{c}\text { Dating } \\
\text { and Marriage }\end{array}$ & Overall \\
\hline $\begin{array}{l}\text { 1. Child's Proficiency } \\
\text { With Native Language }\end{array}$ & -.01 & .04 & $.11^{*}$ & .03 \\
\hline $\begin{array}{l}\text { 2. Parents' Proficiency } \\
\text { With English Language }\end{array}$ & $-.11^{*}$ & -.05 & $-.14^{*}$ & -.10 \\
\hline
\end{tabular}

Note. ${ }^{*} p<.05 .(2$-tailed)

Consideration of Relationship Status and Education Level

Relationship Status. Because some of this study's population of Asian American emerging adults indicated their relationship status to be married, consideration was given to whether these individuals may have experienced different levels of conflict related to dating/marriage issues than those who were not married. Only three questions of the Intergenerational Conflict Inventory (ICI; Chung, 2001) assessed conflict related to dating/marriage issues, and these questions were restricted to the emerging adult's choice of when/whom to date/marry. As such, the items assessing dating/marriage issues may 
not have been applicable to emerging adults who were already married. If a married emerging adult indicated high levels of conflict on these items, it was unclear whether he/she responded to the level of conflict they used to experience prior to getting married or the level of conflict they experienced now regarding their marriage. Thus, inclusion of married emerging adults in the analyses may have confounded the findings for conflict related to dating and marriage issues.

So as to address this potential confounding factor, the current study's hypotheses for conflict related to dating/marriage issues were tested again, except the emerging adults who reported to be married were not included in the analyses. When the hypotheses were tested again with married emerging adults removed, only one difference from the previous findings obtained was detected: with regard to Hypothesis 1, emerging adults' generational status was no longer significantly correlated with conflict related to dating/marriage issues. As such, there was no longer a relationship between generational status and conflict related to dating/marriage issues for White acculturation gap to mediate. All other trends observed from the hypothesis testing with married emerging adults removed were similar to the trends obtained when married emerging adults were included in the analyses.

Highest Level of Education. Because Asian American cultures are believed to place a strong emphasis on obtaining educational and career achievements (Mordkowitz \& Ginsberg, 1987; Sue \& Okazaki, 2009), consideration was given to whether participants' highest level of education could influence the findings obtained regarding level of conflict related to education/career issues. If an emerging adult has not obtained 
an advanced educational degree, for instance, will he/she be more vulnerable to conflict related to education/career issues?

So as to address this question, the current study's hypotheses for conflict related to education/career issues were tested again, except the most educated emerging adults (i.e., those with a Master's or doctoral degree) were not included in the analyses. Only one difference in the findings was observed when the most educated emerging adults were removed from the analyses: with regard to Hypothesis 2, birth order was found to be significantly and positively correlated with conflict related to education/career issues $(\mathrm{r}(281)=.12, \mathrm{p}<.05)$. No significant correlations had been found between emerging adults' birth order status and level of conflict related to education/career issues when the study's total sample was used in the analyses. All other trends observed from the hypothesis testing with the most educated emerging adults removed were similar as when the most educated emerging adults were included in the analyses.

\section{Additional Research Questions}

After testing each of the study's proposed hypotheses, some secondary analyses were performed to investigate additional research questions of interest. Because limited research has been conducted among Asian American emerging adults, particularly when they are living with their parents, this study had an important exploratory component. Specific hypotheses had not been formulated a priori for these additional research questions. The goal of the secondary analyses was simply to explore different factors that may or may not improve our understanding of intergenerational conflict as experienced by Asian American emerging adults when they live with their parents. 
Best Overall Predictor of Intergenerational Conflict. Over the course of the current study, multiple factors were examined in terms of how they relate to intergenerational conflict, including acculturation gap, generational status, gender, birth order, and language proficiency. Standard regression analyses were performed in order to evaluate whether one particular factor emerged as the most consistent or powerful predictor of conflict. All necessary assumptions were met in order to justify these analyses, including normality and an absence of multicolinearity and singularity (Tabachnick \& Fidell, 2007). The analyses revealed White acculturation gap to be the best overall predictor of intergenerational conflict among all variables, and the only variable that consistently predicted level of conflict across all six measures of conflict. Two other variables emerged as significant predictors for at least one measure of conflict: birth order significantly predicted likelihood of conflict $(\beta=.11, p<.05)$, and Asian acculturation gap significantly predicted seriousness of conflict $(\beta=.13, p<.05)$. All beta values, significance levels, and effect sizes are reported in Table 17. 
Table 17

Overall Predictors of Intergenerational Conflict - Standard Regression Analyses

\begin{tabular}{lccccc}
\hline Variable & Adj. $\mathrm{R}^{2}$ & $\Delta \mathrm{R}^{2}$ & $\mathrm{~B}$ & $\beta$ & $\mathrm{sr}_{\mathrm{i}}{ }^{2}$ \\
\hline $\begin{array}{l}\text { FCS: Likelihood } \\
\text { White Acculturation Gap }\end{array}$ & .06 & .08 & & & \\
Birth Order & & & .20 & $.20^{* *}$ & .02 \\
\end{tabular}

FCS: Seriousness

$.04 \quad .06$

White Acculturation Gap

$.14 \quad .15^{*} \quad .01$

Asian Acculturation Gap

.13

$.13^{*} \quad .01$

ICI: Family Expectations

.05

.07

White Acculturation Gap

.16

$.20^{* *} \quad .02$

ICI: Education and Career

.02

.04

White Acculturation Gap

.17

$.17^{*} \quad .02$

ICI: Dating and Marriage

.06

.08

White Acculturation Gap

.28

$.20^{* *} \quad .02$

ICI: Overall

.04

.06

White Acculturation Gap

.18

$.21^{* *} \quad .03$

Note. $\mathrm{N}=350$.

${ }^{*} p<.05 .{ }^{* *} p<.01$. 
Boomerang Children. A population of interest in this study were emerging adults who have returned home after living away from their parents for a certain period of time (i.e., boomerang children). Additional secondary analyses were conducted to explore this group's specific experience with intergenerational conflict when they return home to live with their parents. In the current study, emerging adults who were currently living with their parents after returning home were recruited as well as those who once returned home after living away but were no longer living with their parents. Information was collected regarding the circumstances surrounding the emerging adults' move away from home and their transition in returning home. These circumstances included the extent of communication and contact with parents while away from home, the length of time away from home, the duration of their stay at home since returning, and whether the decision to return home was a mutual or forced decision for either the emerging adult or the parents. Statistical analyses were performed to evaluate whether these factors were significantly related to the level of intergenerational conflict experienced for this particular sub-group of participants.

In terms of the decision to return home after living away, participants in this subgroup indicated whether one of three possible scenarios applied to their situation: a mutual decision was made, in which both the parents and emerging adult wanted the emerging adult's return home; the decision was somewhat forced for the emerging adult, in that the parents wanted the move but the emerging adult did not; and the decision was somewhat forced for the parents, in that the emerging adult wanted the move but the parents did not. A one-way between-subjects analysis of variance (ANOVA) was performed to determine whether different levels of intergenerational conflict were 
obtained depending upon how the decision to return home was made. All necessary assumptions were met in order to justify running this analysis, including normality of sampling distributions of means and homogeneity of variance (Aron \& Aron, 2003). Of the 121 participants who had returned home after living away for an extended period of time (whether recently or in the past), only a small portion of this subgroup reported that the decision to return home was forced (11.57 percent, $n=14)$, with the majority of participants reporting a mutual decision having been made ( 88.43 percent, $n=107)$. The unequal group sizes were not expected to be problematic, given that only one-way between-subjects ANOVAs were performed and the assumption of homogeneity of variance was not violated (Tabachnick \& Fidell, 2007).

The overall ANOVA yielded a significant between-groups effect for likelihood of conflict, $F(2,118)=5.33, p<.01$, partial $\eta^{2}=.08$. A Tukey HSD post-hoc comparison revealed that those emerging adults who were forced to move home when they desired not to reported significantly greater conflict $(M=3.43, S D=.80)$ than those emerging adults who mutually decided to return home with their parents $(M=2.53, S D=.88)$. A significant between-groups effect was also found for seriousness of conflict, $F(2,118)=$ $5.43, p<.01$, partial $\eta^{2}=.08$, with emerging adults who were forced to move home against their wishes again reporting significantly greater conflict $(M=3.06, S D=.91)$ than their counterparts in the mutual decision group $(M=2.21, S D=.82)$. A medium effect size was found for both main effects (Cohen, 1988). See Table 18 for all means and standard deviations, and Table 19 for the ANOVA source table. 
Table 18

Means and Standard Deviations for Intergenerational Conflict by Decision to Return Home

Decision to Return Home

$n$

Mean

$S D$

FCS: Likelihood of Conflict

Mutual - Both Parents and

$2.52 \mathrm{a}$

.88

Children Wanted

Forced - Children Did Not Want

11

$3.43_{b}$

.80

Forced - Parents Did Not Want

3

2.63

.80

FCS: Seriousness of Conflict

Mutual - Both Parents and

107

$2.21_{\mathrm{a}}$

.82

Children Wanted

Forced - Children Did Not Want

11

$3.06_{b}$

.91

Forced - Parents Did Not Want

3

2.53

.71

Note. Means within rows having a different subscript are significantly different from each other according to the Tukey HSD test. 
Table 19

Analysis of Variance Source Table for Differences in Intergenerational Conflict Based on Decision to Return Home

\begin{tabular}{|c|c|c|c|}
\hline Source & $d f$ & $F$ & $\eta^{2}$ \\
\hline & \multicolumn{3}{|c|}{ FCS: Likelihood of Conflict } \\
\hline Decision to Return Home & 2 & $5.33 * *$ & .08 \\
\hline \multirow[t]{2}{*}{ Error } & 118 & & \\
\hline & \multicolumn{3}{|c|}{ FCS: Seriousness of Conflict } \\
\hline Decision to Return Home & 2 & $5.43 * *$ & .08 \\
\hline Error & 118 & & \\
\hline
\end{tabular}

The extent of contact with parents when emerging adults lived away was also explored, and whether it significantly related to level of intergenerational conflict upon emerging adults' return home. Qualitative data was collected regarding frequency of contact when children lived away and coded on the following scale: daily $=1$, every few days $=2$, weekly $=3$, monthly $=4$, every few months $=5$, and more than 6 months without contact $=6$. Contact was defined as communication via phone, e-mail, or inperson visits, with no differentiation between the various methods, duration, or content of the communication. A one-way between-subjects ANOVA was performed to analyze whether level of intergenerational conflict after emerging adults returned home varied depending on the frequency of contact when emerging adults lived away. All appropriate assumptions for this analysis were met. A significant between-groups effect was found 
for conflict related to education and career, $F(6,105)=2.33, p<.05$, partial $\eta^{2}=.12$, with a medium effect size obtained (Cohen, 1988). A Tukey HSD post-hoc comparison revealed that emerging adults who had contact with their parents only every few months when they lived away $(M=3.11, S D=.75)$ reported significantly greater conflict related to education and career when they returned home than emerging adults who had more frequent contact with their parents, such as every few days $(M=2.06, S D=.73)$ or at least once a week $(M=2.10, S D=.78)$. See Table 20 for all means and standard deviations, and Table 21 for the ANOVA source table.

Table 20

Means and Standard Deviations for Intergenerational Conflict by Frequency of Contact While Away

\begin{tabular}{llll}
\hline Frequency of Contact While Away & $n$ & Mean & $S D$
\end{tabular}

\section{ICI: Education and Career}

Daily

Every Few Days

Weekly

Monthly

Every Few Months

More than 6 Months Without Contact
12

27

41

13

8

$3.11 b$

2.40

2.36

2.48

8
1.05

$2.06_{a}$

$2.10_{\mathrm{a}}$ .78

.75

1.08

Note. Means having a different subscript are significantly different from each other according to the Tukey HSD test. 
Table 21

Analysis of Variance Source Table for Differences in Intergenerational Conflict Based on Frequency of Contact While Away

\begin{tabular}{|c|c|c|c|}
\hline Source & $d f$ & $F$ & $\eta^{2}$ \\
\hline \multicolumn{4}{|c|}{ ICI: Education and Career } \\
\hline Frequency of Contact While Away & 6 & $2.33^{*}$ & .12 \\
\hline Error & 105 & & \\
\hline
\end{tabular}

Qualitative data was also collected regarding the length of time emerging adults lived away from home and the duration of their stay at home upon returning. In terms of emerging adults' time away from home, responses were coded into six categories: 6 months or less, 7 months to 1 year, more than 1 year to 2 years, more than 2 years to 3 years, more than 3 years to 4 years, and more than 4 years. In terms of emerging adults' stay at home upon returning, five categories were created: less than 1 month, 1 to 3 months, 4 to 6 months, 7 months to 1 year, and more than 1 year to 2 years. One-way between-subjects ANOVAs were performed for each variable, with all necessary assumptions met to justify the analyses. No significant between-groups effects were found across all measures of intergenerational conflict, such that level of conflict upon emerging adults' return home did not seem to significantly differ depending on how long they lived away from home and how long they have been living or had lived at home after their return. 


\section{CHAPTER 4}

\section{DISCUSSION}

The overall purpose of the current study was to investigate intergenerational conflict between Asian American emerging adults and their parents when emerging adults reside in the home with their parents. Although conflict in Asian American families has been explored among children up until and during the college years, few studies have examined the nature and extent of intergenerational conflict when children are emerging adults. This study sought to help close that research gap by exploring whether various demographic and cultural variables may be useful in predicting level of intergenerational conflict between Asian American emerging adults and their parents when emerging adults reside in the home. In measuring intergenerational conflict, both the likelihood and severity of conflict were considered, as was conflict across multiple domains, specifically family expectations, education/career, and dating/marriage.

Overall, a gap in acculturation to White mainstream culture was found to be the most powerful and consistent predictor of intergenerational conflict, as well as a mediator in the relationship between generational status and intergenerational conflict.

A total of 350 Asian American emerging adults were surveyed in this study. A low to medium level of intergenerational conflict was generally reported across all six measures of conflict. The extent of conflict found in this study was comparable to the level of conflict that has been reported among Asian American children in other studies. Also using the Family Conflict Scale (FCS), Lee and Liu (2001) and Lee, Su, and Yoshida (2005) similarly detected low to medium levels of conflict reported among 
Asian American college students $(M=2.73$ for Likelihood, and $M=2.84$ for Likelihood and $M=2.37$ for Seriousness, respectively).

Group differences in level of intergenerational conflict were detected across several demographic variables, including emerging adults' ethnicity, gender, age, living situation, and what language they most frequently use for communicating with their parents. No group differences in level of conflict were found across emerging adults' highest level of education, annual income, or relationship status (e.g., married, single, or in a relationship).

In terms of ethnic differences in conflict, Vietnamese emerging adults and those of another Asian ethnicity not listed (e.g., Indian, Japanese, Thai, or Laotian) tended to report significantly more conflict, whereas Korean emerging adults and those of mixed ethnicities (e.g., Asian and White) tended to report significantly less conflict. Few studies have investigated differences in intergenerational conflict across multiple Asian ethnic groups, so it was unclear to what extent this study's trends were consistent with prior research. Among her sample of Asian American college students, Chung (2001) found Japanese Americans to report less conflict than other Asian ethnicities. In the current study, Japanese Americans were included in the "Other Asian Ethnicity" category, which was found to report significantly more conflict. Because Japanese Americans were grouped with other ethnic groups, however, it was difficult to assess trends in conflict for Japanese Americans specifically. Indeed, Indian Americans were also included in the "Other Asian Ethnicity" category, and some research suggests that Indian Americans may experience higher levels of conflict than other Asian ethnic groups (Shah, 2005). With regard to mixed ethnic groups, who reported significantly lower 
levels of conflict in the current study, perhaps emerging adults and families of multiracial backgrounds may be somewhat accustomed to cultural differences, such that they may be more aware of and accepting of cultural differences, compared to their peers who do not come from a multiracial family. As such, multiracial emerging adults may be more equipped to better manage conflict with their parents or less likely to experience conflict altogether.

In terms of gender differences in conflict, the findings were consistent with the literature, with females reporting more conflict related to dating and marriage issues than males (Chung, 2001). With regard to level of conflict across age groups, differences were only found for conflict related to education and career issues, with 18- to 22-yearold emerging adults reporting more conflict than their 23- to 28-year-old peers. This trend was not surprising given that 18 to 22 years of age is the traditional period in which a college education is pursued, which may lead to greater conflict related to education and career issues if parents are not pleased with their children's educational performance and choices.

With regard to emerging adults' living situation, those emerging adults who were currently living with their parents and who had never once left home for an extended period of time (i.e., minimum of four months) were found to report the highest levels of conflict with their parents. Perhaps, living away from the home for a certain period of time was associated changes within an emerging adult's relationship with his/her parent, such that conflict may be reduced. It may be the case, for instance, that living away from the home created greater appreciation among emerging adults for their parents, which may reduce the likelihood or severity of conflict with parents. It may also be possible 
that living away from home helped parents and children to learn different ways of relating to and communicating with one another, since parents and children may no longer have in-person and daily interactions with one another. As such, these new skills may have helped parents and children to better manage conflict as compared to when emerging adults have never left the home and parents and children may not have had to learn different ways of relating and communicating with each other.

The final group difference in level of intergenerational conflict that was found was for the language that emerging adults' most frequently used to communicate with their parents, whether that be their parents' native language, English, an equal combination of both parents' native language and English, or another language altogether. This group difference was only detected for conflict related to dating and marriage issues, with emerging adults who relied primarily on their parents' native language in communication reporting more conflict than those who used English most frequently. One possible conclusion that can be derived from this finding was that dating and marriage issues were more difficult to discuss or conflict related to these issues were most difficult to manage in parents' native language as opposed to English. It was uncertain to what degree parents' and emerging adults' language proficiency and acculturation contributed to this finding, which deserves further research.

In terms of level of acculturation, the current study's sample of Asian American emerging adults reported medium to moderately high levels of acculturation to their own Asian culture of origin and moderately high levels of acculturation to White mainstream culture. These levels of acculturation were similar to the medium to moderately levels of acculturation obtained by Chung et al. (2004), who used the Asian American 
Multidimensional Acculturation Scale (AAMAS) to assess level of acculturation among 342 Asian American college students. Emerging adults were significantly less acculturated to their Asian culture of origin than their parents, but significantly more acculturated to the White mainstream culture than their parents. These trends were consistent with the prior literature on differences in acculturation between parents and children (Kim, 2007; Szapocznik \& Kurtines, 1993).

\section{Hypothesis 1}

Comparable to previous studies (Ying \& Han, 2007), the current study found that larger acculturation gaps between emerging adults and their parents was associated with more intergenerational conflict. This trend was found in terms of both a gap in acculturation to both Asian culture of origin and to White mainstream culture. That is, the extent to which parents and emerging adults differed in how much they identified with their own Asian culture as well as the White mainstream culture was associated with the level of intergenerational conflict reported. For both Asian culture of origin and White mainstream culture, if parents and children significantly differed in how much they have adopted the values, customs, and norms of a culture, they were more likely to report conflict in general and their conflict tended to be more intense when it occurred.

Differences emerged in terms of the specific conflict experienced, however, depending on the type of acculturation gap. For a gap in acculturation to Asian culture of origin, larger gaps predicted more conflict on issues related to family expectations only. Larger gaps in acculturation to White mainstream culture, too, correlated with more conflict on issues related to family expectations, but they also correlated with more conflict on issues related to education and career, as well as dating and marriage issues. 
It was uncertain why conflict related to education/career and dating/marriage was more likely to be present when emerging adults and parents differed along White mainstream values but not when they differed along Asian values. It seemed as though emerging adults and parents adopted different views on family expectations, depending on their level of acculturation to Asian culture, but that they still tended to share views on education/career and dating/marriage, regardless of an acculturation gap. In terms of differences in acculturation to White mainstream culture, however, it appeared that different views were adopted across all domains of life rather than being restricted to one specific domain. As such, an acculturation gap between emerging adults and parents with respect to White mainstream culture was associated with greater conflict across multiple domains.

Along the same lines as previous research (Dinh et al., 1994; Ying et al., 2001), first generation status among emerging adults was found to be significantly associated with greater intergenerational conflict in this study compared to later generation status (e.g., second or third generation). This relationship was only detected with conflict related to dating and marriage issues, however. Based on these findings, it appeared that emerging adults who are first generation were more likely to experience conflict related to dating and marriage issues, but were not necessarily more likely to experience conflict in general or conflict specifically related to family expectations or education/career. They were also not more likely to experience more intense conflict than their second, third, and later generation peers. It was uncertain why dating and marriage issues but not other measures of conflict were influenced by generational status, or whether emerging adults had immigrated to or were born in the United States. What was clear, however, 
was the mechanism through which generational status seemed to influence dating and marriage-related conflict: through its connection to level of acculturation. Rather than generational status directly contributing to conflict, it seemed that generational status contributed to differences in level of acculturation, which was the stronger and more direct predictor of conflict. Moreover, it was differences in level of acculturation to White mainstream culture specifically that seemed to underlie the relationship between generational status and conflict, as opposed to a gap in acculturation to the Asian culture of origin.

This unique relationship between generational status, White mainstream acculturation gap, and intergenerational conflict has important implications in that whether or not an emerging adult had immigrated to the U.S. in and of itself did not necessarily make him/her more vulnerable to experiencing conflict. The more fundamental question was whether emerging adults and their parents have acculturated to White mainstream culture to a similar extent, regardless of the family's immigration history and generational status. The findings suggested that if a first generation emerging adult identified with White mainstream culture to a similar extent that his/her parent had, he/she was not any more likely to experience conflict related to dating and marriage than his/her second, third, or later born generation counterparts. Moreover, any emerging adult who identified with White mainstream culture to a very different extent than his/her parent may have been more likely to experience conflict related to dating and marriage regardless of whether he/she was of first, second, third, or later generational status.

Another important implication of the findings is that generational status was not correlated with differences in level of acculturation to Asian culture of origin as much as 
it was correlated with differences in acculturation to White mainstream culture. Perhaps, this was because acculturation to one's Asian culture of origin likely occurs via one's family/home environment, which may not necessarily differ as much depending on whether one immigrated to the U.S or not. In contrast, acculturation to White mainstream culture likely occurs the most via one's external environment, which would certainly be more likely to differ depending on whether one immigrated to or was born in the U.S.

Overall, these findings suggested that Asian American families with larger gaps in acculturation to White mainstream culture may be most vulnerable to experiencing dating and marriage conflict, regardless of generational status and gaps in acculturation to Asian culture. Although gaps in acculturation to Asian culture of origin did exist, they were not as correlated with intergenerational conflict as were gaps in acculturation to White mainstream culture. Generational status and Asian acculturation gaps may certainly influence a family's experience and dynamics between members in general, but when it comes to specifically influencing level of conflict related to dating and marriage issues, it was White acculturation gaps that appeared to be the most consistently correlated with intergenerational conflict. These findings have significant implications for designing and implementing prevention and intervention efforts to address and minimize intergenerational conflict in Asian American families. Although parents and children may wish to focus on differences in their Asian identity, for instance, it may be most helpful to focus the discussion on their identification with the White mainstream culture, increasing their awareness of each others' perspective in this domain and, ideally and ultimately reducing conflict related to these differences. 


\section{Hypothesis 2}

Contrary to what was expected, first born emerging adults were not found to report greater intergenerational conflict than later born emerging adults. This hypothesis was generated based on literature showing more strict standards of achievement and responsibility held for first born children, which could place them at risk for greater conflict when children are unable to meet parents' expectations (Liu, 1998). In contrast to this prediction, however, results of the analyses showed that later born emerging adults reported both greater likelihood and intensity of conflict than their first born counterparts.

These findings differed from previous research, which found less conflict reported between parents and second born children as compared to first born children when they were at the same age as their siblings (Whiteman et al., 2003). Whiteman et al. (2003) theorized that parents were able to learn from their earlier experiences in raising their first born children such that conflict could be prevented or better managed with their second born children. This prior research was limited, however, in that it only examined parentchild conflict at one point in time. Thus, it was uncertain whether parents and second born children also experienced less conflict at other points in time. It may be the case that later born children simply experienced a different trajectory of conflict with their parents, such that their conflict may peak at a different point than was the case for first born children. It is also important to note that children in Whiteman et al. (2003)'s study were assessed during early adolescence (i.e., ages 11,13 , and 15), whereas the current study's sample consists of emerging adults, many of whom are well into their 20 's. Conflict was measured at a much later developmental stage in the current study than in 
previous studies, so the findings obtained may reflect differences in how conflict appears and is experienced when children are older.

When evaluating other literature, the finding that later born children experience greater conflict than first born children may not be so incongruent after all. Rohde et al. (2003) found later born children to be more rebellious than their first born counterparts, and to have reported feeling less close to their parents. Along the same lines, Sulloway (1996) noted later born children to identify less closely with their parents' values compared to first born children. These findings were consistent with the current study's finding that acculturation gaps between parents and children tended to be greater among later-born children than first born children. Indeed, this suggested that later born children tended to differ more from their parents in terms of how much they subscribed to the values of a certain culture, whereas first born children were more similar to their parents in their level of acculturation.

As can be seen, the literature on the relationship between birth order status and intergenerational conflict is equivocal, with the findings obtained in this study supporting research suggesting greater conflict among later born children but contradicting research indicating greater conflict among first born children. As such, the exact relationship between birth order status and intergenerational conflict remains unclear. It may be the case that the precise nature of the relationship depends a great deal on interactions with other moderating variables, necessitating further research in this area.

In terms of how gender relates to intergenerational conflict, the findings obtained showed higher levels of conflict reported among female emerging adults, but only in the realm of dating and marriage. No gender differences were found in terms of the 
likelihood and seriousness of conflict, and conflict in the realm of education and career or family expectations. These findings corroborated the current literature, which has found gender of children to be an inconsistent predictor of conflict with parents. Although the research is equivocal, one trend that has emerged consistently is greater conflict between daughters and parents when dealing with dating and marriage issues, which the findings of this study supported as well (Chung, 2001). The finding that no gender differences were detected for the other measures of conflict may suggest that a general equalization of expectations has occurred for males and females, such that parents do not necessarily hold different standards of behavior for their sons and daughters. The one exception may be within the dating and marriage arena, where parents may still retain more traditional attitudes and expectations for their daughters, such that greater conflict may arise for daughters than sons when dealing with dating and marriage issues.

Because of the equivocal nature of the literature on the relationship between birth order status, gender, and intergenerational conflict, it was hypothesized that birth order and gender may interact in how they predict conflict. In contrast to the hypothesis, however, no interaction effect was detected. Gender was not shown to be a moderating variable in the relationship between birth order status and conflict. That is, how first born and later born children experienced conflict with their parents did not differ depending on whether children were male or female. A possible explanation for this finding may be that birth order status and gender influence different realms or aspects of intergenerational conflict. Birth order, for instance, was found to be more predictive of general conflict in this study, whereas gender was more specifically predictive of conflict 
in the realm of dating and marriage. In this way, birth order and gender influenced conflict in separate realms, so one would not necessarily expect an interaction to occur.

\section{Hypothesis 3}

Consistent with prior research (Tseng \& Fuligni, 2000), the findings supported a significant relationship between intergenerational conflict and limited language proficiency. Emerging adults who reported lower ratings of their parents' proficiency in English also reported greater likelihood of conflict in general, and specifically greater conflict related to family expectations and dating/marriage issues.

Due to the correlational nature of these findings, limited conclusions can be drawn, such as what may be the underlying cause of this relationship. It is possible that parents' limited English proficiency could directly contribute to greater conflict, perhaps by affecting emerging adults' feelings towards or their perception of their parents. It may also be the case that parents' limited English proficiency could influence conflict indirectly, such as by hindering parents' acculturation to Western culture, which may increase the extent of an acculturation gap between parents and emerging adults and subsequently result in greater conflict. Rather than causing conflict itself, whether directly or indirectly, it is also feasible that parents' limited English proficiency may simply impair their ability to resolve conflict when it naturally arises. In this way, parents' limited English proficiency may not contribute to greater conflict at all but may make conflict more difficult to address when it does arise. It is certainly possible that each of these scenarios may be occurring simultaneously, but without more detailed research, the exact mechanisms underlying the relationship between parents' limited English proficiency and conflict remain unknown. 
Another area of ambiguity was why parents' limited English proficiency did not seem to affect intergenerational conflict universally. In this study, parents' limited English proficiency was associated with increased conflict related to family expectations and dating and marriage issues, but not education and career issues. Perhaps, discussing issues related to family expectations and dating and marriage requires more abstract language skills than discussing issues related to education and career, so the task would be significantly more challenging for parents with lower levels of proficiency. As such, less proficient parents may experience greater difficulty articulating their perspectives or understanding their children's perspectives, leaving them more vulnerable to conflict as misunderstandings and frustration build. It is also possible that issues related to family expectations and dating and marriage may provoke more intense feelings than issues related to education and career. Thus, even if similar levels of misunderstandings and frustration due to the language barrier occurred when discussing family expectations, dating and marriage, and education and career, less conflict may occur for education and career issues because parents and children are less sensitive or reactive to those issues.

In terms of emerging adults' proficiency in speaking their parents' native language, limited language proficiency was associated with increased conflict related to dating and marriage issues only. No significant findings were found related to the likelihood and seriousness of conflict, nor for conflict related to family expectations and education and career issues. Perhaps, this trend contributed to the group differences in level of conflict related to dating and marriage issues found between emerging adults who most relied on their parents' native language of communication and those who relied primarily on English, which was discussed earlier. If the emerging adults are 
communicating in their parents' native language when they may not be highly proficient in it, it would not be surprising for them to experience greater conflict with their parents. As was the case for parents' limited English proficiency, it was unclear what mechanisms may be causing this relationship between emerging adults' limited proficiency in their parents' native tongue and increased conflict related to dating and marriage issues, but not other issues. More research is needed to uncover the exact nature of the relationship between language proficiency and intergenerational conflict. Consideration of Relationship Status and Education Level

Because a portion of the emerging adults assessed in this study were married and highly educated, there were concerns about whether including these groups in the analyses would confound the findings for conflict related to dating/marriage issues and education/career issues, respectively. The same analyses performed to test each of they hypotheses were executed again, except married and the most highly educated emerging adults were removed from the sample. When married emerging adults were not included, generational status was no longer found to significantly correlate with conflict related to dating and marriage issues. When the most highly educated emerging adults (i.e., those with Master's or doctoral degrees) were not included, birth order was now found to significantly and positively correlate with conflict related to education and career issues.

At this time, it is difficult to make clear conclusions from these findings. Prior to hypothesis testing, group differences in level of conflict across demographic variables had been assessed, with no group differences detected across relationship status and highest level of education. Thus, differences in emerging adults' relationship status and highest level of education were not associated with differences in level of conflict related 
to dating/marriage issues and education/career issues, respectively. When married and highly educated emerging adults were removed from the sample, however, different trends were found in terms of the relationship between other demographic factors and intergenerational conflict, compared to when these groups were included in the analyses. Perhaps, what can be gathered from these findings is that relationship status and education level may not directly be associated with differences in conflict, but they may influence how other demographic variables (e.g., generational and birth order status) are associated with conflict. It may be the case that relationship status and education level may be two factors that can influence the nature of how other factors relate to intergenerational conflict.

Best Overall Predictor of Intergenerational Conflict

Among all the various predictors of conflict investigated in this study, a gap in acculturation to White mainstream culture was found to be the most powerful and most consistent predictor of intergenerational conflict. This gap in acculturation to White mainstream culture was found to significantly predict both the likelihood and seriousness of conflict, as well as all common areas of disagreement in Asian American families that were investigated in this study: family expectations, education and career, and dating and marriage. In contrast, a gap in acculturation to parents' and children's Asian culture of origin only predicted seriousness of conflict. Essentially, what appeared to be most important in terms of predicting conflict was not how "Asian" an emerging adult was but, rather, how "White" that emerging adult was - or even more accurately, how "White" a emerging adult was in relation to how "White" his/her parents are. In the sample of Asian American emerging adults and parents obtained in this study, emerging adults and 
parents were found to differ in how much they identified with both their Asian culture of origin and the White mainstream culture. The degree of both acculturation gaps were virtually equivalent. Although the degree of difference was the same, it was the gap in acculturation to White mainstream culture that significantly predicted conflict the most strongly and the most consistently.

Based on these findings, it may be possible that if emerging adults and parents differed in how "Asian" they were but were equally "White," then they may not experience a great deal of conflict. What conflict they do experience, however, may be more intense or serious given that larger gaps in acculturation to Asian culture were associated with more serious conflict. If parents and emerging adults were equally "Asian," they could still experience much conflict if they differed significantly in how "White" they were. An important implication of these findings is that evaluating parents and emerging adults' acculturation to White mainstream culture may be more helpful in predicting conflict than evaluating their acculturation to their Asian cultures of origin. Moreover, interventions geared to prevent or reduce conflict may be most effective if they focus on increasing understanding and communication about White mainstream culture and parents' and emerging adults' attitudes towards White mainstream culture.

Because parents may have a more limited understanding of the mainstream culture or identify less with the mainstream culture than emerging adults, discussing the mainstream culture can certainly provoke feelings of uncertainty and increase awareness of differences. It would be understandable if this would be difficult to tolerate over time, and if parents and emerging adults eventually preferred to avoid such discussions. The unfortunate result, however, is that they may be more vulnerable to greater conflict at a 
later point due to the virtual inevitability and ubiquity of the mainstream culture and its influence. If parents and emerging adults were to be provided with a safe atmosphere in which these discussions could occur (e.g., a workshop in the community), and with the help of professionals facilitating discussions, the natural uncertainty and stress would perhaps subside. With skills-training in navigating the discussions, and more positive experiences surrounding them, it is hoped that parents and emerging adults would have a greater understanding of each others' perspectives regarding the mainstream culture and be more likely to have future discussions as issues continue to arise.

\section{Boomerang Children}

Among the Asian American emerging adults sampled in this study, a group of interest was the group of emerging adults who had recently (i.e, current boomerang children) or previously returned home (i.e., past boomerang children) to live with their parents after living on their own for an extended period of time. Various factors surrounding the circumstances of these boomerang children's time away from home and their return home were assessed. In terms of the decision to return home, emerging adults who had returned home against their wishes reported greater likelihood of conflict as well as more serious conflict compared to those emerging adults who had mutually decided with their parents to return home. A medium effect size was obtained, underscoring the strength of the relationship. Additional research is needed in order to determine the exact nature of the relationship, however. It may be the case, for instance, that emerging adults who were forced to move home may be less willing to compromise with their parents, which could account for the greater likelihood and seriousness of conflict after returning home. It may also be the case, however, that emerging adults who 
felt forced to move home had more conflictual relationships with their parents even before they first moved out. Thus, it was the conflictual relationship that contributed to a reluctance to move home rather than the forced decision to move home contributing to the conflictual relationship.

In terms of frequency of contact with parents during emerging adults' time away from home, more frequent contact occurring every few days to once a week was associated with less conflict related to education and career when emerging adults returned home compared with less frequent contact occurring every few months. Perhaps, more frequent contact with parents during emerging adults' time away provided protection against conflict when emerging adults returned home. However, it may also be possible that emerging adults who only had less contact with their parents already experienced higher levels of conflict with their parents during their time away, which was why little contact was desired. In this way, it was uncertain whether the frequency of contact contributed to level of conflict when emerging adults returned home or whether frequency of contact was influenced by premorbid level of conflicts. It is important to note that contact was assessed only in terms of frequency, with no differentiation made between the methods (e.g., phone calls or e-mails), duration, and content or quality of the communication. As these variables can vary significantly, assessing these variables could be more predictive of conflict after emerging adults return home than simply frequency of contact.

\section{Limitations and Strengths of the Current Study}

Various aspects of the study's methodology placed limitations on the conclusions that could be drawn from the findings. The statistical analyses performed in the study 
were correlational in nature, such that causal inferences could not be made. Although a large acculturation gap may predict conflict, it was uncertain whether acculturation gap caused conflict. Indeed, it may be the case that acculturation gap may both contribute to conflict and be a result of conflict, based on research documenting the bidirectional influence between conflict and parent/child variables. Indeed, Shek (2002) found parenting style to affect parent-adolescent conflict, but also found parent-adolescent conflict to predict parenting style over time.

Several limitations of the study were due to the particular methods of assessment that were used. In many instances, including level of intergenerational conflict, parents were assessed as a unit rather than separately. It may be the case that the extent or type of conflict experienced may differ depending on the gender of the parent. Therefore, measuring conflict with parents as a unit may not have fully captured the exact nature of the intergenerational conflict experienced. Assessment of parents was also limited in that emerging adults were asked to estimate their parents' level of acculturation and only the emerging adults' report of intergenerational conflict was obtained. Parents' level of acculturation was not directly measured and parents' perspectives on the intergenerational conflict were not ascertained. Although this study's sample provided similar estimations of their parents' level of acculturation as found in previous research (Ying \& Han, 2007), it was still uncertain whether emerging adults' estimations and reports may be biased or skewed in some way such that they may not have accurately reflected parents' true acculturation levels or portrayed the complete picture of the intergenerational conflict experienced in the family. Future research should endeavor to obtain both children's and parents' reports in order to ensure greater accuracy. It may 
also be helpful to compare children's estimations and parents' own self-assessments and to evaluate the degree to which children's and parents' reports match.

Another limitation in the study's methods of assessment was relying upon retrospective accounts of conflict among former boomerang children. In hopes of capturing the experience of Asian American emerging adults when they return home to their parents after living away for an extended period of time, data from both current and past boomerang children were collected. Whereas current boomerang children responded based on their current home-returning experience, past boomerang children were asked to reflect on their past home-returning experience and the level of conflict they recall experiencing then. Although some past boomerang children' home-returning experiences may be very recent, others' experiences may have occurred quite some years ago, calling into question the accuracy of their retrospective accounts.

Aspects of the study's methodology also limited the generalizability of the findings. Participants were recruited primarily through communities and organizations geared towards Asian American issues and groups, and it was uncertain whether individuals who participated in these communities and organizations were different from those individuals who did not participate in these communities and organizations. One could presume, for instance, that an individual who identified strongly with Asian culture would likely be more motivated to join Asian American-oriented communities and organizations, or would identify more strongly with Asian culture because of their involvement with these groups. Because many participants were recruited through these communities and organizations, it may be the case that the particular sample collected in this study may have identified more strongly with Asian culture than other Asian 
Americans who did not participate in the study. In this way, the findings could be skewed to reflect more accurately the experiences of Asian Americans who do identify strongly with their respective Asian culture but not capture the experiences of others. Subsequently, it was uncertain whether the findings of the study would generalize to all Asian American emerging adults, particularly those who were not active members of Asian American communities and organizations.

Another limit of the study's generalizability was that the findings only apply to the particular conflicts assessed via the two measures used, which may or may not have captured the entirety of the conflict that can occur in Asian American families. Although the likelihood and seriousness of general conflict was measured in addition to more specific types of conflict, it may be the case that other types of conflict occur in Asian American families that may relate differently with the various demographic and cultural factors explored in the study. Qualitative studies of intergenerational conflict as it occurs today in Asian American families may be helpful in obtaining a more contemporary and comprehensive picture of conflict.

Although many limitations certainly existed with regard to the study's methodology and findings, many strengths also present and should be highlighted. The current study was the first empirical study to investigate the experiences of Asian American emerging adults in their post-college years with regard to intergenerational conflict. Prior to this study, intergenerational conflict had only been studied among Asian American families with children up until and during college. Another strength of the study was that it explored intergenerational conflict within the context of emerging adults residing in the home, which there is also very little understanding of within the 
current literature. Given the higher rates of co-residence in recent years, particularly among Asian American families, there was a great need for more research on this topic.

Another strength of the current study was its large sample size, and its representation of multiple Asian American ethnicities across the country. Because data collection occurred entirely via the Internet, the participant pool was not limited to only those Asian Americans living within a specific region of the country. Instead, participants from across the country were recruited and assessed. A final strength of the study was its use of several measures of conflict, so as to capture emerging adults' experience of intergenerational conflict as fully as possible and the multiple facets of it. Acculturation, too, was measured from a multidimensional perspective rather than unidimensionally. In this study, the current study capitalized on the collection of existing measures among the literature so as to be as comprehensive as possible in assessing intergenerational conflict as it occurs in Asian American families and the factors that may influence intergenerational conflict (e.g., acculturation).

\section{Future Directions for Research}

The findings of the current study highlighted the multi-faceted and complex nature of intergenerational conflict as it occurs in Asian American families between emerging adults and their parents. A number of demographic and cultural factors were explored in terms of their relationship with intergenerational conflict, and, although significant relationships were often found, the exact nature of those relationships remains unclear. It was uncertain, for instance, why some factors were found to be significant predictors of conflict related to some topics (e.g., dating and marriage) but not other topics (e.g., family expectations). In this way, the mechanism through which certain 
factors may contribute to or affect conflict needs to be studied further and in more specific detail. Along the same lines, some factors may have a direct relationship with conflict (e.g., acculturation gap) whereas others may have a more indirect relationship with conflict (e.g., generational status, relationship status, highest level of education). Further exploration of the intricacies of the relationships between the factors studied and the nature of intergenerational conflict is warranted, so as to generate a more comprehensive understanding of conflict as it is experienced by emerging adults in Asian American families.

Another future direction for research is to investigate similarities and differences across Asian ethnic groups, where a gap in the literature exists. Although this study's population of Asian American emerging adults was ethnically diverse and resembled the ethnic breakdown of all Asian Americans in the U.S., many Asian ethnic groups were included together in one category of "Other Asian Ethnicity Not Listed." These include Japanese, Indian, Thai, Laotian, and Cambodian individuals, among others. These ethnic groups certainly deserve to be studied separately, as each is its own culture. 


\section{CHAPTER 5}

\section{CONCLUSIONS}

As reflected in the literature and supported by the findings of the current study, intergenerational conflict as it occurs in Asian American families is multi-faceted and variable in nature. The exact nature of the intergenerational conflict that occurs varies significantly depending upon a multitude of factors, such that conflict may present and be experienced very differently across families. These factors include, but are certainly not limited to, children and parents' acculturation to both Asian and American cultures, emerging adults' generational status, birth order, and gender, and emerging adults' and parents' language proficiency in both Asian and English languages. Individually, these factors can independently influence conflict, but they can also have a combined impact as they intersect to shape the frequency, intensity, and type of conflict that is experienced. Other factors that may also influence the nature of intergenerational conflict between emerging adults and their parents in Asian American families include ethnicity, age, living situation, and the language used in communication.

Even among the factors found to be statistically significant predictors of intergenerational conflict in this study, it is important to note that only a small percentage of the variability in conflict was actually accounted for (i.e., 1 to 9 percent), leaving reasons for the rest of the variability still yet to be determined. Other factors that could be helpful to investigate in future research include parenting style and emerging adults' and parents' communication patterns, which may certainly influence how intergenerational conflict arises and is addressed. Because Asian American emerging adults have not received much focus in the research, there is limited understanding of 
what their unique experiences are with intergenerational conflict and how it may occur or be addressed. With much research demonstrating the impact of intergenerational conflict and the parent-child relationship on children's psychological, academic, and social functioning among younger Asian American children and early adults (Gil et al., 1994; Kibria, 1993; Lau et al., 2002; Lee et al., 2005; Preventive Medicine Week, 2008; Yao, 1985; Ying \& Han, 2007), greater research is warranted for increasing understanding of later adult children's experiences with the hope of developing and improving upon prevention and intervention effects geared towards addressing or preventing conflict. 


\section{REFERENCES}

American Psychological Association. (2002). Ethical principles of psychologist and code of conduct. American Psychologist, 47, 1597-1611.

Arnett, J. J. (2000). Emerging adulthood: A theory of development from the late teens through the twenties. American Psychologist, 55(5), 469-480.

Aron, A, \& Aron, E. N. (2003). Statistics for Psychology ( $3^{\text {rd }}$ ed.). Upper Saddle River, NJ: Prentice Hall.

Baron, R. M., \& Kenny, D. A. (1986). The moderator-mediator variable distinction in social psychological research: Conceptual, strategic, and statistical considerations. Journal of Personality and Social Psychology, 51, 1173-1182.

Barrett Singer, A. T. (2000). Differential parental expectations and treatment in Asian American and European American families. (Unpublished doctoral dissertation). University of California, Berkeley.

Blinn-Pike, L., Worthy, S. L., Jonkman, J. N., \& Smith, G. R. (2008). Emerging adult versus adult status among college students: Examination of explanatory variables. Adolescence, 43(171), 577-591.

Chiu, M. L., Feldman, S. S., \& Rosenthal, D. A. (1992). The influence of immigration on parental behavior and adolescent distress in Chinese families residing in two western nations. Journal of Research on Adolescence, 2(3), 207-239.

Chung, I. W. (2006). A cultural perspective on emotions and behavior: An empathic pathway to examine intergenerational conflicts in Chinese immigrant families. Families in Society, 87(3), 367-376.

Chung, R. H. G. (2001). Gender, ethnicity, and acculturation in intergenerational conflict of 
Asian-American college students. Cultural Diversity and Ethnic Minority Psychology, 7, 376-386.

Chung, R. H. G., Kim, B. S. K., \& Abreu, J. M. (2004). Asian American Multidimensional Acculturation Scale: Development, factor analysis, reliability and validity. Cultural Diversity and Ethnic Minority Psychology, 10, 66-80.

Cohen, J. (1988). Statistical Power Analysis for the Behavioral Sciences $\left(2^{\text {nd }}\right.$ ed.). Mahwah, NJ: Lawrence Erlbaum Associates.

Dhruvarajan, V. (1993). Ethnic cultural retention and transmission among first generation Hindu Asian Indians in a Canadian Prairie City. Journal of Comparative Family Studies, 24(1), 63-79.

Dinh, K. T., Sarason, B. R., \& Sarason, I. G. (1994). Parent-child relationships in Vietnamese immigrant families. Journal of Family Psychology, 8(4), 471-488.

Farver, J. A. M., Narang, S. K., \& Bhadha, B. R. (2002). East meets west: Ethnic identity, acculturation, and conflict in Asian Indian families. Journal of Family Psychology, 16(3), 338-350.

Florsheim, P. (1997). Chinese adolescent immigrants: Factors related to psychosocial adjustment. Journal of Youth and Adolescence, 26(2), 143-163.

Gil, A. G., Vega, W. A., \& Dimas, J. M. (1994). Acculturative stress and personal adjustment among Hispanic adolescent boys. Journal of Community Psychology, $22,43-54$.

Gil-Rivas, V., Greenberger, E., Chen, C., \& Lopez-Lena, M. M. (2003). Understanding depressed mood in the context of a family-oriented culture. Adolescence, 38, 93109. 
Goldscheider, F., \& Goldscheider, C. (1994). Leaving and returning home in the twentieth century. Population Bulletin, 48(4), 1-35.

Goldscheider, F., \& Goldscheider, C. (1999). The changing transition to adulthood: Leaving and returning home. Thousand Oaks, CA: SAGE Publications, Inc.

Greenberger, E., \& Chen, C. (1996). Perceived family relationships and depressed mood in early and late adolescence: A comparison of European and Asian Americans. Developmental Psychology, 32(4), 707-716.

Hamilton, B. (1996). Ethnicity and the family life cycle: The Chinese-American family. Family Therapy, 23, 199-212.

Ho, D. Y. F. (1993). Relational orientation in Asian social psychology. In U. Kim \& J. W. Berry (Eds.), Indigenous psychologies: Research and experience in crosscultural context (240-259). Newbury Park, CA: Sage.

Inman, A. G., Howard, E. E., Beaumont, R. L., \& Walker, J. A. (2007). Cultural transmission: Influence of contextual factors in Asian Indian immigrant parents' experiences. Journal of Counseling Psychology, 54(1), 93-100.

Kibria, N. (1993). Family tightrope: The changing lives of Vietnamese Americans. Princeton, NJ: Princeton University Press.

Kim, B. S. K. (2007). Acculturation and enculturation. In F. T. L. Leong, A. G. Inman, A. Ebreo, L. H. Yang, L. Kinoshita, \& M. Fu (Eds.), Handbook of Asian American Psychology (2 ${ }^{\text {nd }}$ ed., 141-158). Thousand Oaks, CA: Sage Publications, Inc.

Kwak, K., \& Berry, J. W. (2001). Generational differences in acculturation among 
Asian families in Canada: A comparison of Vietnamese, Korean, and East-Indian groups. International Journal of Psychology, 36(3), 152-162.

Lau, A. S., Jernewall, N. M., Zane, N., \& Myers, H. F. (2002). Correlates of suicidal behavior among Asian American outpatient youths. Cultural Diversity \& Ethnic Minority Psychology, 8, 199-213.

Laursen, B., Coy, K. C., \& Collins, W. A. (1998). Reconsidering changes in parentchild conflict across adolescence: A meta-analysis. Child Development, 69, 817832.

Lee, R. M., Choe, J., Kim, G., \& Ngo, V. (2000). Construction of the Asian American Family Conflicts Scale. Journal of Counseling Psychology, 47(2), 211-222.

Lee, J., \& Cynn, V. (1991). Issues in counseling 1.5 generation Korean Americans. In C. Lee \& B. Richardson (Eds.), Multicultural issues in counseling: New approaches to diversity (pp. 127-140). Alexandria, VA: American Association for Counseling and Development.

Lee, R. M., \& Liu, H. T. (2001). Coping with intergenerational family conflict: Comparison of Asian American, Hispanic, and European American college students. Journal of Counseling Psychology, 48(4), 410-419.

Lee, R. M., Su, J., \& Yoshida, E. (2005). Coping with intergenerational family conflict among Asian American college students. Journal of Counseling Psychology, 52(3), 389-399.

Leong, F. T. L., \& Okazaki, S. (2009). History of Asian American psychology. Cultural Diversity and Ethnic Minority Psychology, 15(4), 352-362.

Liu, R. W. (1998). Educational and career expectations of Chinese-American college 
students. Journal of College Student Development, 39(6), 577-588.

MacKinnon, D. P., Warsi, G., \& Dwyer, J. H. (1995). A simulation study of mediated effect measures. Multivariate Behavioral Research, 30, 41-62.

Messineo, M. J., \& Wojtkiewicz, R. A. (2004). Coresidence of adult children with parents from 1960 to 1990 : Is the propensity to live at home really increasing? Journal of Family History, 29(1), 71-83.

Mitchell, B. A. (1998). Too close for comfort? Parental assessments of "boomerang kid" living arrangements. Canadian Journal of Sociology, 23(1), 21-46.

Mitchell, B. A. (2006). The boomerang age from childhood to adulthood: Emergent trends and issues for aging families. Canadian Studies in Population, 33(2), 155178.

Mitchell, B. A., \& Gee, E. M. (1996). 'Boomerang kids' and midlife parental marital satisfaction. Family Relations, 45(4), 442-448.

Mordkowitz, E. R., \& Ginsberg, H. P. (1987). Early academic socialization of successful Asian-American college students. Quarterly Newsletter of the Laboratory of Comparative Human Cognition, 9, 85-91.

Padilla, A., Wagatsuma, Y., \& Lindholm, K. J. (1985). Acculturation and personality as predictors of stress in Japanese and Japanese-American. Journal of Social Psychology, 125, 295-305.

Pew Research Cenger (2009). Millennials: Confident. Connected. Open to Change. Retrieved from http://pewsocialtrends.org/assets/pdf/millennials-confidentconnected-open-to-change.pdf

Pew Research Center (2010). The Return of the Multi-Generational Family Household. 
Retrieved from http://pewsocialtrends.org/assets/pdf/752-multi-generationalfamilies.pdf

Preventive Medicine Week. (2008). Suicide in Asian Americans. Retrieved August 28, 2008 , from the newsgroup: psycport.com

Rohde, P. A., Atzwanger, K., Butovskaya, M., Lampert, A., Mysterud, I., SanchezAndres, A., \& Sulloway, F. J. (2003). Perceived parental favoritism, closeness to kin, and the rebel of the family: The effects of birth order and sex. Evolution and Human Behavior, 24, 261-276.

Rumbaut, R. G. (1996). The crucible within: Ethnic identity, self-esteem, and segmented assimilation among children of immigrants. In A. Portes (Ed.), The new second generation (119-179). New York: Russell Sage Foundation.

Shah, N. (2005). An assessment of intergenerational conflict and adjustment in Indian American college students and an empirical evaluation of self-construal theory. (Unpublished doctoral dissertation). Emory University.

Shanahan, L., McHale, S. M., Wayne Osgood, D., \& Crouter, A. C. (2007). Conflict frequency with mothers and fathers from middle childhood to late adolescence: Within- and Between-Families Comparisons. Developmental Psychology, 43(3), 539-550.

Shek, D. T. L. (2002). Parenting characteristics and parent-adolescent conflict: A longitudinal study in the Chinese culture. Journal of Family Issues, 23, 189-208.

Shon, S. P., \& Ja, D. Y. (1982). Asian families. In M. McGoldrick, J. K. Pearce, \& J. Giordana (Eds.), Ethnicity and family therapy (208-228). New York: Guilford Press. 
Sue, S., \& Okazaki, S. (2009). Asian-American educational achievements: A phenomenon in search of an explanation. Asian American Journal of Psychology, $S(1), 45-55$.

Sulloway, F. J. (1996). Born to Rebel: Birth Order, Family Dynamics, and Creative Lives. New York: Pantheon.

Szapocznik, J., \& Kurtines, W. M. (1993). Family psychology and cultural diversity: Opportunities for theory, research, and application. American Psychologist, 48(4), 400-407.

Tabachnick, B. G., \& Fidell, L. S. (2007). Using Multivariate Statistics $\left(5^{\text {th }}\right.$ ed.). Boston: Allyn \& Bacon.

Tseng, V., \& Fuligni, A. J. (2000). Parent-adolescent language use and relationships among immigrant families with East Asian, Filipino, and Latin American backgrounds. Journal of Marriage and the Family, 62(2), 465-476.

Turcotte, M. (2006). Parents with adult children living at home. Canadian Social Trends, 11(8), 2-10.

Uba, L. (1994). Asian Americans: Personality patterns, identity, and mental health. New York: Guilford Press.

Umberson, D. (1992). Relationships between adult children and their parents:

Psychological consequences for both generations. Journal of Marriage \& Family, 54(3), 664-674.

U.S. Census Bureau. (2007). American Community Survey: Asian alone or in 
combination with one or more other races [Data file]. Retrieved on December 28, 2009, from http://factfinder.census.gov/servlet/IPCharIterationServlet? _lang $=$ en\& _ts $=285544348829$

Whiteman, S. D., McHale, S. M., \& Crouter, A. C. (2003). What parents learn from experience: The first child as a first draft? Journal of Marriage and Family, 65(3), $608-621$.

Yao, E. L., (1985). Adjustment needs of Asian immigrant children in schools. Elementary School Guidance and Counseling, 19, 222-227.

Ying, Y.-W., \& Chao, C. C. (1996). Intergenerational relationship in Iu Mien American families. Ameriasia Journal, 22, 47-64.

Ying, Y.-W., Coombs, M., \& Lee, P. A. (1999). Family intergenerational relationship of Asian American adolescents. Cultural Diversity and Ethnic Minority Psychology, $5(4), 350-363$.

Ying, Y.-W., \& Han, M. (2007). The longitudinal effect of intergenerational gap in acculturation on conflict and mental health in Southeast Asian American adolescents. American Journal of Orthopsychiatry, 77(1), 61-66.

Ying, Y., Lee, P. A., Tsai, J. L., Lee, Y. L., \& Tsang, M. (2001). Relationship of young adult Chinese Americans with their parents: Variation by migratory status and cultural orientation. American Journal of Orthopsychiatry, 7l(3), 342-349. 
Appendix A

List of Asian American Contacts

Postings on Forums of Online Communities

Asianave.com

Listservs/Mailing List

UCLA Asian American Studies Center

Queer Asian Pacific Alliance

College Student Organizations

General Asian American Associations or Greek Organizations:

$\begin{array}{ll}\text { Ball State University } & \text { U of Michigan } \\ \text { UC Berkeley } & \text { U of Minnesota } \\ \text { UCLA } & \text { U of Missouri } \\ \text { UC San Diego } & \text { Miami } \\ \text { UC Davis } & \text { MIT } \\ \text { UC Irvine } & \text { U of Notre Dame } \\ \text { Columbia University } & \text { NYU } \\ \text { Cornell University } & \text { Ohio State } \\ \text { George Mason University } & \text { Princeton } \\ \text { Georgetown } & \text { Rice } \\ \text { Harvard } & \text { Stanford } \\ \text { University of Illinois, Urbana } & \text { SUNY at Albany } \\ \text { Indiana University } & \text { University of Pennsylvania } \\ \text { Johns Hopkins } & \text { U of Washington } \\ \text { University of Maryland, CP } & \text { U of Wisconsin, Madison } \\ \text { University of Maryland, BC } & \text { Wellesley }\end{array}$


Vietnamese Student Associations:

University of Arizona
Baylor University
Binghamton University
Boston College
Boston University
Brown University
UC Berkeley
UC Davis
UC Irvine
UCLA
UC Riverside
California Polytechnic State
University of San Luis Obispo
University of Central Florida
Columbia University
Cornell
Cal State San Barnardino
Cal State Los Angeles
Cal State Long Beach
Cal Poly Pomona
George Washington University
Harvard
Indiana University
Kansas State University
UMCP

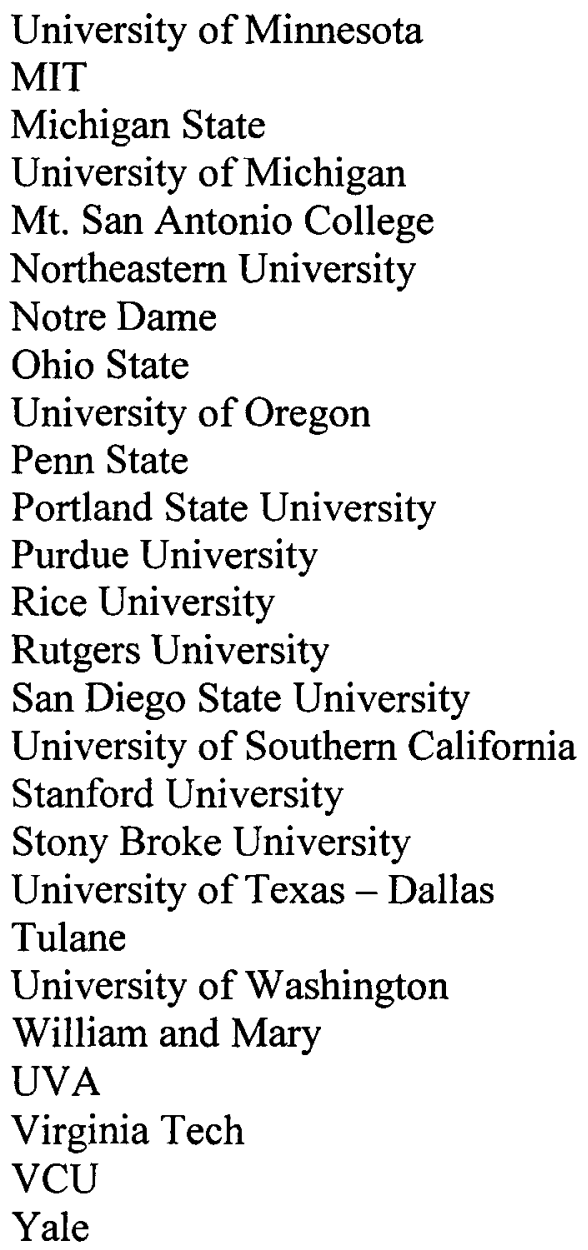

Korean Student Associations:

Amherst College
University of Arizona
Boston College
Boston University
Case Western Reserve University
University of Chicago
University of Cincinnati
UC Riverside
Columbia University
Dartmouth College
Duke University
George Mason University
George Washington University
University of Maryland
Miami University

University of Minnesota

Missouri State

MIT

University of New Mexico

NC State

UNC

University of North Texas

Northwestern University

University of Oklahoma

Penn State

University of Pennsylvania

University of Pittsburgh

Princeton University

Rice University

University of Rochester

San Francisco State 
University of Southern California Stanford University

Syracuse

Chinese Student Associations:

Boston College

Boston University

Brown

Cal Poly

Cal Poly Pomona

UC Berkeley

UCLA

UC Irvine

UC Riverside

UC San Diego

University of Colorado, Boulder

Cooper Union

Cornell

Georgia Tech

Harvard

Johns Hopkins

JMU

University of Maryland, CP

University of Maryland, BC

University of Memphis

Miami

University of Minnesota

MIT

NC State
Texas A \& M

UVA

Yale
UNC Chapel Hill

Northwestern

Oklahoma State

Oregon State

University of Oregon

University of Pennsylvania

Princeton

Rice University

Rochester

Rutgers

Seattle University

Stanford

SUNY at Albany

University of Southern California

Texas A \& M

Tufts

Tulane

UVA

University of Washington

University of Wisconsin,

Whitewater

VCU

Wellesley

Yale

Taiwanese Student Associations:

Arizona

Auburn

Columbia

Cornell

Harvard

Johns Hopkins

MIT
Ohio University

Princeton

Seattle University

UCLA

UMASS Amherst

UVA

$\mathrm{U}$ of Washington 
Filipino Student Associations:

Cal Poly

Indiana U

Johns Hopkins

Northwestern

Penn State

Purdue

Stanford
SUNY at Albany

$\mathrm{U}$ of Illinois

$\mathrm{U}$ of Michigan

$\mathrm{U}$ of Minnesota

UVA

$\mathrm{U}$ of Washington

Indian American/South Asian:

Ball State
Miami
Ohio State
SUNY at Albany

$\mathrm{U}$ of Minnesota

UVA

\section{Professional Organizations}

Vietnamese Professional Society

Young Korean American Network

Korean-American Scientists and Engineers Association

Asian Professional Exchange - Youth Outreach apexyo@apex.org

Asian American Institute - aai@aaichicago.org

Asian American LEAD (Leadership, Empowerment, and Development of Youth and Families) - info@aalead.org

Asian Americans for Community Outreach - info@aaco-sf.org

Asian and Pacific Islander American Health Forum - healthinfo@apiahf.org

Asian/Pacific American Heritage Association - info@apaha.org

Coalition for Asian American Children \& Families - cacf@cacf.org

Koreantown Youth and Community Center - info@kyccla.org

Korean American Professional Society - andrew@kaps.org

Korean American Coalition - kacdc@kacdc.org

National Federation of Filipino American Association - via website

Young Korean American Network - via website

YKASEC - Young Korean American Service and Education Center - via website

National Association of Asian American Professionals

Chapters:

$\begin{array}{ll}\text { Atlanta } & \text { Chicago } \\ \text { DC } & \text { Cincinnati } \\ \text { Boston } & \text { Cleveland }\end{array}$


Colorado

Columbus

Connecticut

Florida (Southwest)

Houston

Minnesota

Nashville

New York

North Carolina
Orange County

Philadelphia

Phoenix

San Diego

San Francisco

Seattle

Toronto

Tucson

Vancouver

Youth Organizations

Organization of Chinese Americans

Chapters:
Chicago
Cleveland
Columbus
Dallas/Fort Worth
Detroit
Florida (South)
Houston
LA
Las Vegas
New England
New Jersey

New York

Orange County

Philadelphia

Pittsburgh

Sacramento

Seattle

St. Louis

Tennessee

Virginia

Washington, DC

\section{Religious Organizations:}

Ambassador Bible Church - Fairfax, VA

Christ Central Presbyterian Church Youth Group - Vienna, VA

Embrace Ministry - Fairfax Station, VA

Emmaus United Methodist Church - Richmond, VA

Eternal Grace Bible Church - McLean, VA

Korean Central Presbyterian Church - Vienna, VA

Korean United Methodist Church of Greater Washington Youth Group - McLean, VA

New Life Church - Washington, DC

Open Door Presbyterian Church - Herndon, VA

Powerhouse Ministry - Burke, VA

Vision of Peace Church - McLean, VA

Young Saeng Korean Presbyterian Church - Centreville, VA 
Appendix B

Notification Letter

Dear Participant:

The purpose of this study is to investigate the nature of intergenerational conflict in Asian American families, specifically between parents and their adult children. Although much research has been conducted when children are of college-age or younger, very little is known about how parents and children interact when children are well into adulthood. This study is interested in conflicts that may arise when Asian American adult children live in the home.

This study will consist of completing several questionnaires on intergenerational conflict, cultural issues, and demographic information. The questionnaires will take about 20-30 minutes to complete. Your participation in this study is completely voluntary. If you are participating as a registered student in the psychology research program, you will receive one point of research credit for your participation. All other participants have the option of being entered into a raffle to receive one of three $\$ 30$ Visa gift cards. Winners will be selected and notified upon completion of the study.

At the end of the survey, you will be directed to a separate survey where you can provide contact information to obtain research credit or enter into the raffle. Please be assured that your contact information cannot be linked back to your survey responses. If you do not feel comfortable answering the survey questions, you are free to withdraw from this study at any point, without penalty, by simply closing your browser window.

The student investigator of this study is Kathy Nguyen, M.A., who is working under the supervision of Dr. Janis Sanchez, Department of Psychology at Old Dominion University. This study has been reviewed by the Human Subjects Review Board of the College of Sciences at Old Dominion University (exempt \# 008-09-009). If you have any questions or concerns about the study, please forward them to knguy012@odu.edu or jsanchez@odu.edu.

Thank you for your participation.

Kathy Nguyen, M.A. Student Investigator knguy012@odu.edu

Janis Sanchez, Ph.D.

Principal Investigator jsanchez@odu.edu (757) 683-4448 


\section{Appendix C}

\section{Asian American Family Conflicts Scale (FCS)}

The following statements are parent-child situations that may occur in families.

Consider how likely each situation occurs in your present relationship with your parents and how serious these conflicts are.

Family Situations:

1) Your parents tell you what to do with your life, but you want to make your own decisions.

How likely is this type of situation to occur in your family?

\{Choose one
( ) 1 - Almost never
( ) 2 - Once in a while
() 3 - Sometimes
( ) 4 - Often or frequently
( ) 5 - Almost always

How serious a problem is this situation in your family?

\{Choose one\}
( ) 1 - Not at all
( ) 2 - Slightly
( ) 3 - Moderately
( ) 4 - Very much
( ) 5 - Extremely

2) Your parents tell you that a social life is not important at this age, but you think that it is.

How likely is this type of situation to occur in your family?

\{Choose one\}
( ) 1 - Almost never
( ) 2 - Once in a while
( ) 3 - Sometimes
( ) 4 - Often or frequently
( ) 5 - Almost always

How serious a problem is this situation in your family?

\{Choose one\}
( ) 1 - Not at all
( ) 2 - Slightly
( ) 3 - Moderately 

( ) 4 - Very much
() 5 - Extremely

3) You have done well in school/at work, but your parents' academic/career expectations always exceed your performance.

\{Choose one\}
( ) 1 - Almost never
( ) 2 - Once in a while
( ) 3 - Sometimes
() 4 - Often or frequently
() 5 - Almost always

How serious a problem is this situation in your family?

\{Choose one\}
( ) 1 - Not at all
() 2 - Slightly
( ) 3 - Moderately
() 4 - Very much
( ) 5 - Extremely

4) Your parents want you to sacrifice personal interests for the sake of the family, but you feel this is unfair.

How likely is this type of situation to occur in your family?

\{Choose one\}
( ) 1 - Almost never
( ) 2 - Once in a while
( ) 3 - Sometimes
( ) 4 - Often or frequently
( ) 5 - Almost always

How serious a problem is this situation in your family? \{Choose one\}
( ) 1 - Not at all
() 2 - Slightly
( ) 3 - Moderately
( ) 4 - Very much
( ) 5 - Extremely

5) Your parents always compare you to others, but you want them to accept you for being yourself.

How likely is this type of situation to occur in your family?

\{Choose one\}
( ) 1 - Almost never 
() 2 - Once in a while

( ) 3 - Sometimes

( ) 4 - Often or frequently

( ) 5 - Almost always

How serious a problem is this situation in your family?

\{Choose one\}
( ) 1 - Not at all
( ) 2 - Slightly
( ) 3 - Moderately
( ) 4 - Very much
( ) 5 - Extremely

6) Your parents argue that they show you love by housing, feeding, and educating you, but you wish they would show more physical and verbal signs of affection.

How likely is this type of situation to occur in your family?

\{Choose one\}
( ) 1 - Almost never
( ) 2 - Once in a while
( ) 3 - Sometimes
( ) 4 - Often or frequently
( ) 5 - Almost always

How serious a problem is this situation in your family?

\{Choose one\}
() 1 - Not at all
() 2 - Slightly
() 3 - Moderately
( ) 4 - Very much
( ) 5 - Extremely

7) Your parents don't want you to bring shame upon the family, but you feel that your parents are too concerned with saving face.

How likely is this type of situation to occur in your family?

\{Choose one
( ) 1 - Almost never
( ) 2 -Once in a while
() 3 - Sometimes
( ) 4 - Often or frequently
( ) 5 - Almost always

How serious a problem is this situation in your family? \{Choose one\} 

( ) 1 - Not at all
( ) 2 - Slightly
() 3 - Moderately
( ) 4 - Very much
( ) 5 - Extremely

8) Your parents expect you to behave like a proper Asian male or female, but you feel your parents are being too traditional.

How likely is this type of situation to occur in your family?

\{Choose one\}
( ) 1 - Almost never
( ) 2 - Once in a while
( ) 3 - Sometimes
( ) 4 - Often or frequently
( ) 5 - Almost always

How serious a problem is this situation in your family?

\{Choose one\}

() 1 - Not at all

( ) 2 - Slightly

() 3 - Moderately

( ) 4 - Very much

() 5 - Extremely

9) You want to state your opinion, but your parents consider it to be disrespectful to talk back.

How likely is this type of situation to occur in your family?

\{Choose one\}

( ) 1 - Almost never

( ) 2 - Once in a while

() 3 - Sometimes

( ) 4 - Often or frequently

( ) 5 - Almost always

How serious a problem is this situation in your family?

\{Choose one\}
() 1 - Not at all
() 2 - Slightly
() 3 - Moderately
( ) 4 - Very much
( ) 5 - Extremely 
10) Your parents demand that you always show respect for elders, but you believe in showing respect only if they deserve it.

How likely is this type of situation to occur in your family?

\{Choose one\}
( ) 1 - Almost never
() 2 - Once in a while
( ) 3 - Sometimes
( ) 4 - Often or frequently
( ) 5 - Almost always

How serious a problem is this situation in your family?

\{Choose one\}
( ) 1 - Not at all
( ) 2 - Slightly
( ) 3 - Moderately
( ) 4 - Very much
( ) 5 - Extremely 


\author{
Appendix D \\ Intergenerational Conflict Inventory (ICI)
}

Directions: For each of the items below, use the following scale to indicate how much conflict each item causes between you and your parents. If you have different level of conflict with each parent, answer according to the most conflict you experience regardless of which parent.

No conflict over
this issue

1
Some conflict over this issue

3

\section{A lot of conflict over this issue}

4

5

1. Lack of communication with your parent

2. Your desire for greater independence and autonomy

3. Following cultural traditions

4. Pressure to learn one's own Asian language

5. Expectations based on being male or female

6. Expectations based on birth order

7. Family relationships being too close

8. Family relationships being too distant

9. How much time to spend with the family

10. How much to help around the house

11. How much time to help out in the family business

12. How much time to spend on studying

13. How much time to spend on recreation

14. How much time to spend on sports

15. How much time to spend on practicing music

16. Importance of academic achievement

17. Emphasis on success and materialism

18. Which school to attend

19. What to major in college

20. Which career to pursue

$\begin{array}{lllll}1 & 2 & 3 & 4 & 5 \\ 1 & 2 & 3 & 4 & 5 \\ 1 & 2 & 3 & 4 & 5 \\ 1 & 2 & 3 & 4 & 5 \\ 1 & 2 & 3 & 4 & 5 \\ 1 & 2 & 3 & 4 & 5 \\ 1 & 2 & 3 & 4 & 5 \\ 1 & 2 & 3 & 4 & 5 \\ 1 & 2 & 3 & 4 & 5 \\ 1 & 2 & 3 & 4 & 5 \\ 1 & 2 & 3 & 4 & 5 \\ 1 & 2 & 3 & 4 & 5 \\ 1 & 2 & 3 & 4 & 5 \\ 1 & 2 & 3 & 4 & 5 \\ 1 & 2 & 3 & 4 & 5 \\ 1 & 2 & 3 & 4 & 5 \\ 1 & 2 & 3 & 4 & 5 \\ 1 & 2 & 3 & 4 & 5 \\ 1 & 2 & 3 & 4 & 5 \\ 1 & 2 & 3 & 4 & 5\end{array}$


21. Being compared to others

22. Whom to date

23. When to marry

24. Whom to marry $\begin{array}{lllll}1 & 2 & 3 & 4 & 5\end{array}$

$\begin{array}{lllll}1 & 2 & 3 & 4 & 5\end{array}$

$\begin{array}{lllll}1 & 2 & 3 & 4 & 5\end{array}$

$\begin{array}{lllll}1 & 2 & 3 & 4 & 5\end{array}$ 
Appendix E

Asian American Multidimensional Acculturation Scale (AAMAS)

Instructions: Use the scale below to answer the following questions. Please circle the number that best represents your view on each item. Please note that reference to "Asian" hereafter refers to Asians in America and not Asia.

\begin{tabular}{ccccccc} 
Not very well & & \multicolumn{2}{c}{ Somewhat } & & Very well \\
1 & 2 & 3 & 4 & 5 & 6
\end{tabular}

1. How well do speak the language of --

$\begin{array}{lllllll}\text { a. your own Asian culture of origin? } & 1 & 2 & 3 & 4 & 5 & 6 \\ \text { b. English? } & 1 & 2 & 3 & 4 & 5 & 6\end{array}$

2. How well do you understand the language of --

$\begin{array}{lllllll}\text { a. your own Asian culture of origin? } & 1 & 2 & 3 & 4 & 5 & 6 \\ \text { b. English? } & 1 & 2 & 3 & 4 & 5 & 6\end{array}$

3. How well do you read and write in the language of --

$\begin{array}{lllllll}\text { a. your own Asian culture of origin? } & 1 & 2 & 3 & 4 & 5 & 6 \\ \text { b. English? } & 1 & 2 & 3 & 4 & 5 & 6\end{array}$

4. How often do you listen to music or look at movies and magazines from
a. your own Asian culture of origin?
2
b. the White mainstream groups?
2

3
45
45
6
6

5. How much do you like the food of -
a. your own Asian culture of origin? 1
23
4
b. the White mainstream groups?
2

3
4
5
6

6. How often do you eat the food of -
a. your own Asian culture of origin?

2
4
5
6
b. the White mainstream groups?

2

3

$\begin{array}{lll}4 & 5 & 6\end{array}$




\begin{tabular}{ccccccc} 
Not very well & & \multicolumn{2}{c}{ Somewhat } & & Very well \\
1 & 2 & 3 & 4 & 5 & 6
\end{tabular}

7. How knowledgeable are you about the history of -

$\begin{array}{lllllllll}\text { a. your own Asian culture of origin? } & 1 & 2 & 3 & 4 & 5 & 6\end{array}$

$\begin{array}{llllllll}\text { b. the White mainstream groups? } & 1 & 2 & 3 & 4 & 5 & 6\end{array}$

8. How knowledgeable are you about the culture and traditions of -
a. your own Asian culture of origin?

2
b. the White mainstream groups?

2

3

$\begin{array}{lll}4 & 5 & 6 \\ 4 & 5 & 6\end{array}$

9. How much do you practice the traditions and keep the holidays of -
a. your own Asian culture of origin?
23

34
45
6
b. the White mainstream culture?

2

3

45
6

10. How much do you identify with -
a. your own Asian culture of origin? 1

2
b. the White mainstream groups?

2

3

$\begin{array}{lll}4 & 5 & 6 \\ 4 & 5 & 6\end{array}$

11. How much do you feel you have in common with people from -
a. your own Asian culture of origin? 1

2
b. the White mainstream groups? 1

23

$\begin{array}{lll}4 & 5 & 6 \\ 4 & 5 & 6\end{array}$

12. How much do you interact and associate with people from -
a. your own Asian culture of origin? 1

2
b. the White mainstream groups?

2

3

13. How much would you like to interact and associate with people from -
a. your own Asian culture of origin?

2

23
b. the White mainstream groups?

1

$\begin{array}{llll}3 & 4 & 5 & 6 \\ 3 & 4 & 5 & 6\end{array}$




\begin{tabular}{ccccccc} 
Not very well & \multicolumn{2}{c}{ Somewhat } & \multicolumn{2}{c}{ Very well } \\
1 & 2 & 3 & 4 & 5 & 6
\end{tabular}

14. How proud are you to be part of -
a. your own Asian culture of origin?
2

34
45
b. the White mainstream groups?
2

3

$\begin{array}{lll}4 & 5 & 6\end{array}$

15. How negative do you feel about people from -
a. your own Asian culture of origin?
23

34
45
6
b. the White mainstream groups?

2

32

45
6 


\section{Appendix F}

\section{Demographic Questionnaire}

Please answer the following questions as accurately as you can. The answers you provide are completely anonymous.

\section{Adult Children:}

Gender:

\{Choose one\}

( ) Female

( ) Male

Age:

\{Choose one\}

() 18

() 19

() 20

() 21

() 22

() 23

() 24

() 25

() 27

() 28

() 29

() 30

() 31

() 32

() 33

() 34

() 35

() 36

() 37

() 38

() 39

( ) 40 or older

Ethnicity:

\{Choose all that apply\}
() Chinese
() Filipino
() Indian
() Japanese 

() Laotian
() Korean
() Vietnamese
( ) Other [

Highest Level of Education:

\{Choose one\}
() Some high school or less
( ) High school degree
() Some college
() Associate's
() Bachelor's
() Masters
() Doctorate

Annual Income:

\{Choose one
() Less than $\$ 20,000$
() $\$ 20,000-29,000$
() $\$ 30,000-39,000$
() $\$ 40,000-49,000$
() $\$ 50,000-59,000$
() $\$ 60,000-69,000$
() $\$ 70,000-79,000$
() $\$ 80,000-89,000$
() $\$ 90,000-99,000$
( ) $\$ 100,000$ or more

Current Relationship Status:

\{Choose one\}
() Married
() Divorced
() Separated
() Single (Not in a relationship)
() In a Relationship

If you are currently married or in a relationship, what is your partner's race? \{Choose all that apply\}
() Not applicable
() African-American/Black
() Asian
() Caucasian
() Hispanic/Latino
() American Indian
() Other [ 
Sexual orientation:

\{Choose one\}
() Straight
() Gay
() Lesbian
() Bisexual
() Uncertain
() None of the Above

Birth Order:

\{Choose one\}
() Only child
() 1st-born child
() 2nd-born child
() 3rd-born child
() 4th-born child
() 5th-born child
() 6th-born child or greater

Generation Status:

\{Choose one

() 1st generation (I was not born in the U.S.)

() 2nd generation (I was born in the U.S. but either parent was not born in the U.S.)

( ) 3rd generation (I was born in the U.S., both parents were born in the U.S., but no grandparent was born in the U.S.)

( ) 4th generation (I was born in the U.S., both parents were born in the U.S., one grandparent was born in the U.S., but at least one grandparent was not born in the U.S.

() 5th generation (I was born in the U.S., both parents were born in the U.S., and all grandparents were also born in the U.S.)

( ) Don't know what generation best fits since I lack some information.

If you are 1st generation, how long have you lived in the U.S.?

\{Choose one

() Less than a year

() 1-2 years

() $3-5$ years

() 6-10 years

() $11-15$ years

( ) 16-20 years

() 21 years or more

How would you rate your proficiency in speaking and understanding English? 
\{Choose one\}

() 1 - Very little to no proficiency

() 2 - A little proficient

() 3 - Somewhat proficient

() 4 - Very proficient

( ) 5 - Completely proficient

How would you rate your proficiency in speaking and understanding your parents' native language?

\{Choose one\}

() Very little to no proficiency

() A little proficient

() Somewhat proficient

() Very proficient

() Completely proficient

Are you currently living with your parents? (Please note: If you are currently living away at school, answer "No" to this question)

\{Choose one

() Yes

() No

() Unsure - Please describe why [

Living Situation (Currently living with Parents)

Are you currently:

\{Choose one\}

() Working

() In school

() Neither working nor in school

( ) Both working and in school

After turning 18, have you ever lived away from home for more than 4 months? \{Choose one\}
() Yes
( ) No

How long did you live away from home before returning home?

\{Enter answer in paragraph form\}

[

]

Why did you leave home?

\{Enter answer in paragraph form\} [ 
Please describe the frequency of contact with your parents while you lived away from home (including visits home, phone calls, emails/instant messaging/text messages):

\{Enter answer in paragraph form\} [

Why did you eventually come back home? (e.g., was the decision financially motivated, did you have a choice, what other alternatives were you considering?) \{Enter answer in paragraph form

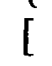

How long have you been living at home since returning?

\{Choose one

() Less than 1 month

() 1-3 months

() 4-6 months

() 7 months - 1 year

() $1-2$ years

() 3 years or more

From today, how long do you intend on living at home?

\{Choose one\}

() Less than 6 more months

() Another 7 months - 1 year

() Another 2-3 years

() Longer than 3 more years

( ) Not sure

Please describe your transition back home (Was it hard and, if so, what was hard? Were you surprised by anything you experienced when you returned? If you had a choice to change your decision, would you and what would you do differently?) \{Enter answer in paragraph form $\}$

[

]

\section{Living Situation - Currently NOT Living with Parents}

Where are you currently living?

\{Choose one\}

() Living away at school (undergraduate, graduate, etc.)

() Living on my own (but not at school)

Other than right now, have you ever lived away from your parents for more than 4 months after turning 18 ? 
\{Choose one\}

() Yes

() No

Did you ever return home after living away for more than 4 months after turning 18 ?

\{Choose one\}

() Yes

() No

How long did you live away from home before returning home? \{Enter answer in paragraph form\} [

Why did you leave home?

\{Enter answer in paragraph form $\}$ [

Please describe the frequency of contact with your parents while you lived away from home (including visits home, phone calls, emails/instant messaging/text messages):

\{Enter answer in paragraph form\} [

Why did you eventually come back home? (e.g., was the decision financially motivated, did you have a choice, what other alternatives were you considering?) \{Enter answer in paragraph form\} [

How long did you live at home after returning?

\{Choose one\}

() Less than 1 month

() 1-3 months

() 4-6 months

( ) 7 months - 1 year

() $1-2$ years

( ) 3 years or more

Please describe what your transition back home was like: Was it hard and, if so, what was hard? Were you surprised by anything you experienced when you returned? If you had a choice to change your decision, would you and what would you do differently?

\{Enter answer in paragraph form [ 
Please describe the circumstances of your previous move away from home (e.g., why did you move?) \{Enter answer in paragraph form $\}$

[

Please describe the current frequency of your contact with your parents (including visits home, phone calls, emails/instant messaging/text messages): \{Enter answer in paragraph form\}

[

How long has it been since you moved out after returning home?

\{Choose one\}

() Less than 6 months

() 6 months - less than 1 year

() 1 year -2 years

() 3 years -4 years

() More than 4 years

\section{Parents:}

The following questions assess your parents' demographic information. Please answer them as accurately as you can. The answers you provide are completely anonymous.

Parents' Relationship Status:

\{Choose one

() Married

() Divorced

() Separated

() Never Married

Are both of your parents of Asian heritage?

\{Choose one\}

() Yes

() No

Mother's Ethnicity:

\{Choose all that apply\}

() Chinese

() Filipino

() Indian

() Japanese

() Laotian

() Korean

() Vietnamese 
() Other [

Father's Ethnicity:

\{Choose all that apply\}
() Chinese
() Filipino
() Indian
( ) Japanese
() Laotian
() Korean
() Vietnamese
() Other [

Mother's Age:

\{Choose one
() 30 or younger
() 31
() 32
() 33
() 34
() 35
() 36
() 37
() 38
() 39
( ) 40
() 41
() 42
() 43
() 44
() 45
() 46
() 47
() 48
() 49
() 50
() 51
() 52
() 53
() 54
() 55
() 56
() 57
() 58 

() 59
() 60
() 61
() 62
() 63
( ) 64
( ) 65 or older

Father's Age:

\{Choose one\}
() 30 or younger
() 31
() 32
() 33
() 34
() 35
() 36
() 37
() 38
() 39
( ) 40
() 41
() 42
() 43
() 44
() 45
() 46
( ) 47
() 48
() 49
() 50
() 51
() 52
() 53
() 54
() 55
() 56
() 57
() 58
() 59
() 60
( ) 61
() 62
( ) 63
() 64 
( ) 65 or older

Mother's Highest Level of Education:

\{Choose one\}

() Some high school or less

() High school degree

() Some college

() Associate's

() Bachelor's

( ) Masters

() Doctorate

Father's Highest Level of Education:

\{Choose one\}

() Some high school or less

() High school degree

() Some college

() Associate's

() Bachelor's

() Masters

() Doctorate

Parents' Combined Annual Income:

\{Choose one\}

() Less than $\$ 25,000$

( ) $\$ 25,000-\$ 49,999$

( ) $\$ 50,000-\$ 99,999$

() $\$ 100,000-149,999$

() $\$ 150,000-199,999$

() $\$ 200,000-299,999$

() $\$ 300,000-399,999$

() $\$ 400,000$ or more

Mother's Generational Status:

\{Choose one\}

( ) 1st generation (Was not born in the U.S.)

( ) 2nd generation (Was born in the U.S. but either parent was not born in the

U.S.)

( ) 3rd generation (Was born in the U.S., both parents were born in the U.S., but no grandparent was born in the U.S.)

( ) 4th generation (Was born in the U.S., both parents were born in the U.S., one grandparent was born in the U.S., but at least one grandparent was not born in the U.S.

( ) 5th generation (Was born in the U.S., both parents were born in the U.S., and all grandparents were also born in the U.S.) 
( ) Don't know what generation best fits since I lack some information.

If your mother is 1st generation, how long has she lived in the U.S.?

\{Choose one\}

() Less than a year

() $1-2$ years

() $3-5$ years

( ) 6-10 years

() $11-15$ years

() 16-20 years

() 21-30 years

() 31 or more years

Father's Generational Status:

\{Choose one\}

( ) 1st generation (Was not born in the U.S.)

( ) 2nd generation (Was born in the U.S. but either parent was not born in the U.S.)

( ) 3rd generation (Was born in the U.S., both parents were born in the U.S., but no grandparent was born in the U.S.)

( ) 4th generation (Was born in the U.S., both parents were born in the U.S., one grandparent was born in the U.S., but at least one grandparent was not born in the U.S.

() 5th generation (Was born in the U.S., both parents were born in the U.S., and all grandparents were also born in the U.S.)

() Don't know what generation best fits since I lack some information.

If your father is 1 st generation, how long has he lived in the U.S.? \{Choose one

() Less than a year

() $1-2$ years

() $3-5$ years

() 6-10 years

() $11-15$ years

() $16-20$ years

() 21-30 years

() 31 or more years

How would you rate your parents' proficiency in speaking and understanding English?

\{Choose one

() 1 - Very little to no proficiency

() 2 - A little proficient

() 3 - Somewhat proficient

() 4 - Very proficient 


\section{() 5 - Completely proficient}

In what language do you most communicate with your parents?

\{Choose one\}

() Parents' native language

() English

() Other [ 
VITA

KATHY NGUYEN, M.A.

\section{EDUCATION}

2006 - present

2008

2006
Psy.D. in Clinical Psychology, Virginia Consortium Program in Clinical Psychology (APA-Accredited), Virginia Beach, VA

University-based program, jointly sponsored by: The College of William \& Mary, Eastern Virginia Medical School, Norfolk State University, and Old Dominion University

M.A. in Community/Clinical Psychology, Norfolk State University, Norfolk, VA

B.A. in Psychology and Religious Studies, University of Virginia, With Highest Distinction, Charlottesville, VA

\section{CLINICAL TRAINING}

Aug 2009 - present

Aug 2008 - Jun 2009

May 2008 - Aug 2008

Jan 2008 - May 2008

Aug 2007 - Jun 2008

May 2007 - Feb 2008

Jan 2007 - May 2007
Clinical Intern

American University Counseling Center (APA-Accredited), Washington, D.C.

Advanced Graduate Student Counselor Norfolk State University Counseling Center, Norfolk, VA

Graduate Student Counselor Hampton Veterans Affairs Medical Center (VAMC), Hampton, VA

Graduate Student Counselor Virginia Wesleyan College Counseling Center, Norfolk, VA

Graduate Student Counselor Virginia Beach City Public Schools, Virginia Beach, VA

Graduate Student Assessment Clinician Virginia Beach City Public Schools, Virginia Beach, VA

Graduate Student Assessment Clinician Riverside Rehabilitation Institute, Neuropsychology and Behavioral Medicine, Newport News, VA 